Portland State University

PDXScholar

Fall 1-7-2015

\title{
Enzymatic Control of the Related Pathways of Fatty Acid and Undecylprodiginine Biosynthesis in Streptomyces coelicolor
}

Renu Singh

Portland State University

Follow this and additional works at: https://pdxscholar.library.pdx.edu/open_access_etds

Part of the Chemistry Commons

Let us know how access to this document benefits you.

Recommended Citation

Singh, Renu, "Enzymatic Control of the Related Pathways of Fatty Acid and Undecylprodiginine Biosynthesis in Streptomyces coelicolor" (2015). Dissertations and Theses. Paper 2112.

https://doi.org/10.15760/etd.2110

This Dissertation is brought to you for free and open access. It has been accepted for inclusion in Dissertations and Theses by an authorized administrator of PDXScholar. Please contact us if we can make this document more accessible: pdxscholar@pdx.edu. 
Enzymatic Control of the Related Pathways of Fatty Acid and Undecylprodiginine Biosynthesis in Streptomyces coelicolor

by

\title{
Renu Singh
}

A dissertation submitted in partial fulfillment of the requirements for the degree of

\author{
Doctor of Philosophy \\ in \\ Chemistry
}

\author{
Dissertation Committee: \\ Kevin A. Reynolds, Chair \\ Carl Wamser \\ Dirk Iwata-Reuyl \\ John J. Perona \\ Kenneth Stedman
}

Portland State University

2014 


\section{ABSTRACT}

Streptomyces coelicolor produces fatty acids for both primary metabolism and for production of the components of natural products such as undecylprodiginine. Primary metabolism makes the longer and predominantly branched-chain fatty acids, while undecylprodiginine utilizes shorter and almost exclusively straight chain fatty acids. The first step in fatty acid biosynthetic process is catalyzed by FabH ( $\beta$-ketoacyl synthase III), which catalyzes a decarboxylative condensation of an acyl-CoA primer with malonyl-acyl carrier protein (ACP). The resulting 3-ketoacyl-ACP product is reduced by NADPHdependent FabG into 3-hydroxyacyl-ACP, which is dehydrated by FabA to form enoyl-ACP. The NADH-dependent FabI (InhA) completes the cycle. Subsequent rounds of elongations in the pathways are catalyzed by the condensing enzyme FabF. For undecylprodiginine biosynthesis in S. coelicolor, homologues of the condensing enzymes (FabH and FabF) and the ACP (FabC) are encoded by redP, redR and redQ respectively in the red gene cluster. The genes encoding 3ketoacyl-ACP reductase (FabG), 3-hydroxyacyl-ACP dehydratase (FabA), and enoyl-ACP reductase (Fabl), are putatively shared between fatty acid and undecylprodigine biosynthesis, since the corresponding genes are not present within the red gene cluster of $S$. coelicolor. RedP is proposed to initiate biosynthesis of undecylprodiginine alkane chain by condensing an acetyl-CoA with a malonyl-RedQ, in contrast to FabH which process a broad range of acylCoA with malonyl-FabC The 3-keto group of the resulting 3-ketoacyl-RedQ is then reduced to provide butyryl-RedQ, presumably by the type II FAS enzymes 
FabG, FabA and Fabl. These enzymes would not differentiate between straight and branched-chain substrates, and have equal preference for FabC and RedQ ACPs. RedR would then catalyze four subsequent elongation steps with malonylRedQ, with appropriate 3-keto group processing after each step. The proposed role and substrate specificities of condensing enzymes RedP and FabH have not been investigated in S. coelicolor. The genes encoding FabG, FabA, and Fabl have not been characterized in Streptomyces. Analysis of the $S$. coelicolor genome sequence has revealed the presence of one fabl gene (SCO1814, encoding an enoyl-ACP reductase), and three likely fabG genes (SCO1815, SCO1345, and SCO1346, encoding $\beta$-ketoacyl-ACP reductase).

In the current study the substrates specificities of both RedP and FabH were determined from assays using pairings of two acyl-CoA substrates (acetylCoA and isobutyryl-CoA) and two malonyl-ACP substrates (malonyl-RedQ and malonyl-FabC) (FabC is a dedicated ACP for fatty acid biosynthesis and RedQ for undecylprodiginine biosynthesis in S. coelicolor). For RedP, activity was only observed with a pairing of acetyl-CoA and malonyl-RedQ. No activity was observed with isobutyryl-CoA consistent with the proposed role for RedP and the observation that acetyl CoA-derived prodiginines predominate in S. coelicolor. Malonyl-FabC is not a substrate for RedP, indicating that ACP specificity is one of the factors that permit a separation between prodiginine and fatty acid biosynthetic processes. In contrast to RedP, $\mathrm{FabH}$ was active with all pairings but demonstrated the greatest catalytic efficiency with isobutyryl-CoA using malonylFabC. Lower catalytic efficiency was observed using an acetyl-CoA and malonyl- 
FabC pairing consistent with the observation that in streptomycetes, a broad mixture of fatty acids are biosynthesized, with those derived from branched chain acyl-CoA starter units predominating. Diminished but demonstrable FabH activity was also observed using malonyl-RedQ, with the same preference for isobutyrylCoA over acetyl-CoA, completing biochemical and genetic evidence that in the absence of RedP this enzyme can also play a role in prodiginine biosynthesis, producing branched alkyl chain prodiginines.

The identification and characterization of both enzymes FabG and Fabl was also carried out. A series of straight and branched-chain $\beta$-ketoacyl and enoyl substrates tethered to either NAC or ACP were synthesized and used to elucidate the functional role and substrate specificity of these enzymes. Kinetic analysis demonstrates that of the three S. coelicolor enzymes, SCO1815 and SCO1345 have NADPH-dependent $\beta$-ketoacyl-reductase activity, in contrast to SCO1346, which has NADH-dependent $\beta$-ketoacyl-reductase activity. Spectrophotometric assays revealed that all three FabGs are capable of utilizing both straight and branched-chain $\beta$-ketoacyl-NAC substrates. These results are consistent with FabGs role in fatty acid and undecylprodiginine biosynthesis, wherein it processes branched-chain for primary metabolism as well as straight-chain products for undecylprodiginine biosynthesis. LC/MS assays demonstrate that these FabG enzymes do not discriminate between primary metabolism ACP (FabC) and secondary metabolism ACP (RedQ) (except for SCO1345, which does not have any activity with RedQ). This relaxed substrate specificity allows these enzymes to process 3-ketoacyl-FabC substrates for fatty acid biosynthesis as well as 3- 
ketoacyl-RedQ substrates for undecylprodiginine biosynthesis. Similar to FabG, spectrophotometric and LC/MS assays were also carried out to elucidate the functional role and substrate specificity of $S$. coelicolor Fabl. The kinetic analyses demonstrate that SCO1814 has NADH-dependent enoyl-ACP reductase activity. Spectrophotometric and LC/MS assays demonstrated that Fabl does not differentiate between straight and branched-chain substrates, and has equal preference for FabC and RedQ ACPs. These observations provide experimental support for the hypothesis that these enzymes are shared and process the intermediates in the elongation cycle of both fatty acid and undecylprodiginine biosynthesis. In summary, these studies have demonstrated the activity of enzymes RedP, FabH, FabG and Fabl (InhA) previously uncharacterized in S. coelicolor and clarified their role in fatty acid and undecylprodiginine biosynthesis. 


\section{Acknowledgements}

First and foremost, I wish to express my deepest gratitude to Dr. Kevin A. Reynolds for giving me the opportunity to work in his research group. I have been amazingly fortunate to have one of the best advisors one can wish for. Without his continuous supervision, encouragement and support this thesis would not have been possible. I am also greatly thankful to Dr. Galina Florova (now at UT Health Northeast, TX), for being a great source of invaluable help and advice, and also for being a great lab mate and someone I always enjoyed working with. The same goes for Chris Hazzard (now medical student at Mount Sinai in NY), who also helped me a lot and I really appreciate that. It has been a great pleasure working with both of them, and the same must be said for all other members of Reynolds' group for sharing their expertise with me and for creating such an exciting and fun-filled environment of learning and growth.

I am also extremely indebted to members of my advisory committee, Dr. Carl Wamser, Dr. Dirk Iwata-Reuyl, Dr. John J. Perona and Dr. Kenneth Stedman for their generous time, and helpful suggestions through the different stages of my graduate career. I also want to extend my sincere thanks to the Chemistry Department of Portland State University for providing all the necessary research facilities and a healthy learning environment throughout my research. My special thanks to Dr. Andrea DeBarber for mass spectroscopy and Rob Jensen for the NMR service.

Last but definitely not least, words are not enough to express my heartfelt 
gratitude to my best friend and also my husband Veerpal Singh and my beloved kids Anaya and Advik for their unconditional love, endless support and also for always cheering me up. This journey would not have been possible for me without them. 


\section{Table of Contents}

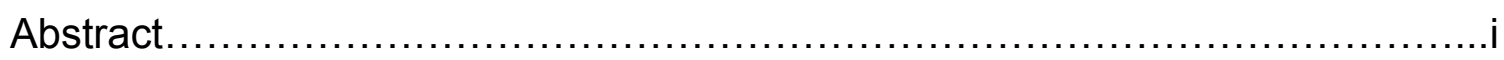

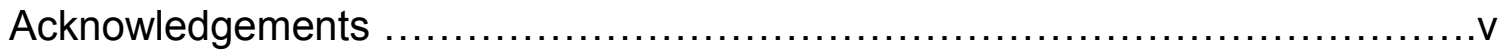

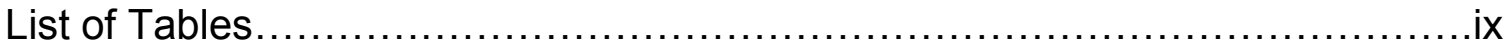

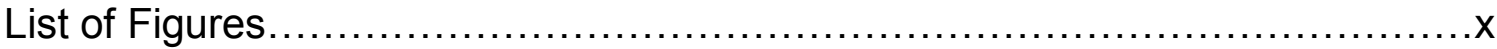

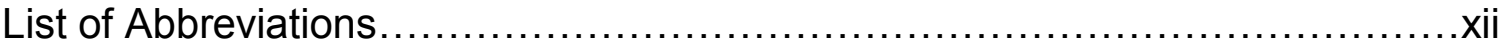

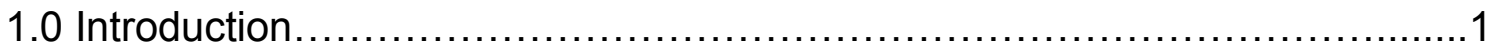

1.1 General introduction to Streptomyces and secondary metabolites 1

1.2 The life cycle of Streptomyces .......................................

1.3 Fatty acid biosynthesis in Streptomyces coelicolor........................

1.4 Undecylprodiginine biosynthesis in Streptomyces coelicolor............5

1.5 The interface between fatty acid and undecylprodiginine biosynthesis

in Streptomyces coelicolor............................................ 8

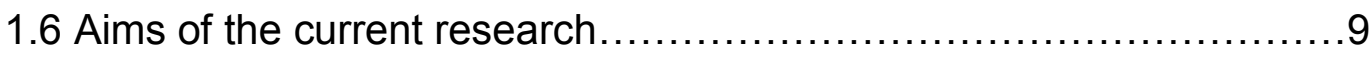

2.0 Streptomyces coelicolor RedP and FabH enzymes, initiating undecylprodiginine and fatty acid biosynthesis, exhibit distinct acyl-CoA and malonyl-acyl carrier protein substrate specificities............................. 12

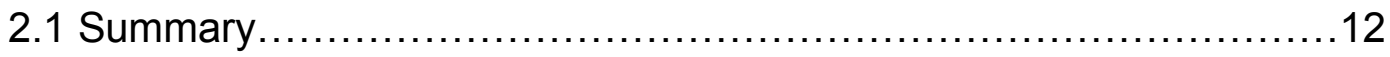


2.2 Introduction.

2.3 Materials and Methods .16

2.4 Results and Discussion. 19

3.0 Characterization of FabG and Fabl of the Streptomyces coelicolor, Dissociated Fatty Acid Synthase 29

3.1 Summary 29

3.2 Introduction. 30

3.3 Materials and Methods 35

3.4 Results and Discussion 44

3.5 NMR spectral data of the intermediates and final compounds 63

4.0 Conclusions and recommendations for future work. .98

References 102 


\section{List of Tables}

Table 1. Kinetic data of RedP and FabH ......................................21

Table 2. Kinetic data of S. coelicolor SCO1815, SCO1345, SCO1346 and E.coli

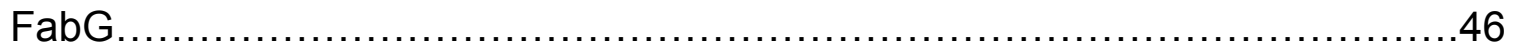

Table 3. Kinetic data of S. coelicolor and E.coli Fabl.............................57 


\section{List of Figures}

Figure 1. The life cycle of Streptomyces.....................................

Figure 2. Fatty acid biosynthesis by a type II fatty acid synthase $\ldots \ldots \ldots \ldots \ldots \ldots . \ldots$

Figure 3. The undecylprodiginine biosynthetic gene cluster in S. coelicolor

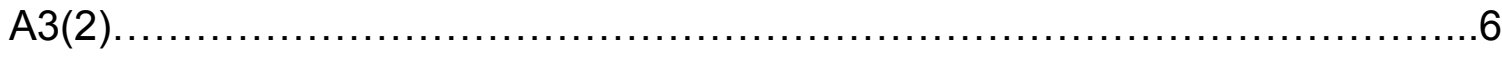

Figure 4. Proposed bifurcated biosynthetic pathway of undecylprodiginine .........7

Figure 5. Interface between fatty acid and undecylprodiginine biosynthesis in S.

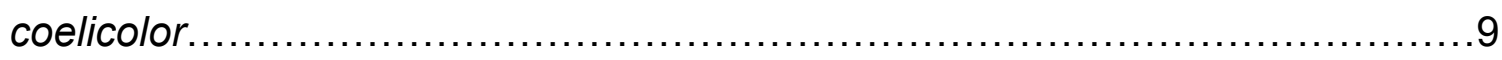

Figure 6. Proposed role of FabH and RedP in initiating biosynthesis of fatty acids 13

Figure 7. SDS-PAGE of the Ni-NTA purified FabH (Left) and RedP (Right).......19

Figure 8. Comparison of FabH activity for isobutyryl-CoA (A) and acetyl-CoA (B) using either malonyl-FabC or malonyl-RedQ..........................................24

Figure 9. Interface between fatty acid and undecylprodiginine biosynthesis in $S$.

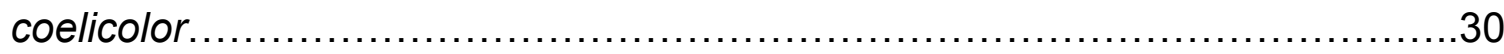

Figure 10. SDS-PAGE of purified S. coelicolor FabG's (SCO1815, SCO1346, SCO1345), and E. coli FabG.

Figure 11. Comparison of S. coelicolor FabG's (SC01815, SCO1346, SCO1345), and E. coli FabG. activities with NADPH and NADH .47 
Figure 12. Coupled assay of FabH and FabG.

Figure 13. Coupled assay of FabH and FabG, with butyryl-CoA and malonylFabC (or malonyl-RedQ). .52

Figure 14. SDS-PAGE of purified S. coelicolor InhA (A) and E. coli Fabl (B).....55

Figure 15. Comparison of $S$. coelicolor InhA (A) and E. coli Fabl (B).activities with $\mathrm{NADPH}$ and $\mathrm{NADH}$.

Figure 16. LC/MS analysis of Fabl reaction with crotonoyl-AcpP (or crotonoylRedQ) and NADH. .59 


\section{List of Abbreviations}

$\begin{array}{ll}\text { ACP } & \text { Acyl Carrier Protein } \\ \text { CoA } & \text { Coenzyme A } \\ \text { CID } & \text { Collision induced dissociation } \\ \text { EDTA } & \text { Ethylenediaminetetraacetic acid } \\ \text { FAS } & \text { Fatty Acid Synthase } \\ \text { His } & \text { Histidine } \\ \text { HPLC } & \text { High performance liquid chromatography } \\ \text { h } & \text { Hours } \\ \text { IPTG } & \text { isopropyl- } \beta \text {-D-thiogalactopyranoside } \\ \text { LB } & \text { Luria broth } \\ \text { NMR } & \text { Nuclear magnetic resonance spectroscopy } \\ \text { Min } & \text { Minutes } \\ \text { MS } & \text { Mass spectrometry } \\ \text { NADH } & \text { Nicotinamide adenine dinucleotide, reduced form } \\ & \text { Nicotinamide adenine dinucleotide phosphate, reduced form } \\ \text { NADH } & \\ \text { Nickel-nitrilotriacetate } & \\ & \end{array}$


S. coelicolor Streptomyces coelicolor

SDS-PAGE Sodium dodecyl sulphate polyacrylamide gel electrophoresis

UP Undecylprodiginine 


\subsection{Introduction}

\subsection{General introduction to Streptomyces and secondary metabolites}

Streptomycetes are Gram-positive filamentous bacteria, which belong to the order Actinomycetales. This genus is characterized with high $\mathrm{G}+\mathrm{C}$ content in their genome and a complex life cycle [1]. They are among the most abundant and wide-spread soil bacteria playing an important role in the breakdown of biological polymers such as lignocellulose, chitin and proteins that makes them central organism in carbon recycling. For years Streptomyces have been center of research and discussion because of their complex mycelium life cycle, which involves morphological differentiation and ability to produce secondary metabolites that have a wide range of biological activities in human medicine [24]. Streptomyces is the largest antibiotic producing genus, it has been estimated that they produce approximately $70 \%$ of the world's known antibiotics, as well as a wide range of other bioactive compounds such as antimalarial, immunosuppressant, anticancer agents, etc. These natural products are synthesized in complex secondary metabolic pathways; there is much interest to understand how these pathways are regulated and what influences the secondary metabolites productivity, as it is expected that this may lead to improving industrial process and also improve our understanding of secondary metabolism in general and help us search for novel biologically active compounds. 


\subsection{The Life Cycle of Streptomyces}

The Streptomyces life cycle begins with the germination of a single spore under favorable conditions to form hyphae (Fig 1) [4]. Growth and branching of the primary hyphae lead to the formation of a substrate mycelium. Subsequently in response to nutrient depletion and other signals, some hyphae start growing away from the surface to form the aerial mycelium. Aerial growth coincides with the initiation of both production of secondary metabolites and morphological differentiation [5]. When growth of the aerial mycelium stops, they develop septa which include one nucleoid per cell compartment. Each cellular compartment of the separated aerial hyphae matures into a grey-pigmented spore.

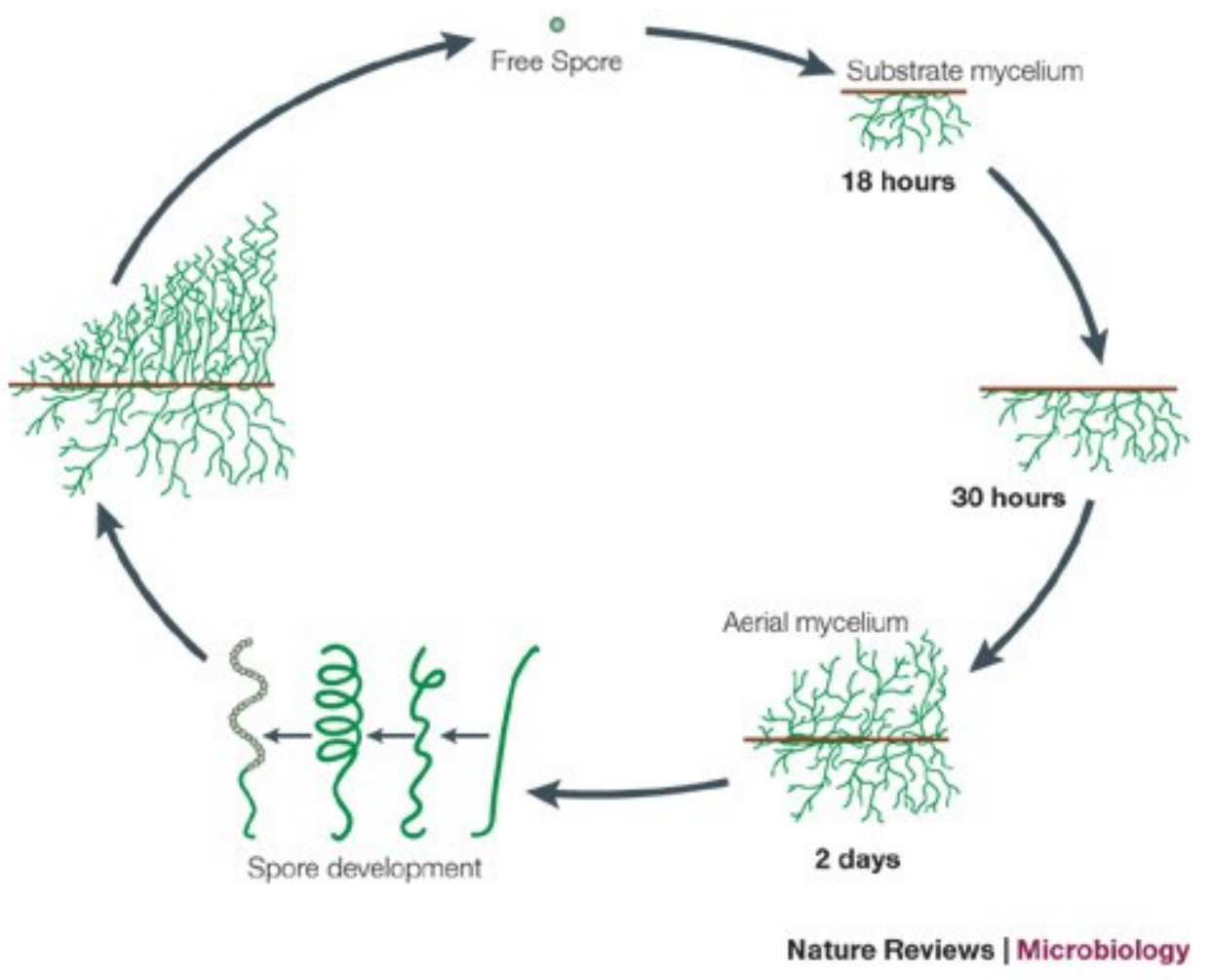

Figure 1. The Life Cycle of Streptomyces 


\subsection{Fatty acid biosynthesis in Streptomyces coelicolor}

Fatty acids are one of the most important building blocks of cellular materials. In bacterial cells, fatty acids occur mainly in the cell membranes as the acyl constituents of phospholipids. Fatty acid synthesis (FAS) is a vital facet of cell physiology. In nature, there are two basic types of FAS architectures. The prototypical FAS I is found in mammals and consists of a single gene that produces a polypeptide, which contains all of the reaction centers required to produce a fatty acid. FAS II is found in most bacteria and plants, it is a dissociated system wherein each component is encoded by a separate gene that produces a unique protein, which catalyzes a single step in the pathway [6].

Streptomycetes, like many other bacteria, utilizes a type II FAS to catalyze the formation of fatty acids. The majority of their fatty acids are made from branched-chain starters such as isobutyryl, isovaleryl and anteisovaleryl units to give odd- and even-numbered fatty acids with a methyl branch chain at the wterminus ( 80 to $90 \%$ of total fatty acid contents), the remainder are synthesized from straight chain starters such as acetyl and propionyl units [7-9]

Initiation of a type II FAS process involves a direct condensation of an acyl-CoA with malonyl-ACP to form 3-ketoacyl-ACP (Fig. 2). This condensation is catalyzed by 3-ketoacyl-ACP synthase $(\mathrm{FabH})$. The 3-ketoacyl-ACP product is processed through two reductive and one dehydration steps to generate acylACP. First, FabG, a nicotinamide adenine dinucleotide phosphate (NADPH) 
dependent 3-ketoacyl-ACP reductase reduces the 3-keto group and gives rise 3hydroxyacyl-ACP intermediate. Second, this intermediate is dehydrated by the 3hydroxylacyl-ACP dehydratase, known as FabZ or FabA. The third step involves the reduction of the enoyl-ACP by the NADH-dependent enoyl-ACP reductase (Fabl) to complete the cycle. Subsequent rounds of elongations in the pathways are catalyzed by the condensing enzymes FabF or FabB. These enzymes condense the growing acyl-ACP with malonyl-ACP to extend the fatty acid chain by two carbons.

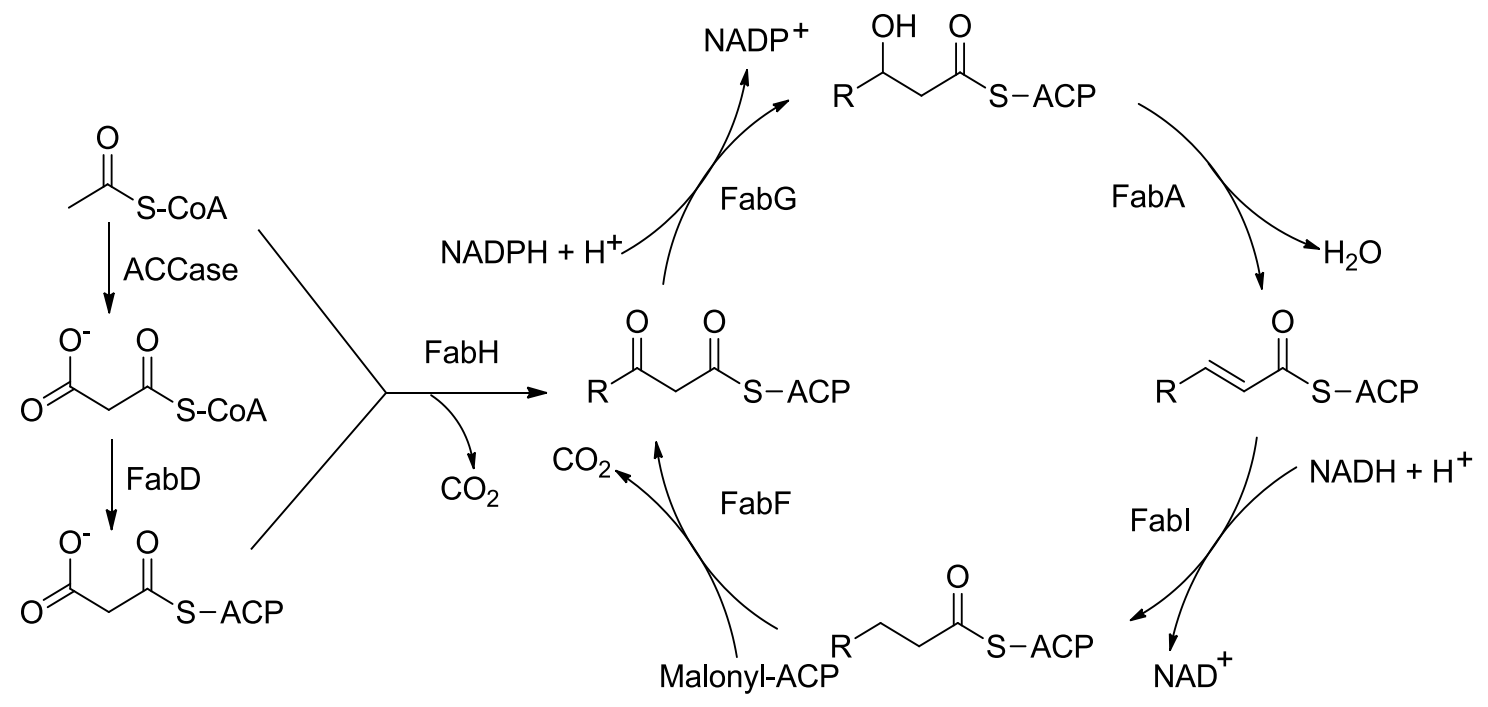

Figure 2. Fatty acid biosynthesis by a type II fatty acid synthase.

Malonyl-ACP used for each of the elongation steps of fatty acids biosynthesis is derived from malonyl-CoA by the action of malonyl-CoA: ACP 
transacylase $(F a b D)$. All the reaction intermediates (growing acyl-chains) in the fatty acid biosynthesis are covalently attached to the acyl carrier protein (ACP) through a thioester linkage to the sulphydryl of the 4'-phosphopanteine prosthetic group.

Streptomycetes are unusual bacteria not only because of the complexity of their life-cycle but also because of their ability to produce an array of secondary metabolites (organic molecules that are not directly involved in the normal growth and development of an organism). These secondary metabolites possess interesting pharmacological properties and widely used in human health as antibacterial, anticancer, and antifungal agents. Also, in agriculture these compounds acts as growth promoters, antiparasitic agents and herbicides. This novel characteristic makes the streptomycetes not only interesting organisms for research, but also commercially important.

\subsection{Undecylprodiginine biosynthesis in Streptomyces coelicolor.}

Undecylprodiginine is one of a number of secondary metabolites produced by S. coelicolor, one of the best genetically characterized streptomycetes [11]. It is a tripyrrole red pigmented compound with a linear alkyl chain, which have gained much attention because of its wide range of biological activities such as antibacterial, immunosuppressive, antimalarial, and anticancer [12,13]. It has been demonstrated that the 23 red genes in S. coelicolor encode a fascinating and unusual pathway leading to formation of undecylprodiginine (Fig. 3). 
Undecylprodiginine biosynthetic process occurs via a complex interface with primary metabolism and involves numerous multifunctional proteins with unusual architecture and catalytic activities. The biosynthesis of undecylprodiginine proceeds via a bifurcated pathway in which 2-undecylpyrrole (UP) and 4methoxy-(2,2'-bipyrrole)-5-carboxaldehyde (MBP) are first assembled and then coupled (Fig. 4). Six of the 23 genes in the cluster (redP, redQ, redR, redJ, redL, and redK) have been proposed to be involved in the formation of the 2undecylpyrrole. Of these, redP, redR and redQ encoded homologs of the type II fatty acid synthases FabH (KASIII) and FabF (KASII) enzymes and an acyl carrier protein (ACP) respectively [14]).

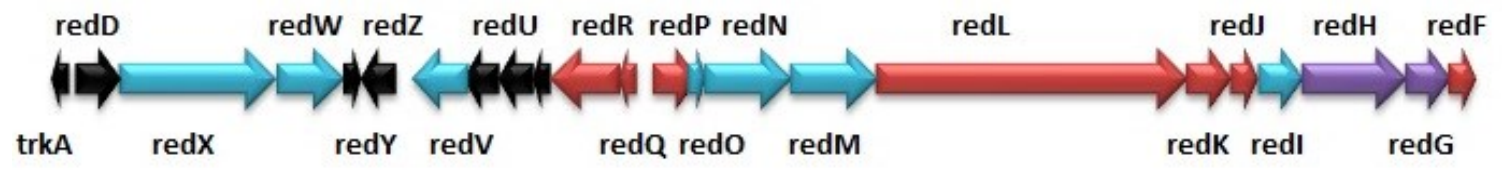

Figure 3. The undecylprodiginine biosynthetic gene cluster in S. coelicolor A3(2).

It has been proposed that RedP and RedR, in tandem with fatty acid biosynthetic enzymes, which catalyze the conversion of 3-ketoacyl-ACP to acylACP, are responsible for formation of a RedQ-activated dodecanoic acid (Fig. 4). RedP is proposed to initiate the biosynthetic process by condensing an acetylCoA starter unit with a malonyl-RedQ (ACP). The 3-keto group of the resulting 
acetoacyl tioester would be reduced to provide butyryl-RedQ, presumably by the type II FAS enzymes (FabG, FabA and Fabl). RedR might catalyze four subsequent elongation steps with malonyl-RedQ, and with appropriate 3-keto group processing after each step. RedJ, a thiosterase catalyzes the hydrolysis of dodecanoyl-RedQ to provide dodecanoic acid, which is elongated by the action of RedL generate 4-keto-2-undecylpyrroline. RedJ has been demonstrated to have much greater activity with longer chain acyl substrates (up to $C_{10}$ in length) and to efficiently discriminate between acyl-RedQ substrates and other acylACPs [15]. The final step in the biosynthesis of 2-undecylpyrrole is the reduction and dehydration of 4-keto-2-undecylpyrroline, catalyzed by RedK.

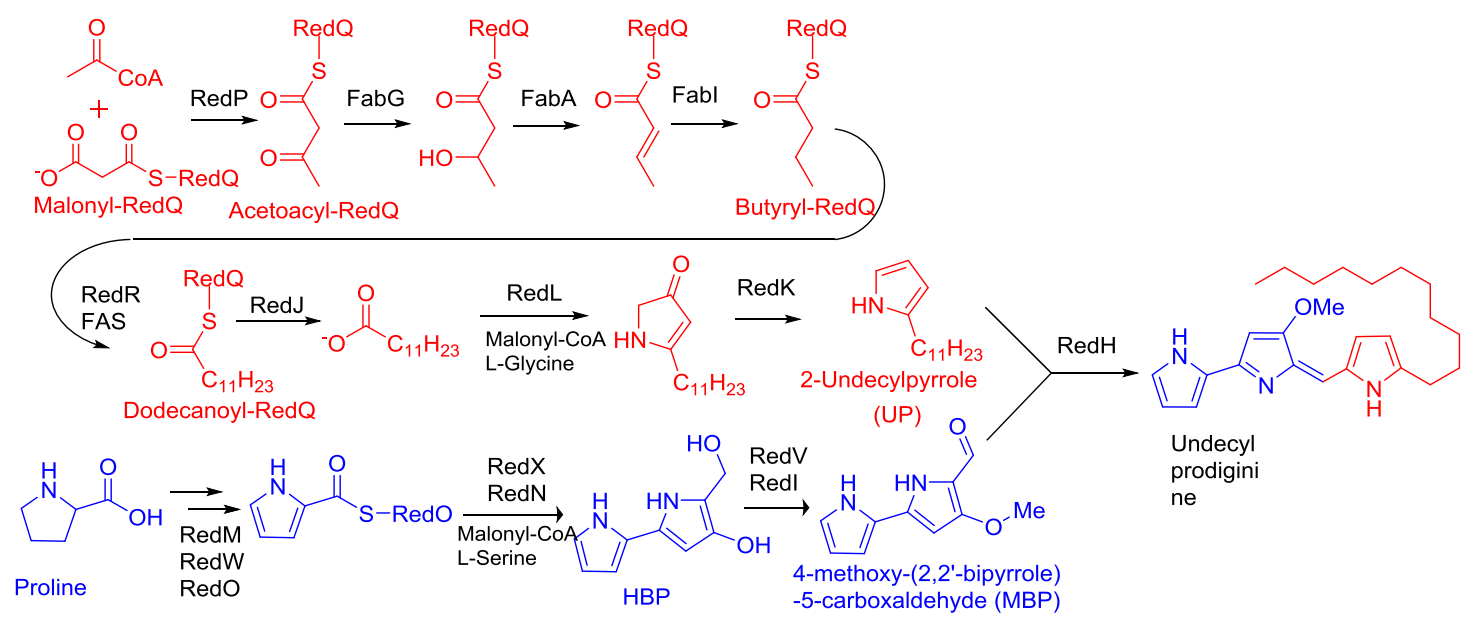

Figure 4. Proposed bifurcated biosynthetic pathway of the undecylprodiginine. 
This ACP selectivity is thus observed at both the first (RedP) and last step (RedJ) in formation of dodecanoic acid for prodiginine biosynthesis, and presumably plays a key role in keeping this process and the fatty acid biosynthetic process separate.

The first steps in the biosynthesis of MBP involve the incorporation of proline to form the pyrrole ring catalyzed by RedM, RedO and RedW. Subsequent steps in MBP biosynthesis involve an elongation of the activated pyrrole-2-carboxylic acid via a decarboxylative condensation with malonyl-CoA and L-serine to generate 4-hydroxy-2,2'-biopyrrole-5-methanol (HBP), and is likely catalyzed by RedX and RedN. The final steps in MBP biosynthesis are a methylation catalyzed by the S-adenosylmethionine dependent Redl and an oxidation by RedV. The last step in the biosynthesis of undecylprodiginine is the RedH catalyzed-condensation between the UP with MBP to form the tripyrrole pigment.

\subsection{The interface between fatty acid and undecylprodiginine biosynthesis in S. coelicolor}

Secondary metabolites are generally synthesized in dedicated biosynthetic pathways, but these are linked to the primary metabolism through the use of specific precursors, various cofactors, and even shared enzymes. Although detailed knowledge is unclear, the link between primary and secondary metabolism has been repeatedly observed [16-18]. The fatty acid biosynthetic 
pathway that provides the undecyl chain of the undecylprodiginine in $S$. coelicolor, gives an opportunity to study one such instance at a genetic and biochemical level. In order to further evaluate the link between primary and secondary metabolism we decided to study the enzymes that are proposed to be separate (FabH and RedP) and common (FabG, and Fabl) to both fatty acid and undecylprodiginine biosynthesis (Fig. 5). The overall objective of this study is to build a compressive understanding of the enzymology of both bacterial FAS and undecylprodiginine biosynthetic processes and the interface between them.

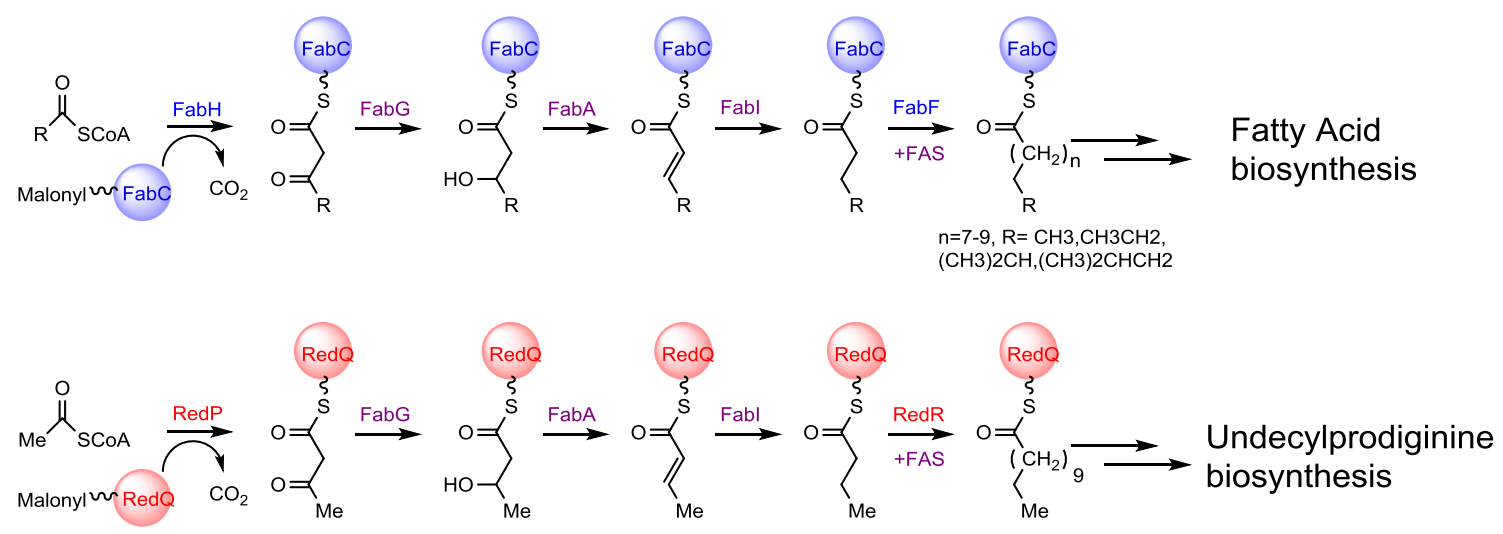

Figure 5. Proposed interface between fatty acid and undecylprodiginine biosynthesis in S. coelicolor.

\subsection{Aims of the current research}

The proposed role and substrate specificity (both acyl-CoA and ACP specificities) of condensing enzymes RedP and FabH have not been investigated in S. coelicolor. We posited that a) FabH and its homologue RedP, which catalyze the initial condensation in fatty acid and undecylprodiginine biosynthesis 
respectively, should be highly selective for either straight (RedP) or branchedchain (FabH) acyl-CoA substrates b) both enzymes should also possess differing ACP specificities. This combination of acyl-CoA and ACP specificity will presumably play a key role in keeping these two processes separate.

The genes encoding FabG, and Fabl, putatively shared between primary and secondary fatty acid synthesis, have also not been characterized in Streptomyces. Analysis of the S. coelicolor genome sequence has revealed the presence of one fabl gene (SCO1814, encoding a putative enoyl-ACP reductase), and three likely fabG genes (SC01815, SC01345, SCO1346, encoding putative $\beta$-ketoacyl-ACP reductase). We hypothesized that a) the Fabl (encoded by SCO1814) and the putative FabG (encoded by SCO1815, which lies immediately adjacent to $f a b l)$ would have enoyl-ACP reductase and 3ketoacyl-ACP reductase activity respectively and b) that neither would show selectivity for the ACP substrate (FabC or RedQ), or the branching in the acyl chain. This activity would permit them to process the acyl chains for both the primary and secondary metabolism and would contrast the initiation enzyme selectivity. We also posited that of the three possible FabG only one (SCO1815) should have ketoreductase activity, as it is cluster with Fabl similar to the other organism such as $M$. tuberculosis, M. smegmatis [19]. Accordingly the catalytic activity and substrate specificity of the other two FabG homologs (encoded by SCO1345 and SCO1346) might be dramatically different if their biological role is unrelated to fatty acid biosynthesis. 
We have tested these hypotheses through the following three specifics aims:

1. Determine the substrate specificities of the primary metabolic enzyme $(\mathrm{FabH})$ and its homolog (RedP), which catalyze the first step in the formation of fatty acid and undecylprodiginine biosynthesis respectively.

2. Identify and characterize of $\beta$-ketoacyl-ACP reductase (FabG) which catalyzes the reduction of 3-ketoacyl-ACP to 3-hydroxyacyl-ACP in both processes.

3. Identify and characterize of enoyl-ACP reductase (Fabl or InhA) which catalyzes the reduction of the double bond of enoyl-ACP and generate saturated acyl-ACP. 


\subsection{Determine the substrate specificities of the primary metabolic enzyme (FabH) and its homolog (RedP) which catalyze the first step in the formation of fatty acid and undecylprodiginine biosynthesis respectively.}

\subsection{Summary}

RedP is proposed to initiate undecylprodiginine biosynthesis in Streptomyces coelicolor by condensing an acyl-CoA with malonyl-ACP, and is homologous to $\mathrm{FabH}$ which catalyzes the same reaction for initiation of fatty acid biosynthesis. Herein, we report the substrate specificities of RedP and FabH from assays using pairings of two acyl-CoA substrates (acetyl-CoA and isobutyryl-CoA) and two malonyl-ACP substrates (malonyl-RedQ and malonyl-FabC). RedP activity was observed only with a pairing of acetyl-CoA and malonyl-RedQ, consistent with its proposed role in initiating formation of acetyl CoA-derived prodiginines. Malonyl-FabC is not a substrate for RedP, indicating that ACP specificity is one of the factors that permit a separation between prodiginine and fatty acid biosynthetic processes. FabH demonstrated greater catalytic efficiency for isobutyryl-CoA in comparison to acetyl-CoA using malonyl-FabC, consistent with the observation that in streptomycetes, a broad mixture of fatty acids is synthesized, with those derived from branched chain acyl-CoA starter units predominating. Diminished FabH activity was also observed using malonyl-RedQ with the same preference for isobutyryl-CoA, completing biochemical and genetic evidence that in the absence of RedP this enzyme can produce branched alkyl chain prodiginines. 


\subsection{Introduction}

Plants and bacteria use a dissociated type II fatty acid synthase (FAS) to generate fatty acids [20]. The first step in this process is catalyzed by FabH, which catalyzes a decarboxylative condensation of an acyl-CoA primer with malonyl-acyl carrier protein (ACP). The resulting 3-ketoacyl-ACP product is processed by the remaining enzymes of the type II FAS to the final elongated acyl-ACP (Fig. 6).

A

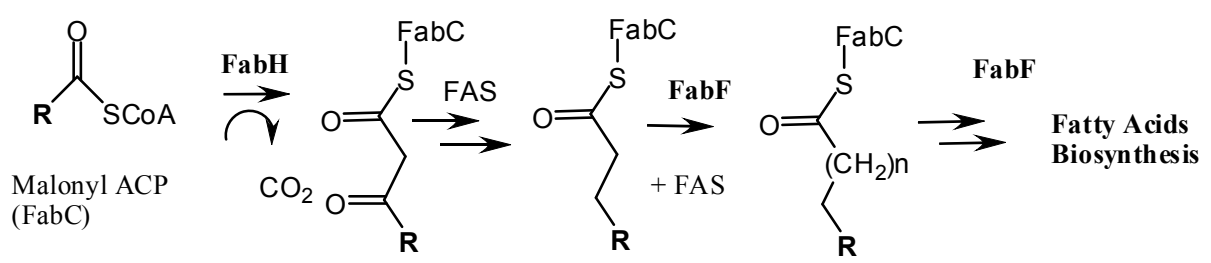

B

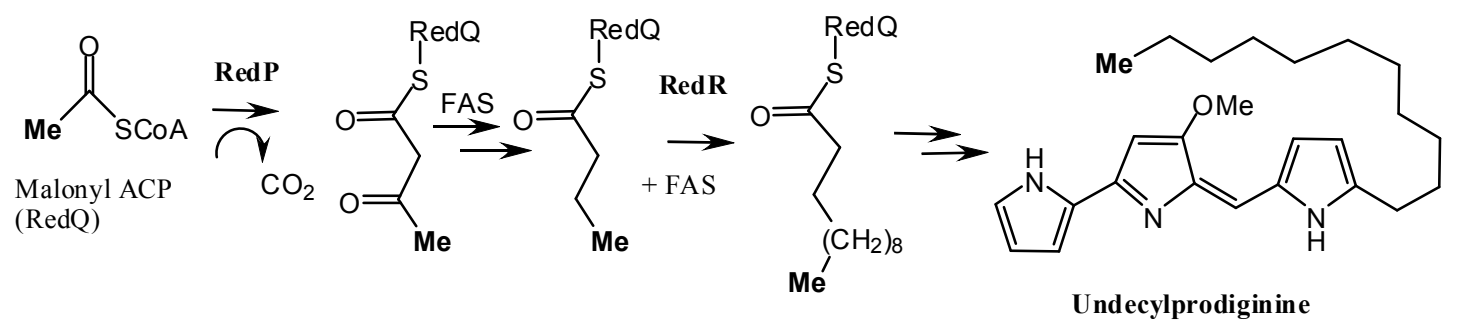

Figure 6. Proposed role of FabH and RedP in initiating biosynthesis of fatty acids (A) and undecylprodiginine (B) in Streptomyces coelicolor. The type II FAS is responsible for subsequent conversion of 3-ketoacyl-ACP products to an acylACP. A subsequent decarboxylative condensation with malonyl-ACP by either FabF or RedR elongates the acyl chain. The alkyl group $(R)$ is typically $C_{1}-C_{5}$ and can be straight or branched. 
FabH enzymes exhibit different acyl-CoA specificities. For organisms which generate only straight chain fatty acids (such as Escherichia coli), the FabH has been shown to be specific for acetyl-CoA [21]. Many microorganisms, including bacilli and streptomycetes generate predominantly branched chain fatty acids [22]. These fatty acids are generated typically using isobutyryl-CoA, and methylbutyrylCoA starter units and $\mathrm{FabH}$ from some of these organisms has been shown to use these as substrates in addition to acetyl-CoA. Crystal structures of numerous FabH enzymes and examination of their acyl binding pockets has provided a structural insight into the basis of this substrate specificity [23-25].

A dramatic shift, from predominantly branched-chain fatty acids to straight chain fatty acids, has been reported for the lipid profile of a $S$. coelicolor YL1 mutant, in which the natural FabH is replaced by the E. coli FabH [26]. This observation has provided clear evidence that the substrate specificity of a FabH plays a pivotal role in determining the type of fatty acid made by an organism.

In streptomycetes, FabH enzymes are also found in processes which generate secondary metabolites such as frenolicin, hedamycin, R1128 and undecylprodiginine [27-30]. Undecylprodiginine, a tripyrrole red pigmented compound, is known to exhibit a wide range of biological activities such as antibacterial, immunosuppressive, antimalarial, and anticancer [31, 32]. For its biosynthesis in S. coelicolor, a FabH and a FabC homolog are encoded by redP and $r e d Q$ in the undecylprodiginine biosynthetic gene cluster. It has been proposed that RedP catalyzes a decarboxylative condensation between acetyl- 
CoA and malonyl-RedQ, as the first step in generating dodecanoic acid (Fig. 6) [30]. This intermediate is then used to generate the alkyl side chain of the final undecylprodiginine product. A $\Delta r e d P$ mutant (SJM1) has been shown to produce about $80 \%$ less of this product and to produce very low levels of new branchedchain alkyl prodiginines (the straight chain prodiginine product predominates). Evidence that in SJM1, undecylprodiginine biosynthesis is initiated by the fatty acid synthase FabH was provided by observation that higher levels of this enzyme led to a partial restoration of overall prodiginine yields [33].

The observations of fatty acid and prodiginine biosynthesis by the $S$. coelicolor wild type, and the YL1 and SJM1 mutants raise several questions regarding the role and specificities of RedP and FabH. For RedP, the proposed preference for acetyl-CoA and malonyl-RedQ has not been investigated. For $\mathrm{FabH}$, the initial characterization of the S. glaucescens $\mathrm{FabH}$ (which has $100 \%$ amino acid sequence identity with $S$. coelicolor FabH) demonstrated comparable enzyme efficiencies for isobutyryl-CoA and acetyl-CoA. A preference for branched chain acyl-CoA substrates would be predicted given that the corresponding long chain fatty acids predominate in S. coelicolor (and are almost completely lost in the YL1 mutant) and that there is no evidence that these substrates are present at higher intracellular concentrations than acetyl-CoA in the cell. On the other hand, a FabH preference (or tolerance) for branched chain acyl-CoA substrates, does not readily explain why it initiates formation of predominantly acetyl-CoA derived prodiginines in the SJM1 mutant. 
In the aim 1 we have characterized with respect to substrate specificity (both acyl-CoA and ACP specificities) of both the S. coelicolor RedP and FabH enzymes. Kinetic studies demonstrate that RedP is specific for the straight chain acetyl-CoA, and FabH for the branched chain isobutyryl-CoA. Additionally both enzymes are shown to have differing ACP specificities. These data provide answers to the questions arising from analyses of the YL1 and SJM1 mutants

\subsection{Materials and methods}

Materials. $\left[1-{ }^{14} \mathrm{C}\right]$ Acetyl-CoA $(60.4 \mathrm{mCi} / \mathrm{mmol})$ was purchased from Moravek Biochemicals, and $\left[1-{ }^{14} \mathrm{C}\right]$ isobutyryl-CoA $(55 \mathrm{mCi} / \mathrm{mmol})$ was obtained from American Radiolabeled Chemicals Inc. Cosmids $3 \mathrm{~F} 7$ and $4 \mathrm{~A} 7$ containing $S$. coelicolor genomic DNA were kindly provided by the John Innes Institute.

Construction of expression Plasmids. The redP gene was amplified from 3F7 cosmid using the forward primer 5'-CGTGCATGCATATGACCCGGGCGTCCGT3 ' and the reverse primer,

5'-GCTACTCGAGGACCGGATCGACGGCGG-3'. The scfabD gene was amplified from 4A7 using the forward primer 5'-GACTCATATGCTCGTACTCGTCGCTCC-3' and the reverse primer 5'-GATTACTCGAGTCAGGCCTGGGTGT-3' (restriction sites are underlined). The redP gene was cloned into expression vector pET28a to construct the plasmid pSJM3 and the scfabD gene was cloned into expression vector $\mathrm{pET} 15 \mathrm{~b}$ to give $\mathrm{pSJM} 5$. 
Protein expression and purification. Both plasmids were used to transform $E$. coli BL21(DE3) cells. The resulting transformants were grown at $37{ }^{\circ} \mathrm{C}$ in LB medium containing either $50 \mu \mathrm{gL}^{-1}$ kanamycin for pSJM3 or $100 \mu \mathrm{g} \mathrm{mL}$ ampicillin for pSJM5 to an $A_{600}=0.6$, induced with $0.1 \mathrm{mM}$ isopropyl- $\beta$-Dthiogalactopyranoside (IPTG) and incubated for approximately $12 \mathrm{~h}$ at $30{ }^{\circ} \mathrm{C}$. Cells were harvested by centrifugation at $12,000 \mathrm{~g}$ for $10 \mathrm{~min}$, at $4{ }^{\circ} \mathrm{C}$ and cell pellets were stored at $-80^{\circ} \mathrm{C}$.

The appropriate E. coli cell pellets were suspended in lysis buffer-A (50 mM sodium phosphate buffer $\mathrm{pH}$ 7.2, $300 \mathrm{mM} \mathrm{NaCl}, 5 \mathrm{mM}$ 2-mercaptoethanol, 10 $\%$ glycerol, $0.05 \%(\mathrm{v} / \mathrm{v})$ Tween-20) with $10 \mathrm{mM}$ imidazole and lysozyme (1 $\mathrm{mg} \mathrm{mL}^{-}$ $\left.{ }^{1}\right)$. The resulting cell suspension was incubated on ice for $30 \mathrm{~min}$ and cell lysate was cleared by centrifugation at $16,000 \mathrm{~g}$ for $20 \mathrm{~min}$. The crude cell extract was loaded onto a Ni-NTA resin column. His-tagged protein was eluted by using buffer-A with $300 \mathrm{mM}$ imidazole. Fractions containing pure protein were pooled, exchanged with $50 \mathrm{mM}$ sodium phosphate buffer $\mathrm{pH} 7.2$, and stored in $20 \%$ glycerol at $-80^{\circ} \mathrm{C}$.

Expression and purification of $\mathrm{FabH}$, holo-FabC and holo-RedQ was carried out in a similar way as previously described [34-36].

Preparation of Malonyl-ACPs. The recombinant S. coelicolor $\mathrm{His}_{6}-\mathrm{FabD}$ was used to prepare malonyl-RedQ and malonyl-FabC (from holo-RedQ or holo-FabC) with a previously described protocol [22]. The purity of each malonyl-ACP product 
was monitored using a microTOF-Q (QqTOF) (Bruker) mass spectrometer, with a similar method to that described previously [37].

RedP and FabH assays. Enzyme activity was determined by monitoring conversion of radioactive acyl-CoA and malonyl-RedQ (or malonyl-FabC) substrates to a radiolabeled 3-ketoacyl-RedQ (or 3-ketoacyl-FabC) product using a standard TCA precipitation assay [22]. Briefly, the reaction mixture contained 50 $\mathrm{mM}$ sodium phosphate buffer $(\mathrm{pH} 7.2), 1 \mathrm{mM}$ dithiothreitol, $40.0 \mu \mathrm{M}$ of malonylRedQ (or malonyl-FabC), $40 \mu \mathrm{M}\left[1-{ }^{14} \mathrm{C}\right]$ acetyl-CoA (or $\left[1-{ }^{14} \mathrm{C}\right]$ isobutyryl-CoA) and $0.1 \mu \mathrm{g} \operatorname{RedP}$ (or $\mathrm{FabH}$ ) in final volume of $20 \mu \mathrm{L}$. The reaction mixture was incubated at $30{ }^{\circ} \mathrm{C}$ for $10 \mathrm{~min}$ and terminated by the addition of $10 \%(\mathrm{w} / \mathrm{v})$ trichloroacetic acid. Precipitation was completed by incubation on ice, and the precipitate was collected by centrifugation. The pellets were resuspended in 200 $\mu \mathrm{L}$ of $2 \% \mathrm{SDS}$ in $20 \mathrm{mM} \mathrm{NaOH}$. The suspension was combined with scintillation fluid and analyzed with a scintillation counter. Steady-state kinetic parameters for acetyl-CoA and isobutyryl-CoA were obtained by determination of RedP and FabH activity using various concentrations of $\left[1-{ }^{14} \mathrm{C}\right]$ acetyl-CoA $(2.5$ to $40 \mu \mathrm{M})$, or [1$\left.{ }^{14} \mathrm{C}\right]$ isobutyryl-CoA $(0.25$ to $10.0 \mu \mathrm{M})$ and a constant concentration $(30 \mu \mathrm{M})$ of either malonyl-RedQ or malonyl-FabC. Similarly, an apparent $K_{M}$ for malonylRedQ and malonyl-FabC was obtained by using a constant concentration of either $30 \mu \mathrm{M}\left[1-{ }^{14} \mathrm{C}\right]$ acetyl-CoA or $10 \mu \mathrm{M}\left[1-{ }^{14} \mathrm{C}\right]$ isobutyryl-CoA and variable concentrations of malonyl-RedQ (2.5 to $40 \mu \mathrm{M})$ and malonyl-FabC (1.0 to $25 \mu \mathrm{M})$. 


\subsection{Results and Discussion}

RedP Specificity. RedP and FabH were expressed as recombinant proteins in $E$. coli and purified by nickel-chelate affinity chromatography to yield homogenous enzymes of expected molecular mass $(\sim 37 \mathrm{kDa})$ based on sodium dodecyl sulfate polyacrylamide gel electrophoresis (SDS-PAGE) (Fig. 7).

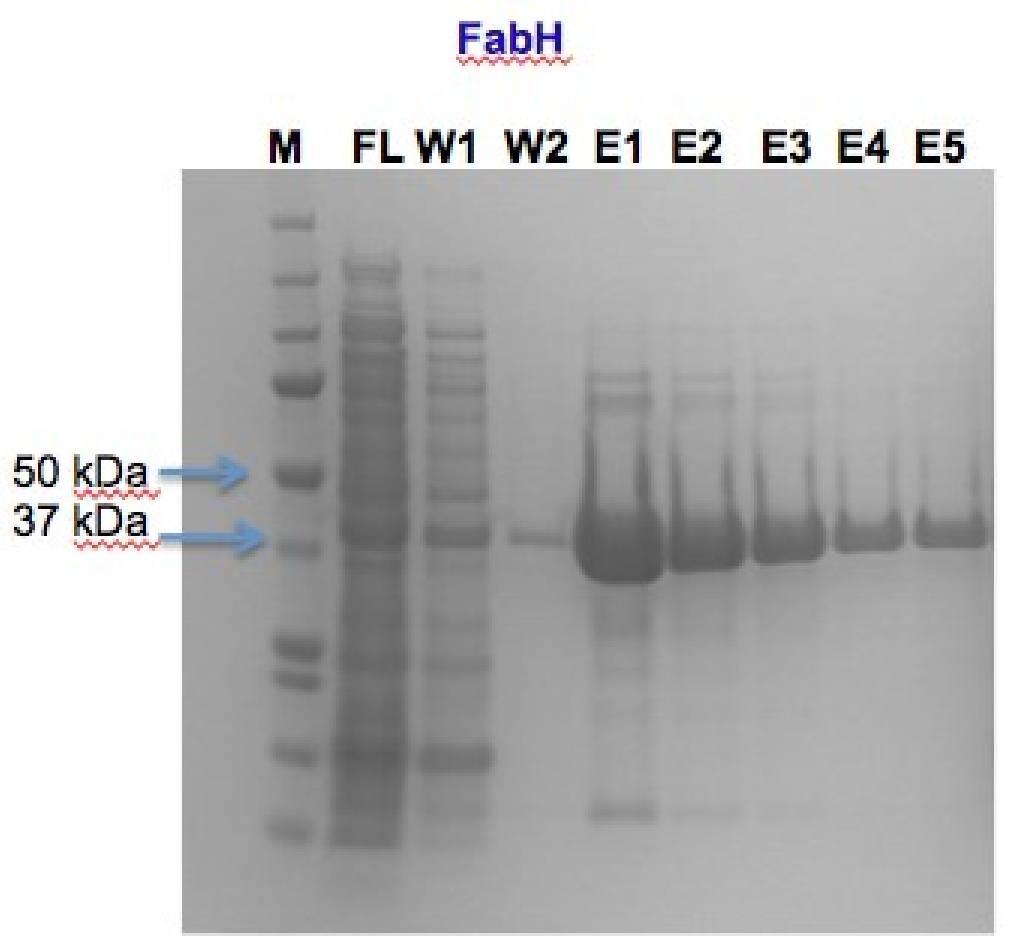

RedP

E1 E2 E3 E4

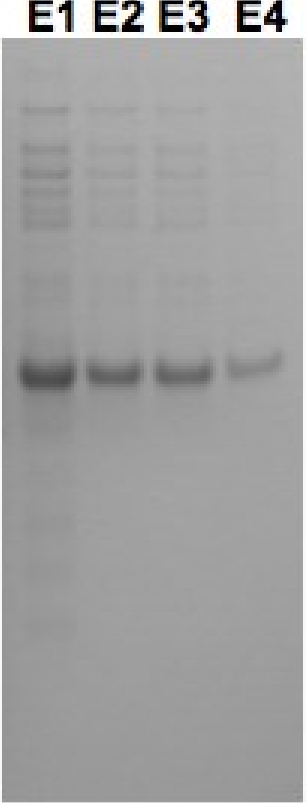

Figure 7. SDS-PAGE of the Ni-NTA purified FabH (Left) and RedP (Right).

M-Standard protein marker; FL-Flow through; W-Wash; E-Protein elution fraction. 
RedP and FabH were assayed using two acyl-CoA substrates (acetyl-CoA and isobutyryl-CoA) and two malonyl-ACP substrates (generated by FabD from RedQ and FabC using malonyl-CoA). The redQ gene has been predicted to encode a protein with ACP homology [30] and is directly adjacent to redP in the prodiginine biosynthetic gene cluster (Fig. 3); thus RedQ is a likely substrate for RedP. In contrast, the fabC gene product is unlikely to be a RedP substrate as this gene is located with $\mathrm{fabH}, \mathrm{fabF}$ and fabD in S. coelicolor [37] and other streptomycetes, and all current data indicate that this provides the ACP for fatty acid biosynthesis.

As predicted, RedP was active (Table 1) with an acetyl-CoA and malonylRedQ pairing $\left(k_{\text {cat }} 1.52 \mathrm{~min}^{-1}, K_{M}\right.$ value for acetyl-CoA $10.35 \pm 2.76 \mu \mathrm{M}$ and for malonyl-RedQ $6.73 \pm 0.31 \mu \mathrm{M}$ ). However no detectable activities were observed with any other pairing (limit of detection was $<1 \%$ of activity observed with acetylCoA and malonyl-RedQ), demonstrating that neither isobutyryl-CoA nor malonylFabC are substrates for RedP.

These observations demonstrate a clear substrate preference of RedP and provide biochemical evidence to support the role of RedP catalyzing the first step in biosynthesis of the undecylpyrrole component of undecylprodiginine. The specificity for acetyl-CoA plays a key role in controlling formation of a straightchain dodecanoyl-ACP and thus formation of acetate-derived alkylprodiginines in S. coelicolor. The RedP specificity for malonyl-RedQ demonstrates that the 
process to generate acetate-derived alkylprodiginines via a dodecanoyl-ACP (Fig.

1) occurs using a dedicated ACP.

Table 1. Kinetic data of RedP and FabH

\begin{tabular}{|c|c|c|c|c|c|c|c|c|}
\hline Fixed & \multicolumn{2}{|c|}{ Malonyl-FabC } & \multicolumn{2}{|c|}{ Malonyl-RedQ } & \multicolumn{2}{|c|}{ Isobutyryl-CoA } & \multicolumn{2}{|c|}{ Acetyl-CoA } \\
\hline $\begin{array}{l}\text { Variable } \\
\text { Conc. }\end{array}$ & $\begin{array}{l}\text { Isobutyryl- } \\
\text { CoA }\end{array}$ & $\begin{array}{l}\text { Acetyl- } \\
\text { CoA }\end{array}$ & $\begin{array}{l}\text { Isobutyryl- } \\
\text { CoA }\end{array}$ & $\begin{array}{c}\text { Acetyl- } \\
\text { CoA }\end{array}$ & $\begin{array}{l}\text { Malonyl- } \\
\text { FabC }\end{array}$ & $\begin{array}{l}\text { Malonyl- } \\
\text { RedQ }\end{array}$ & $\begin{array}{l}\text { Malonyl } \\
\text { FabC }\end{array}$ & $\begin{array}{l}\text { Malonyl- } \\
\text { RedQ }\end{array}$ \\
\hline \multicolumn{9}{|l|}{ FabH } \\
\hline$k_{\text {cat }}\left(\min ^{-}\right.$ & 17.17 & 1.72 & 0.66 & 0.07 & 20.33 & 1.14 & 2.57 & 0.13 \\
\hline \multirow[t]{2}{*}{$K_{\mathrm{M}}(\mu \mathrm{M})$} & 1.74 & 8.36 & 1.66 & 7.13 & 4.53 & 7.8 & 4.11 & 7.93 \\
\hline & \pm 0.32 & \pm 1.5 & \pm 0.37 & \pm 1.84 & \pm 0.87 & \pm 1.1 & \pm 1.17 & \pm 1.25 \\
\hline $\begin{array}{c}k_{\text {cat }} / K_{M} \\
\left(\mu \mathrm{M}^{-1}\right. \\
\left.\min ^{-1}\right)\end{array}$ & 9.84 & 0.20 & 0.40 & 0.01 & 4.84 & 0.14 & 0.66 & 0.017 \\
\hline \multicolumn{9}{|l|}{ RedP } \\
\hline$k_{\text {cat }}\left(\min ^{-}\right.$ & ND & ND & ND & 1.52 & ND & ND & ND & 0.92 \\
\hline$K_{\mathrm{M}}(\mu \mathrm{M})$ & ND & ND & ND & $\begin{array}{c}10.35 \pm \\
2.76\end{array}$ & ND & ND & ND & $\begin{array}{l}6.73 \\
\pm 0.31\end{array}$ \\
\hline $\begin{array}{l}k_{\text {cat }} / K_{\mathrm{M}} \\
\left(\mu \mathrm{M}^{-1}\right. \\
\left.\min ^{-1}\right)\end{array}$ & ND & ND & ND & 0.147 & ND & ND & ND & 0.13 \\
\hline
\end{tabular}

We have recently demonstrated that RedJ is a thioesterase which can catalyze the hydrolysis of dodecanoyl-RedQ to provide dodecanoic acid [36], and genetic evidence has shown that it is converted to undecylpyrrole by the actions of RedL and RedK [38]. RedJ has been demonstrated to have much greater activity with longer chain acyl substrates (up to $C_{10}$ in length) and to efficiently 
discriminate between acyl-RedQ substrates and other acyl-ACPs. This ACP selectivity is thus observed at both the first (RedP) and last step (RedJ) in formation of dodecanoic acid for prodiginine biosynthesis, and presumably plays a key role in keeping this process and the fatty acid biosynthetic process separate.

An $80 \%$ decrease in prodiginine production upon deletion of redP in $S$. coelicolor (SJM1) indicates that RedP is an important enzyme for prodiginine biosynthesis, but not essential [33]. A significant restoration of prodiginine biosynthesis is observed in SJM1 with plasmid-based expression of FabH, indicating that FabH can function in place of RedP. The specificity of RedP and RedJ for malonyl-RedQ would predict that in order to support prodiginine biosynthesis, FabH should be able to utilize malonyl-RedQ as well as malonylFabC.

FabH Specificity. The streptomycetes FabH was initially assayed using the $E$. coli ACP to generate the malonyl-ACP. The cognate ACP from streptomycetes (FabC) was not used in these assays. Isobutyryl-CoA was observed to have a 3fold slower $V_{\max }$ than acetyl-CoA, and a lower $K_{M}$ [22]. In this study we sought to extend these analyses to include both the cognate ACP (malonyl-FabC) and malonyl-RedQ.

As shown in Table 1, a lower $K_{M}(1.74 \mu \mathrm{M})$ for isobutyryl-CoA than acetyl-CoA $(8.36 \mu \mathrm{M})$ was also observed using malonyl-FabC. However, in this case the overall reaction rate $\left(k_{\mathrm{cat}}\right)$ was 10 -times faster for isobutyryl-CoA in comparison to 
acetyl-CoA (Table 1 and Fig. 8). The FabH is approximately 50 -fold more efficient using isobutyryl-CoA versus acetyl-CoA using malonyl-FabC, and provides a much a clearer demonstration of a) the role of the streptomycetes FabH in generating predominantly branched chain fatty acids, and b) the reason why replacement of S. coelicolor FabH with the acetyl-CoA specific E. coli FabH (YL1/ecFabH mutant) results in a dramatic shift to a fatty acid profile of predominantly straight chain fatty acids [26].

As predicted, FabH was able to use malonyl-RedQ in place of malonylFabC. Under saturating malonyl-RedQ conditions FabH was able to use either acetyl-CoA or isobutyryl-CoA (Table 1). The $K_{M}$ values for each of these were comparable to those observed using malonyl-FabC, and again there was almost a 40-fold higher catalytic efficiency $\left(k_{\text {cat }} / K_{M}\right)$ for isobutyryl-CoA compared to acetylCoA. However for both acyl-CoA substrates the reaction rate $k_{\mathrm{cat}}$ was at least 20fold less using malonyl-RedQ versus malonyl-FabC (Fig. 8).

At fixed isobutryl-CoA and acetyl-CoA concentrations and variable malonylRedQ or malonyl-FabC concentrations similar sets of observations were made. Greater catalytic efficiency was seen with isobutyryl-CoA relative to acetyl-CoA and for each acyl-CoA substrate the apparent reaction rate was much faster using malonyl-FabC than with malonyl-RedQ. This set of analyses also demonstrated that the apparent $K_{M}$ for malonyl-FabC $(4.53 \mu \mathrm{M})$ and malonyl-RedQ $(7.80 \mu \mathrm{M})$ were comparable. 
A

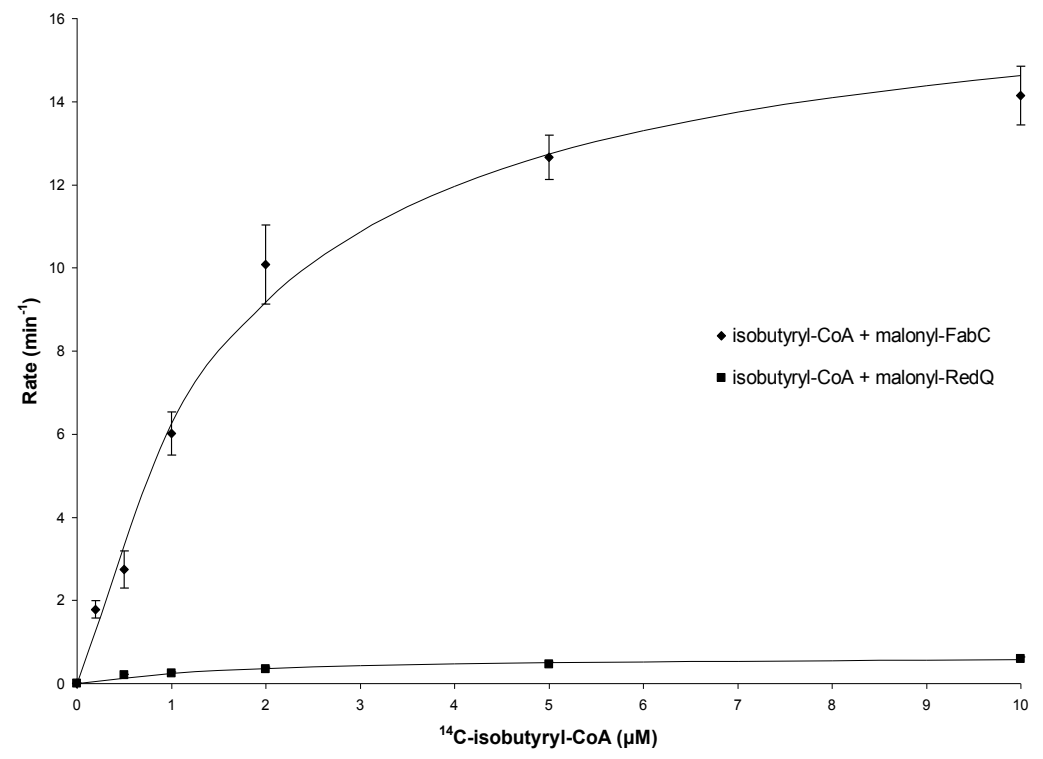

B

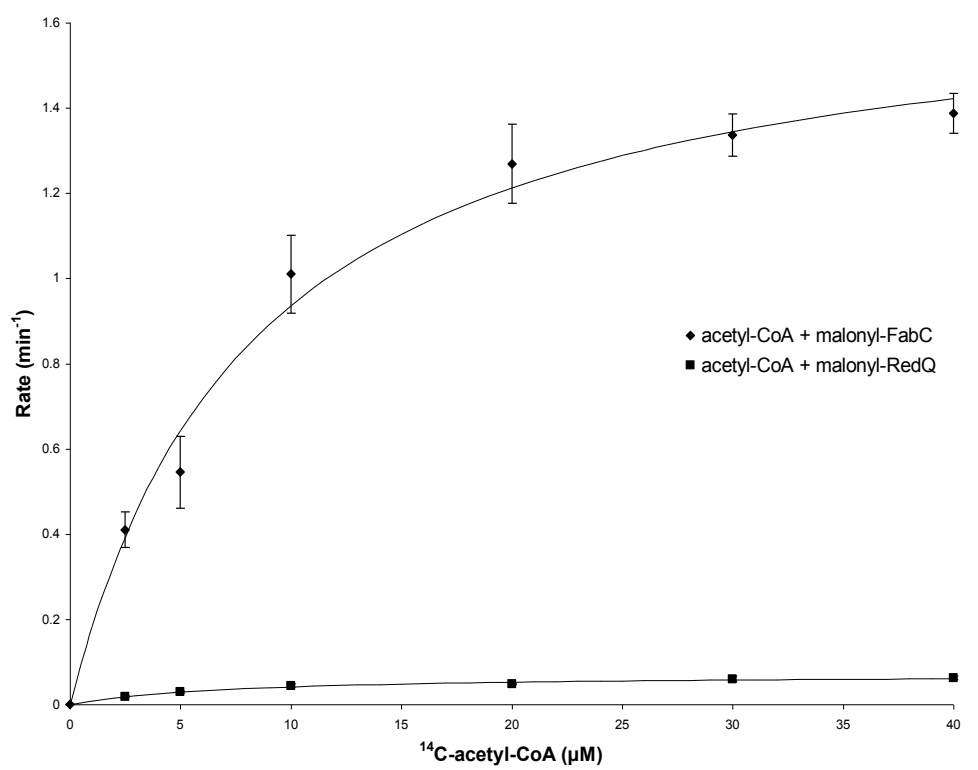

Figure 8. Comparison of FabH activity for isobutyryl-CoA (A) and acetyl-CoA (B) using either malonyl-FabC or malonyl-RedQ. 
Thus the difference in overall catalytic efficiency of FabH using malonylACP substrates arises predominantly from differences in apparent catalytic rates rather than $K_{M}$ values. The ability of FabH to utilize malonyl-RedQ and to have a preference for isobutyryl-CoA is consistent with a) genetic data which suggest FabH can initiate prodiginine biosynthesis in SJM1, the S. coelicolor redP deletion mutant, and b) the observation of a significant increase in branched alkyl chain prodiginines in the SJM1 mutant relative to the wild type S. coelicolor [14]. A final observation from these analyses is that the maximal kinetic efficiency of $\mathrm{FabH}$ $\left(k_{\text {cat }} / K_{M}\right.$ of $9.84 \mu \mathrm{M}^{-1} \mathrm{~min}^{-1}$ using isobutyryl-CoA and malonyl-FabC) is 66-fold higher than that of RedP $\left(k_{\text {cat }} / K_{M}\right.$ of $0.147 \mu \mathrm{M}^{-1} \mathrm{~min}^{-1}$ using acetyl-CoA and malonylRedQ). This difference might arise from the ability of FabH to utilize isobutyrylCoA (the enzymes have comparable efficiencies using acetyl-CoA), or because FabH is a primary metabolic enzyme.

Role of ACP in apparent substrate specificity of FabH and RedP. Initial characterization of many $\mathrm{FabH}$ enzymes, including those from streptomycetes was carried out with a commercially available E. coli ACP [22, 39-41]. Subsequent work has revealed that these enzymes have ACP specificity. Improved catalytic activity and in some cases apparent changes in acyl group specificity can be observed when assays are performed using malonyl-ACP generated from the cognate ACP $[23,42]$. In the case of the Mycobacterium tuberculosis FabH $(\mathrm{mtFabH})$, which has a broad specificity for long chain acyl-CoA substrates, the preferred substrate is dodecanoyl-CoA using the E. coli FAS ACP, and 
octadecanoyl-CoA using the M. tuberculosis FAS ACP enzyme [42]. In the current study, the streptomycetes FabH has been shown to have both a much greater difference in catalytic efficiency between isobutryryl-CoA and acetyl-CoA using FabC (the cognate ACP) than was initially observed using the E. coli ACP, and a much greater catalytic efficiency using malonyl-FabC than with malonyl-RedQ. In addition, RedP has been shown to effectively discriminate between malonyl-RedQ and malonyl-FabC, using only acetyl-CoA as a substrate.

A recent model for FabH catalysis, based on experiments with the $\mathrm{mtFabH}$, has indicated an open form of the enzyme which orders around the acyl-CoA substrate and leads to the formation of an acyl enzyme intermediate. In the case of the $\mathrm{mtFabH}$, a long acyl binding pocket to accommodate acyl chains has been identified from the X-ray crystal structure analyses. imilar structural analyses have shown a small acyl binding pocket for the $E$. coli FabH, which is only able to utilize acetyl-CoA and propionyl-CoA substrates [43-45] and a slightly larger acyl binding pocket for the enzyme in Staphylococcus aureus, which uses branched substrates such as isobutyryl-CoA [43]. Thus it is the acyl binding channel which to some extent dictates FabH specificity. The data obtained in the current study would indicate that the acyl binding channel of RedP (which utilized only acetyl-CoA) is likely to be more restrictive than the corresponding binding channel of the streptomycetes FabH enzyme (which also could utilize isobutyryl-CoA).

The mtFabH model also provides a rationale for how steps subsequent to formation of the acyl-enzyme intermediate, involving the malonyl-ACP, also 
contribute to the overall catalytic reaction rate and differing reaction rates for various acyl-CoA substrates. Reaction of the acyl-enzyme intermediate with the malonyl-ACP leads to formation of the 3-ketoacyl-ACP product and an open form of the enzyme which permits egress of the product via binding of the acyl group to an appropriate region of the ACP [44]. Under certain conditions this final step is the rate determining step and differences in the ability of ACPs to sequester the various acyl groups of the 3-ketoacyl-ACP products and to productively interact with the acyl-enzyme form of the FabH provides a basis for the observations regarding FabH specificity and activity. Thus if FabC can sequester branched chain acyl groups more effectively than the $E$ coli $\mathrm{ACP}$, much faster reactions will be observed using this as the malonyl-ACP substrate with the streptomycete FabH and isobutyryl-CoA. Slower overall rates observed with the Streptomycetes FabH using malonyl-RedQ, indicate it can bind productively with the activated $\mathrm{FabH}$, but there is a slower rate-limiting product release. The higher catalytic rate for isobutyryl-CoA under these conditions would suggest that RedQ, like FabC, has the ability to sequester straight and branched acyl chains. Finally, if malonylFabC cannot bind productively with the activated RedP, formation and release of a 3-ketoacyl-ACP product will only be observed with malonyl-RedQ. 
This work has been published with the following title in FEMS Microbiology Letters, 2012 and I am reusing the article in this dissertation via permission from John Wiley \& Sons and license number for that is $\mathbf{3 5 3 0 9 2 0 1 6 2 1 6 7}$

"Streptomyces coelicolor RedP and FabH enzymes, initiating undecylprodiginine and fatty acid biosynthesis, exhibit distinct acyl-CoA and malonyl-acyl carrier protein substrate specificities"

FEMS Microbiology Letters, volume 328, Issue 1, Copyright @ 1999-2014 John Wiley \& Sons, Inc.

Also I have added one extra following figure to the published article

"Figure 7: SDS-PAGE of the Ni-NTA purified FabH and RedP" 


\subsection{Identification and characterization of $\beta$-ketoacyl-ACP reductase (FabG) and enoyl-ACP reductase (Fabl)}

\subsection{Summary.}

Streptomyces coelicolor produces fatty acids for both primary metabolism and for production of the natural product, undecylprodiginine. The fatty acids are predominantly branched-chain while undecylprodiginine utilizes almost exclusively a straight-chain dodecanoic acid. The first and last reductive steps during the chain elongation cycle of fatty acid biosynthesis are catalyzed by $\mathrm{NADPH}$-dependent $\beta$-ketoacyl-acyl carrier protein reductase (FabG) and an NADH-dependent enoyl-ACP reductase (Fabl or InhA). The Streptomyces coelicolor, FabG, and Fabl, are presumed to be used in both processes, contrasting the condensing enzymes which allow the processes to be controlled for differentiated products. Analysis of the S. coelicolor genome sequence has revealed the presence of one fabl gene (SCO1814), and three likely fabG genes (SC01815, SC01345, and SC01846). Here we report the expression, purification and characterization of the Fabl and the three FabG homologs. A series of straight and branched-chain $\beta$-ketoacyl and enoyl substrates tethered to either an $\mathrm{N}$-acetylcysteamine (NAC) or acyl carrier protein (ACP) were synthesized and used to elucidate the functional role and substrate specificity of these enzymes. Kinetic analyses demonstrate that of the three S. coelicolor enzymes SCO1815, and SCO1345 have NADPH-dependent $\beta$-ketoacylreductase activity and SCO1346 has $\mathrm{NADH}$-dependent $\beta$-ketoacyl-reductase 
activity. Spectrophotometric assays revealed that all three FabGs are capable of utilizing both straight and branched-chain $\beta$-ketoacyl-NAC substrates. An LC/MS assay demonstrated that the FabGs encoded by SCO1815 and 1346 can process 3-ketoacyl-ACP substrates using ACPs involved in the fatty acid and undecylprodiginine biosynthetic processes (FabC and RedQ, respectively). This relaxed acyl and ACP substrate specificity allows these enzymes to process intermediates in both processes and provides the first experimental evidence for this role. Similarly, observations regarding NADH-dependant processing of straight and branched-chain enoyl-NAC substrates as well as enoyl-ACPs with different ACPs substrates, using the $S$. coelicolor Fabl were made. These data represent the first reported analysis of a streptomycetes Fabl and provide the first experimental evidence that both FabG and Fabl catalyzed reductive steps in the fatty acid biosynthetic process are shared with that needed for undecylprodinine biosynthesis.

\subsection{Introduction}

Streptomycetes, like many other bacteria, utilize a type II fatty acid synthase to catalyze the formation of fatty acids. They produce primarily branched-chain fatty acids with only a minor portion of straight-chain fatty acids [46]. The first step in a type II fatty acid synthase (FAS) process is catalyzed by FabH ( $\beta$-ketoacyl synthase III), which catalyzes a decarboxylative condensation of an acyl-CoA primer with malonyl-acyl carrier protein (ACP) (Fig. 9). 

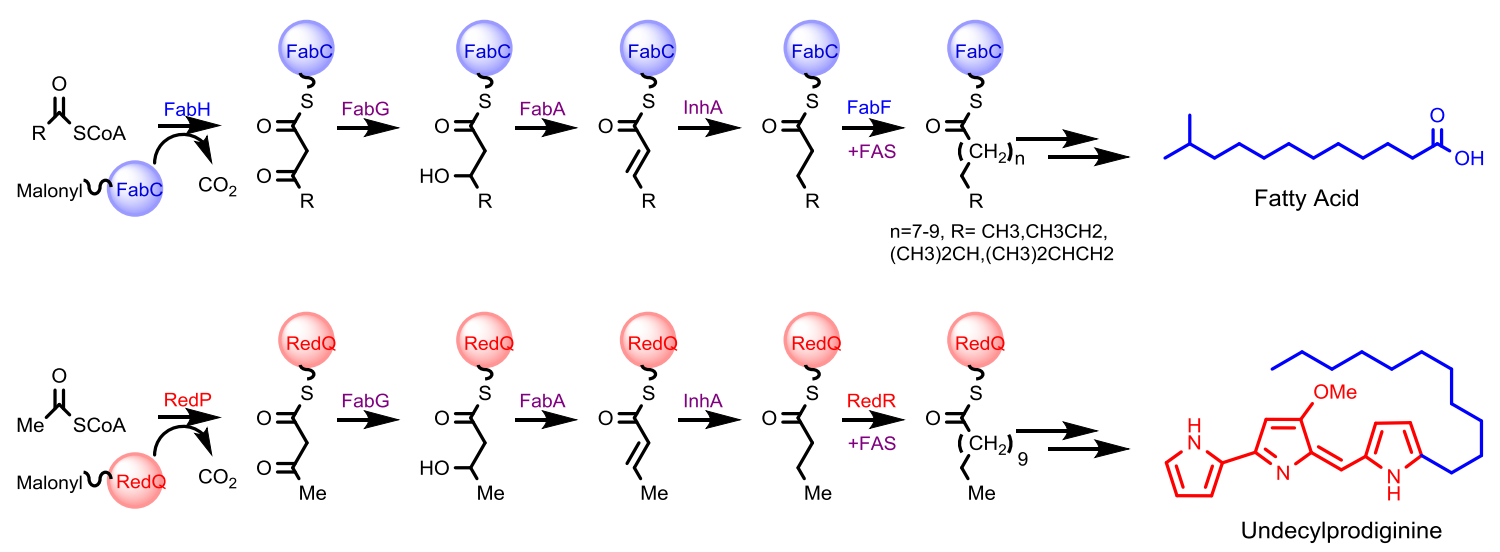

Figure 9. Interface between fatty acid and undecylprodiginine biosynthesis in $S$. coelicolor.

For branched-chain fatty acids the primer is typically either isobutyryl-CoA or methylbutyryl-CoA. For straight-chain fatty acids, acetyl-CoA and propionylCoA serve as the most common primers. The resulting 3-ketoacyl-ACP product is reduced by NADPH-dependent FabG to provide 3-hydroxyacyl-ACP, which is dehydrated by FabA to form enoyl-ACP. The NADH-dependent Fabl completes the cycle by catalyzing a reduction to provide the corresponding acyl-ACP. In subsequent rounds of elongation the condensation step using the acyl-ACP is catalyzed by FabF rather than FabH, which only catalyzes the chain initiating step. The malonyl-ACP utilized in each elongation step is generated from malonyl-CoA by the action of a malonyl CoA:ACP transacylase (encoded by 
$f a b D$ ). In streptomycetes the $f a b H, f a b C$ (encoding the ACP), fabF and fabD are clustered together as an operon [47].

Streptomycetes also produce a vast array of biologically active secondary metabolites widely used in human health such as antibacterial, immunosuppressant, anticancer and antimalarial [48], and in a number of cases these natural products use fatty acids as a building block. These fatty acids often differ in chain length or extent of branching from those made by the primary metabolic type II FAS (e.g. daptomycin, frenolicin, R1128, tunicamycin, and undecylprodiginine [49-54]. The biosynthesis of their alkane chain occurs by a type II FAS pathway which must differ from the primary metabolic pathway in the type of acyl precursors and number of cycles used. One such example is undecylprodiginine, it is a tripyrrole red pigmented compound with a linear alkyl chain, known to exhibit a wide range of biological activities such as antibacterial, immunosuppressive, antimalarial, and anticancer $[55,56]$.

Studies have revealed that the control of the two processes providing fatty acids for primary and secondary metabolism lies partially in the initial condensing enzymes $[46,57,58]$. For undecylprodiginine biosynthesis in S. coelicolor, homologues of the condensing enzymes ( $\mathrm{FabH}$ and $\mathrm{FabF}$ ) and the ACP (FabC) are encoded by redP, redR and redQ respectively in the red gene cluster. RedP is proposed to initiate biosynthesis of undecylprodiginine's alkane chain by condensing an acyl-CoA with a malonyl-RedQ. The 3-keto group of the resulting 3-ketoacyl-RedQ is then reduced to provide butyryl-RedQ, presumably by the 
type II FAS enzymes FabG, FabA and Fabl. RedR would then catalyze the subsequent condensation steps with malonyl-RedQ, and type II FAS enzymes shared with primary metabolism would handle reduction of the 3-keto group during each elongation cycle. In previous chapter, we have demonstrated that FabH and its homologue RedP, which catalyze the initial condensation in fatty acid and undecylprodiginine biosynthesis respectively, are highly selective for either straight (RedP) or branched-chain (FabH) acyl CoA substrates [59]. Specifically RedP will only process acetyl-CoA while FabH is more efficient with branched acyl-CoA substrates. Additionally both enzymes have been shown to possess differing ACP specificities; RedP would only process the RedQ, while FabH was more efficient with FabC. This combination of acyl-CoA and ACP specificity provides for a separation of the two processes and control of the final product, at initiation step.

Separate enzymes and dedicated ACPs thus appear to be key for separating the primary and secondary fatty acid biosynthetic process. As only these genes are found in the secondary metabolite gene cluster, the remaining enzymes to complete each cycles are thus likely to be shared. To date most work on this metabolic crosstalk has focused on FabD (malonyl-CoA:ACP transacylase) is the most well-established and widespread example of a crosstalk between fatty acid biosynthesis (a primary metabolic process) and polyketide biosynthesis (a secondary metabolic process) [60]. The gene for fabD is clustered with $\mathrm{fabH}$, fabF and fabC [2]. Studies have revealed that FabD has 
no significant ACP selectivity and plays an important role in both natural product and fatty acid biosynthetic processes.

The genes encoding 3-ketoacyl-ACP reductase (FabG), 3-hydroxyacyl-ACP dehydratase (FabA), and enoyl-ACP reductase (Fabl), putatively shared between primary and secondary fatty acid synthesis, have not been characterized in Streptomyces (Fig. 9). The corresponding genes are not present within the streptomycetes's FAS gene cluster. Analysis of the S. coelicolor genome sequence has revealed the presence of one fabl gene (SCO1814, encoding an enoyl-ACP reductase), and three potential fabG genes (SCO1815, SCO1345, SC01846, encoding $\beta$-ketoacyl-ACP reductase) [61]. The putative Fabl has not been previously characterized and of the three possible candidates for fabG, only one (SCO1815, which lies immediately adjacent to $f a b l$ ) has been partially characterized [62]. In this study the structure and functional role of SCO1815 was determined. The ketoreductase activity of SCO1815 was monitored by employing the reverse reaction i.e. oxidation of 3-hydroxyacyl-ZhuG to 3-oxoacyl-ZhuG (ACP from R1128, an aromatic polyketide). The activity of this enzyme has not been measured with the cognate ACP (FabC or RedQ), and the specificity for acyl group was not determined. We posited that a) the Fabl (encoded by SCO1814) and the putative FabG (encoded by SCO1815) would have enoylACP reductase and 3-ketoacyl-ACP reductase activity respectively and b) that neither would show selectivity for the ACP substrate (FabC or RedQ), or the branching in the acyl chain. This activity would permit them to process the acyl 
chains for both the primary and secondary metabolism and would contrast the initiation enzyme selectivity. We also posited that SCO1815 would have 3ketoacyl-ACP reductase activity as it is cluster with Fabl similar to the other organism such as $M$. tuberculosis, M. smegmatis [61]. Accordingly the catalytic activity and substrate specificity of the FabG homologs (encoded by SCO1345 and SC01346) might be dramatically different if their biological role is unrelated to fatty acid biosynthesis.

In the aim 2 and 3 we have characterized the three FabG and Fabl homologs. Kinetic studies demonstrated that $S$. coelicolor Fabl and FabG, encoded by SCO1814 and SCO1815, process both straight and branched acyl-chains in their respective substrates. In addition, both enzymes can utilize either FabC or RedQ as the ACP components of the substrate. These findings are consistent with predictions. Surprisingly 3-ketoacyl-ACP activity was also observed with the FabG homologs encoded by SCO1345 and SCO1346. However differences in cofactor specificity, overall activity and ACP selectivity were observed over that for the SCO1815 FabG.

\subsection{Materials and Methods}

Materials: $\beta-N A D H$ and $\beta-N A D P H$ were from Research Products International Corp. All other chemicals including unlabeled CoA derivatives were from Sigma. Cosmid 3F7 and 4A7 containing S. coelicolor genomic DNA were kindly provided by John Innes Institute. FabC, RedQ and AcpP (the Escherichia coli ACP) were sourced as described previously [46, 63, 64]. Preparation of 
malonyl-ACPs and crotonoyl-ACPs was carried out as described previously in aim 1.

S. coelicolor and E. coli fabG. The genes encoding SCO1815, SCO1345 and SCO1346 (fabG) were amplified from the appropriate S. coelicolor cosmids by PCR using the primers 5'- CATATGAGCCGCTCGGTTCTC -3' and 5'GGATCCTCAGTGACCCATTCCCAGTCC-3' (SCO1815); $\quad 5$ CATATGACTGAACTGCCCGAGCCCTCC $-3^{\prime}$ and GGATCCTCAGGCCACGCCGGCGTTC-3' $(\mathrm{SCO1345)}$ and $\quad 5^{\prime}-$ CATATGTCCACCACTGAGCAGCG $-3^{\prime}$

and

5'GGATCCCTAGTCGAGCGGTCCGCC-3' (SCO1346). The E. coli fabG was amplified from E. coli genomic DNA by PCR using 5'CATATGAATTTTGAAGGAAAAATCGCACTG -3' and 5'GGATCCTCAGACCATGTACATCCCGCCG-3' (restriction sites underlined). The amplified inserts were digested with $\mathrm{Ndel}$ and $\mathrm{BamHI}$ and cloned into the $\mathrm{pET} 15 \mathrm{~b}$ to provide the expression plasmid for SC01815 (pRS1), SCO1345 (pRS2) and SC01346 (pRS3) and E. coli fabG (pRSE1).

S. coelicolor and E. coli fabl. The SCO1814 gene (encoding Fabl) was amplified from the appropriate S. coelicolor cosmid using the forward primer 5'CATATGAGCGGAATTCTCGAGGGCAAG-3' (introducing a Ndel restriction site) and a reverse primer 5'-GGATCCTCAGGCGCCGATGGCGTGC-3' (introducing a BamHI restriction site). The E. coli fab/ was amplified from E. coli genomic DNA using the forward primer 5'-CATATGGGTTTTCTTTCCGGTAAG-3' (introducing a 
Ndel restriction site) and reverse primer 5'GGATCCTTATTTCAGTTCGAGTTCG-3' (introducing a BamHI restriction site). The resulting PCR products were digested with $\mathrm{Ndel}$ and $\mathrm{BamHI}$, and ligated into the corresponding sites in pET15b to provide the $S$. coelicolor fabl expression plasmid, pRS4 and the E. coli fabl expression plasmid, pRSE2.

Protein expression and purification. All plasmids were used to transform $E$. coli BL21(DE3) cells. The resulting transformants were grown at $37{ }^{\circ} \mathrm{C}$ in LB medium containing $100 \mu \mathrm{g} \mathrm{mL}^{-1}$ ampicillin to an $\mathrm{A}_{600}=0.6$, induced with $0.1 \mathrm{mM}$ isopropyl- $\beta$-D-thiogalactopyranoside, and incubated for $3 \mathrm{~h}$ at $37^{\circ} \mathrm{C}$. Cells were harvested by centrifugation at $12,000 \mathrm{~g}$ for $10 \mathrm{~min}$ at $4{ }^{\circ} \mathrm{C}$, and stored at $-80{ }^{\circ} \mathrm{C}$.

The resulting $E$. coli cell pellets were suspended in lysis buffer-A (50mM sodium phosphate buffer $\mathrm{pH} 7.2,300 \mathrm{mM} \mathrm{NaCl}, 5 \mathrm{mM}$ 2-mercaptoethanol, 10\% glycerol, $0.05 \%$ (v/v) Tween-20) with $10 \mathrm{mM}$ imidazole and lysozyme (1 $\mathrm{mg} \mathrm{mL}^{-}$ $\left.{ }^{1}\right)$. The resulting cell suspension was incubated on ice for $30 \mathrm{~min}$ and cell lysate was cleared by centrifugation at $16,000 \mathrm{~g}$ for $20 \mathrm{~min}$. The crude cell extract was loaded onto a Ni-NTA resin column. The N-terminal polyhistidine-tagged protein was eluted by using buffer-A with $300 \mathrm{mM}$ imidazole. Fractions containing pure protein were pooled, exchanged with $50 \mathrm{mM}$ sodium phosphate buffer $\mathrm{pH} 7.2$ and stored in $20 \%$ glycerol at $-80^{\circ} \mathrm{C}$.

General procedures for synthesis of (E)-S-(2-acetamidoethyl) alk-2enethioate (enoyl-NAC thioester) substrates for Fabl assays. Straight and 
branched-chain enoyl-NAC compounds, ranging from $\mathrm{C}_{4}$ to $\mathrm{C}_{10}$ in the alkyl chain length were synthesized according to general Scheme 1. Reactions were monitored by TLC and all compounds were characterized by ${ }^{1} \mathrm{H}$ NMR spectroscopy.

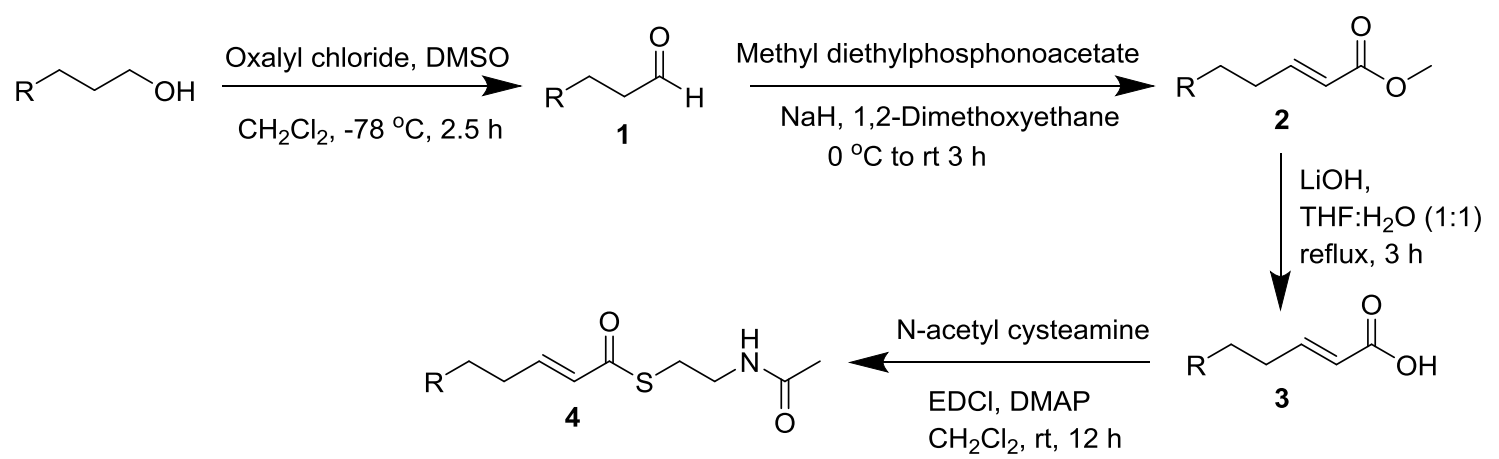

$\mathrm{R}=\mathrm{CH}_{3}, \mathrm{C}_{3} \mathrm{H}_{7}, \mathrm{C}_{5} \mathrm{H}_{11}, \mathrm{CH}_{2} \mathrm{CH}\left(\mathrm{CH}_{3}\right)_{2},\left(\mathrm{CH}_{2}\right)_{3} \mathrm{CH}\left(\mathrm{CH}_{3}\right)_{2}$

Scheme 1. General scheme for synthesis of $(E)$-S-(2-acetamidoethyl) alk-2enethioate (enoyl-NAC).

Synthesis of alkanal (1). Dimethyl sulfoxide (DMSO) $(6.2 \mathrm{~mL}, 88 \mathrm{mmol})$ was added dropwise to a stirred solution of oxalyl chloride $(3.80 \mathrm{~mL}, 44 \mathrm{mmol})$ in dry dichloromethane $\left(\mathrm{CH}_{2} \mathrm{Cl}_{2}\right)(100 \mathrm{~mL})$ at $-78{ }^{\circ} \mathrm{C}$ under argon atmosphere. After 30 min a solution of the starting alcohol $(3.0 \mathrm{~g}, 29 \mathrm{mmol})$ was added dropwise and the reaction mixture was stirred at $-78{ }^{\circ} \mathrm{C}$ for $1.5 \mathrm{~h}$. Triethyl amine $(20.45 \mathrm{~mL}, 147$ mmol) was added dropwise and the reaction mixture was allowed to warm to room temperature. Saturated aqueous solution ammonium chloride $\left(\mathrm{NH}_{4} \mathrm{Cl}\right)$ solution $(30 \mathrm{~mL})$ was added and the organic layer was separated. The resulting aqueous phase was extracted with $\mathrm{CH}_{2} \mathrm{Cl}_{2}(3 \times 40 \mathrm{~mL})$, and combined organic 
layers were dried over anhydrous sodium sulfate $\left(\mathrm{Na}_{2} \mathrm{SO}_{4}\right)$ and concentrated in vacuo to give the corresponding aldehyde (1).

Synthesis of (E)-methyl alk-2-enoate (2). Methyl diethylphosphonoacetate (5.86 g, $27 \mathrm{mmol}$ ) was added dropwise to a stirred solution of the sodium hydride $(0.66 \mathrm{~g}, 27 \mathrm{mmol})$ in 1.2-dimethoxyethane $(15 \mathrm{~mL})$ at $0{ }^{\circ} \mathrm{C}$ under argon atmosphere and stirred for 30 min. After dropwise addition of the aldehyde (1) $(2.0 \mathrm{~g}, 23 \mathrm{mmol})$, reaction mixture was allowed to warm to room temperature and stirred for $3 \mathrm{~h}$. The reaction mixture was quenched with cold water and extracted with ethyl acetate $(\mathrm{EtOAc})(3 \times 15 \mathrm{~mL})$. The combined organic layers were washed with brine $(20 \mathrm{~mL})$, dried over $\mathrm{Na}_{2} \mathrm{SO}_{4}$ and concentrated in vacuo. The crude product was purified by column chromatography (EtOAc : hexane, 7:93) to yield the desired ester (2).

Synthesis of $(E)$-alk-2-enoic acid (3). To a stirred solution of ester (2) $(2.0 \mathrm{~g}$, $14 \mathrm{mmol})$ in tetrahydrofuran $(\mathrm{THF})$ :water $\left(\mathrm{H}_{2} \mathrm{O}\right) \quad(40 \mathrm{~mL} 1: 1)$ was added lithium hydroxide (LiOH) $(1.0 \mathrm{~g}, 42.2 \mathrm{mmol})$, and the mixture was heated at reflux. After $2.5 \mathrm{~h}$ the reaction mixture was cooled down to $0{ }^{\circ} \mathrm{C}$, and acidified with $1 \mathrm{~N}$ hydrochloric acid $(\mathrm{HCl})$. The layers were separated and the aqueous phase extracted with EtOAc $(3 \times 30 \mathrm{~mL})$. The combined organic layers washed with brine, dried over sodium sulfate and concentrated in vacuo to give the corresponding carboxylic acid (3).

Synthesis of (E)-S-(2-acetamidoethyl) alk-2-enethioate (4). To a stirred solution of the carboxylic acid (3) $(1.0 \mathrm{~g}, 7.81 \mathrm{mmol})$ in anhydrous $\mathrm{CH}_{2} \mathrm{Cl}_{2}(20$ 
$\mathrm{mL})$ at $0{ }^{\circ} \mathrm{C}$, under nitrogen atmosphere, was added $\mathrm{N}$-acetyl cysteamine $(0.94$ $\mathrm{mL}, 8.98 \mathrm{mmol})$ followed by $4-(\mathrm{N}, \mathrm{N}$-dimethylamino)pyridine (DMAP) $(0.24 \mathrm{mg}$, $1.95 \mathrm{mmol}$ ), and $\mathrm{N}$-(3-dimethylaminopropyl)-N'-ethylcarbodiimide hydrochloride $(E D C l)(1.5 \mathrm{~g}, 7.81 \mathrm{mmol})$. The reaction mixture was allowed to warm to room temperature and stirred for overnight. The reaction was quenched with saturated aqueous $\mathrm{NH}_{4} \mathrm{Cl}(15 \mathrm{~mL})$ and extracted with $\mathrm{CH}_{2} \mathrm{Cl}_{2}(3 \times 20 \mathrm{~mL})$. The combined organic layers were dried over sodium sulfate, concentrated in vacuo and the residue was purified by column chromatography (hexane/EtOAc 40:60) to yield the desired product 4 .

General procedures for synthesis of S-(2-acetamidoethyl) 3oxoalkanethioate (3-ketoacyl-NAC thioester) substrates for FabG assays. Straight and branched 3-keto acyl-NAC compounds with alkyl chain length ranging from $\mathrm{C}_{4}$ to $\mathrm{C}_{10}$ were synthesized according to general Scheme 2 .

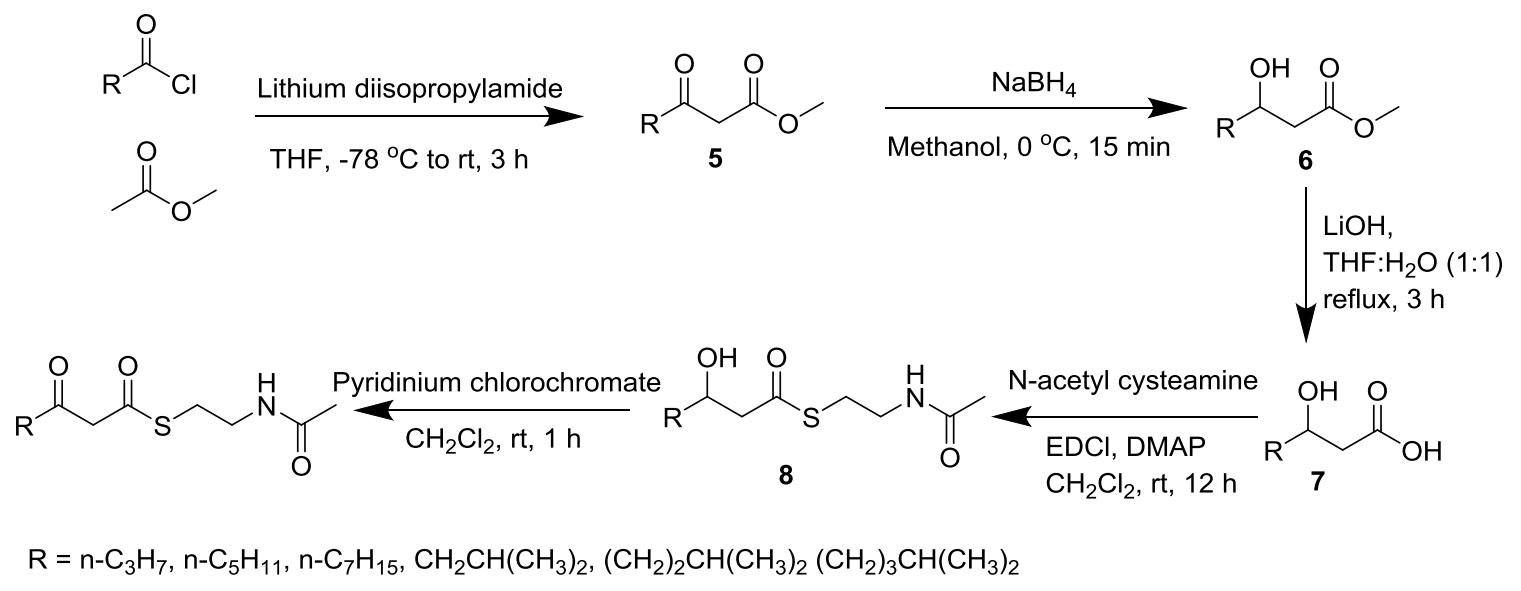

Scheme 2. General scheme for synthesis of S-(2-acetamidoethyl) 3oxoalkanethioate (3-ketoacyl-NAC). 
Reactions were monitored by TLC and all compounds were characterized by ${ }^{1} \mathrm{H}$ NMR spectroscopy.

Synthesis of methyl 3-oxoalkanoate (5). Methyl acetate $(7.50 \mathrm{~mL}, 93.8 \mathrm{mmol})$ was added to a stirred solution of lithium diisopropylamide (LDA) $(39.0 \mathrm{~mL}$ of 1.8 M solution in THF, $70.3 \mathrm{mmol})$ in THF $(100 \mathrm{~mL})$ at $-78^{\circ} \mathrm{C}$. After stirring for 15 min, a solution of the starting acyl chloride in THF was added dropwise and the reaction mixture was stirred at $78{ }^{\circ} \mathrm{C}$ for $1 \mathrm{~h}$ before being warmed to room temperature and stirred for $3.0 \mathrm{~h}$. The reaction mixture was quenched with $1 \mathrm{~N}$ $\mathrm{HCl}$ and extracted with EtOAc $(3 \times 100 \mathrm{~mL})$. The combined organic extract were washed with brine, dried over $\mathrm{Na}_{2} \mathrm{SO}_{4}$ and concentrated in vacuo. The crude product was purified by column chromatography (hexane: EtOAc, 95:5) to afford the desired ester (5).

Synthesis of methyl 3-hydroxyalkanoate (6). Sodium borohydride $\left(\mathrm{NaBH}_{4}\right)$ $(1.90 \mathrm{~g}, 50 \mathrm{mmol})$ was added slowly to a stirred solution of $5(3.0 \mathrm{~g}, 50 \mathrm{mmol})$ in anhydrous methanol $(20 \mathrm{~mL})$ at $0{ }^{\circ} \mathrm{C}$, and the reaction mixture was stirred at $0{ }^{\circ} \mathrm{C}$ for $20 \mathrm{~min}$. The resulting solution was quenched with $1 \mathrm{~N} \mathrm{HCl}$ and extracted with EtOAc $(3 \times 20 \mathrm{~mL})$. The combined organic layers were dried over $\mathrm{Na}_{2} \mathrm{SO}_{4}$, concentrated in vacuo and purified with column to give corresponding methyl 3hydroxyalkanoate (6). 
Synthesis of S-(2-acetamidoethyl) 3-hydroxyalkanoate (8). Hydrolysis of 6 to provide 7 and subsequent conversion to 8 was analogous to the steps for formation of formation of enoyl NAC (described above).

Synthesis of S-(2-acetamidoethyl) 3-oxoalkanethioate (9). A suspension of pyridinium chlorochromate $(1.44 \mathrm{~g}, 6.72 \mathrm{mmol})$ in anhydrous $\mathrm{CH}_{2} \mathrm{Cl}_{2}(50 \mathrm{~mL})$ was treated with $8(1.0 \mathrm{~g}, 4.48 \mathrm{mmol})$. The mixture was stirred at room temperature for $2 \mathrm{~h}$. Diethyl ether $\left(\mathrm{Et}_{2} \mathrm{O}\right)(100 \mathrm{~mL})$ was added to precipitate the chromium salts. After filtration through silica gel pad the solvent was evaporated to yield crude keto compound, which was purified by column chromatography (hexane/ EtOAc 50:50) to afford the desired compound $\mathbf{9 .}$

FabG and Fabl assays. Spectrophotometric assays were used to assess substrate specificity of FabG and Fabl. FabG activity was determined by monitoring the conversion of the 3-ketoacyl-NAC substrate to 3-hydroxyacylNAC. The conversion of the enoyl-NAC substrate to acyl-NAC was monitored to determine the activity of Fabl. Assays were performed in the presence of $50 \mathrm{mM}$ sodium phosphate buffer ( $\mathrm{pH} 7.2), 0.4 \mathrm{mM}$ of $\mathrm{NADH}$ (or NADPH), $1.0 \mathrm{mM}$ substrate (suspended in DMSO to give a final concentration of $1 \%$ ) and $0.05 \mu \mathrm{g}$ of protein in a final volume of $100 \mu \mathrm{L}$. The reaction mixture was incubated at room temperature for 10 min and enzymatic activity was measured by monitoring the decrease in absorbance at $340 \mathrm{~nm}$ due to the consumption of NADH (or NADPH). Steady-state kinetic measurements were obtained by determination of FabG or Fabl activity using variable concentrations $(0.125-16.0 \mathrm{mM})$ of either 3- 
ketoacyl-NAC or enoyl-NAC and constant concentration $(400 \mu \mathrm{M})$ of either $\mathrm{NADPH}$ or $\mathrm{NADH}$ respectively. All reactions were performed at least in triplicate and nonlinear regression analysis with Grafit version 4.012 (Erithacus Software, Horley, United Kingdom) was used to determine $k_{c a t}$ and $K_{M}$ values.

FabG and Fabl activities were also determined with 3-ketoacyl-ACP and enoyl-ACP respectively by using LC-MS based assay under the similar reaction condition as described above. Briefly, Fabl was incubated with either crotonoylAcpP (the E.coli fatty acid synthase ACP), or crotonoyl-RedQ, and NADH in a final volume of $20 \mu \mathrm{L}$ for $10 \mathrm{~min}$. Coupled assays were carried out to obtain the FabG activity. First FabH (or RedP) was incubated with butyryl-CoA (or isobutyryl-CoA) with malonyl-FabC (or malonyl-RedQ) in a similar way as described before in aim 1 in $50 \mathrm{mM}$ sodium phosphate buffer ( $\mathrm{pH} 7.2)$, in a total volume of $20 \mu \mathrm{L}$. The reaction mixture was incubated at $25{ }^{\circ} \mathrm{C}$ for 10 min (leading to generation of the 3-ketoacyl ACP) and then treated with FabG and either NADPH or NADH for 10 min. All reactions were quenched with $20 \mu \mathrm{L}$ of $10 \%$ formic acid and products were analyzed using LC-ESI-MS performed with a high resolution mass spectrometer externally mass calibrated prior to analysis to obtain mass accuracy within $\pm 5 \mathrm{ppm}$. Chromatography was performed with an Accela HPLC system (Thermo Fisher Scientific, Waltham, MA) using a Discovery $(3 \mu \mathrm{m}, 15 \mathrm{~cm} \times 2.1 \mathrm{~mm}$, Supelco) reverse phase column at a flow rate of 200 $\mu \mathrm{L} / \mathrm{min}$. Solvent A was water with $0.05 \%$ formic and Solvent B was acetonitrile with $0.5 \%$ formic acid. The solvent gradient initiated with Solvent A (99\%) for 5 
min and then went to $99 \%$ of Solvent B over 25 min. A final 2 min at $99 \%$ Solvent $B$ was used before re-equilibrated with solvent $A$. The HPLC eluent was directed to a ThermoElectron LTQ-Orbitrap XL Discovery instrument (San Jose, CA, USA), equipped with an ESI ion max source. The ionization interface was operated in the positive mode using the following settings: source voltage, $4 \mathrm{kV}$; sheath and aux gas flow rates, 50 and 10 units respectively; tube lens voltage, $100 \mathrm{~V}$; capillary voltage, $14 \mathrm{~V}$; and capillary temperature, $300^{\circ} \mathrm{C}$. LTQ with collision induced dissociation (CID) values of 30 was used for LC-ESI-MS/MS experiments.

\subsection{Results and Discussion}

$\beta$-Ketoacyl-ACP reductase (FabG). The analysis of the $S$. coelicolor genome sequence has revealed the presence of three likely fabG gene (SCO1815, SC01345, SC01346, encoding $\beta$-ketoacyl-ACP reductase). To probe the physiological role of these three $S$. coelicolor fabG homologs, the genes were expressed in E. coli, and the corresponding recombinant proteins were purified as a soluble $\mathrm{N}$-terminal $\mathrm{His}_{6}$-tag protein. S. coelicolor produces predominantly branched-chain fatty acids, whereas E. coli produces only straight chain fatty acids. In order to facilitate a comparison of $S$. coelicolor ketoacyl-ACP reductase acyl specificity with that of a straight-chain fatty acid producer, the $E$. coli fabG gene was also expressed and purified. Analysis of affinity purified proteins by SDS-PAGE showed a major band with an apparent molecular weight of approximately $28 \mathrm{kDa}$ consistent with the expected molecular weight (Fig. 10). 
On the basis of earlier study which demonstrated that FabH ( $\beta$-KetoacylACP synthase III) from E. coli is specific for acetyl-CoA [12] we hypothesized that E. coli FabG would be specific for the straight-chain substrates. Despite the important role of FabG in FAS, analysis of specificity for straight and branchedchain substrates has not been investigated. Thus, a range of straight and branched-chain carboxylic acids were synthesized and activated as either a NAC or ACP derivative and were tested with the three S. coelicolor FabG homologs and the E. coli FabG.

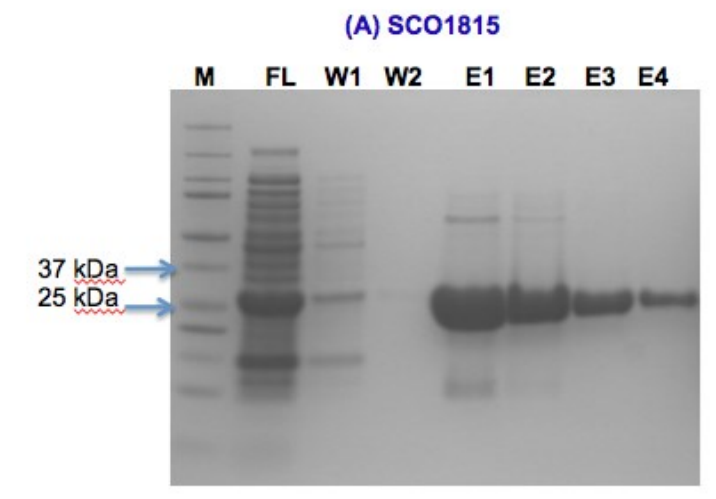

(C) SC01345

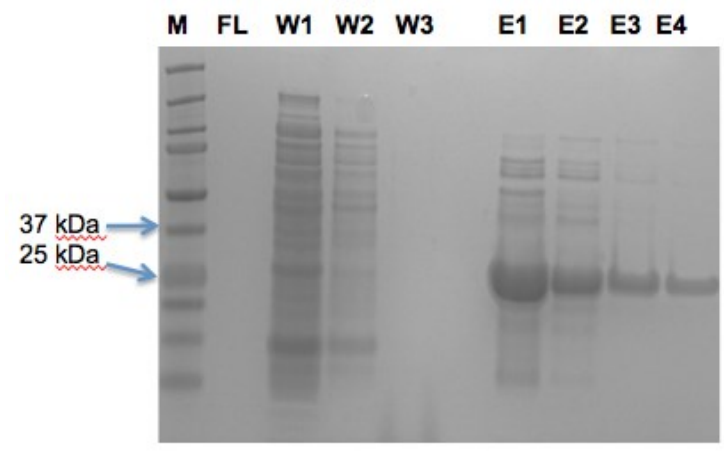

(B) SC01346

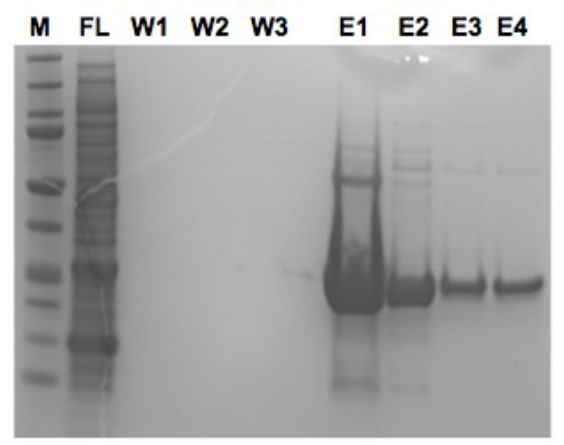

(D) E. coli. FabG

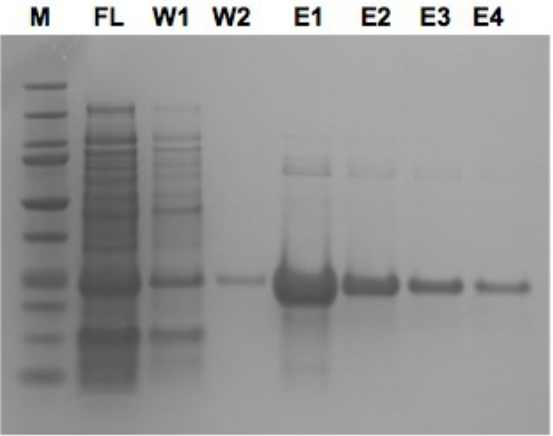

Figure 10. SDS-PAGE of purified S. coelicolor FabG's (SCO1815, SC01346, SCO1345), and E. coli FabG.

M-Standard protein marker; FL-Flow through; W-Wash; E-Protein elution fraction. 
$\beta$-Ketoacyl-NAC Specificity. The activity of FabG's with a series of straight and branched-chain $\beta$-ketoacyl-NAC substrates was determined using a NADPHbased spectrophotometric assay. The apparent $K_{M}$ for all NAC substrates were over $2 \mathrm{mM}$ (the high apparent $K_{M}$ can be attributed to using NAC thioesters in place of the natural ACP substrate), and limiting substrate solubility prevented determination of $\mathrm{V}_{\max }$ and calculating of $k_{\text {cat }}$ with these substrate mimics. Limiting solubility also prevented assays with substrate mimics with chain lengths greater than $\mathrm{C}_{10}$. Therefore, the catalytic efficiency $\left(k_{\text {cat }} / K_{M}\right)$ was determined under substrate-limited conditions. Kinetic analysis revealed that all three FabG homologs are capable of utilizing both straight and branched-chain substrates (Table 2).

For the streptomycetes FabG homologs this result is consistent with a FabGs role in fatty acid and prodiginine biosynthesis, wherein it processes branched-chain products of FabH for primary metabolism, as well as, straightchain products of RedP for undecylprodiginine biosynthesis. Furthermore, all FabGs were also observed to process $\beta$-ketoacyl-NAC substrates with a range of alkyl chain lengths $\mathrm{C}_{6}-\mathrm{C}_{10}$, and catalytic efficiency generally increased as substrate chain length increased. This general trend was observed for all FabGs with branched-chain substrates. In the case of the straight-chain substrates the greatest activity was observed with the $\mathrm{C}_{8}$ substrates. The higher catalytic efficiency with longer chain substrates corresponds to the average chain length of the substrates that are processed in a fatty acid by FabG and potentially reflect 
greater occupancy of the appropriate acyl binding pocket in the overall catalytic process.

Table 2: Kinetic Data of S. coelicolor. SCO1815, SCO1345, SCO1346, and E.coli FabG

\begin{tabular}{|c|c|c|c|c|}
\hline Substrate & $\begin{array}{l}\text { SC01815 } \\
k_{\text {cat }} / K_{M} \\
\left(\mathrm{mM}^{-1} \mathrm{~min}^{-1}\right)\end{array}$ & $\begin{array}{l}\text { SC01345 } \\
k_{\text {cat }} / K_{M} \\
\left(\mathrm{mM}^{-1} \mathrm{~min}^{-1}\right)\end{array}$ & $\begin{array}{l}\text { SC01346 } \\
k_{c a t} / K_{M} \\
\left(\mathrm{mM}^{-1} \mathrm{~min}^{-1}\right)\end{array}$ & $\begin{array}{l}\text { E. coli FabG } \\
k_{\text {cat }} / K_{M} \\
\left(\mathrm{mM}^{-1} \mathrm{~min}^{-1}\right)\end{array}$ \\
\hline Straight-chain & & & & \\
\hline 3-Ketohexanoic-NAC & $38 \pm 1.5$ & $16 \pm 1.2$ & $160 \pm 1.0$ & $280 \pm 17.0$ \\
\hline 3-Ketooctanoic-NAC & $93 \pm 9.0$ & $118 \pm 6.0$ & $205 \pm 7.0$ & $1912 \pm 133.0$ \\
\hline 3-Ketodecanoic-NAC & $75 \pm 3.0$ & $46 \pm 1.0$ & $92 \pm 5.0$ & $1375 \pm 32.0$ \\
\hline Branched-chain & & & & \\
\hline $\begin{array}{l}\text { 5-Methyl-3-ketohexanoic- } \\
\text { NAC }\end{array}$ & $11 \pm 1.1$ & $91 \pm 8.0$ & $15 \pm 3.0$ & $36 \pm 4.0$ \\
\hline $\begin{array}{l}\text { 6-Methyl-3-ketoheptanoic- } \\
\text { NAC }\end{array}$ & $92 \pm 5.0$ & $123 \pm 6.0$ & $292 \pm 5.0$ & $703 \pm 14.0$ \\
\hline $\begin{array}{l}\text { 7-Methyl-3-ketooctanoic- } \\
\text { NAC }\end{array}$ & $122 \pm 2.0$ & $385 \pm 48.0$ & $350 \pm 47.0$ & $1293 \pm 20.0$ \\
\hline
\end{tabular}

The FabG from E. coli, showed a several fold higher apparent efficiency than the S. coelicolor FabGs. This difference of catalytic activity could be innate or a result of assay conditions with substrate mimics. Finally the data demonstrates for the first time that the FabG from E. coli can utilize both straight and branched-chain $\beta$-ketoacyl substrates, with comparable efficiency. This observation is in contrast to the data with the E. coli $\mathrm{FabH}$, which has been 
shown to have a strong preference for straight-chain substrates such as acetyl and propionyl-CoA [57]. While E. coli does not generate branched-chain fatty acids, production of small levels of them has been observed when the natural FabH is replaced with FabH which can process branched acyl-CoA starter units $[58,65]$. This production presumably is dependent upon the relaxed acyl group specificity of the E. coli FabG.

(A) $\mathrm{SC01815}$

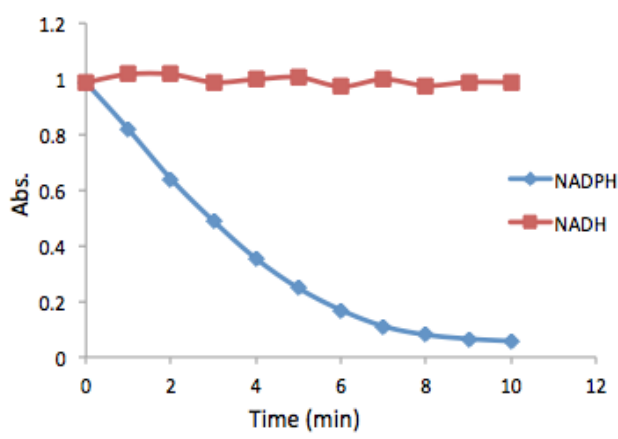

(C) Sc01346

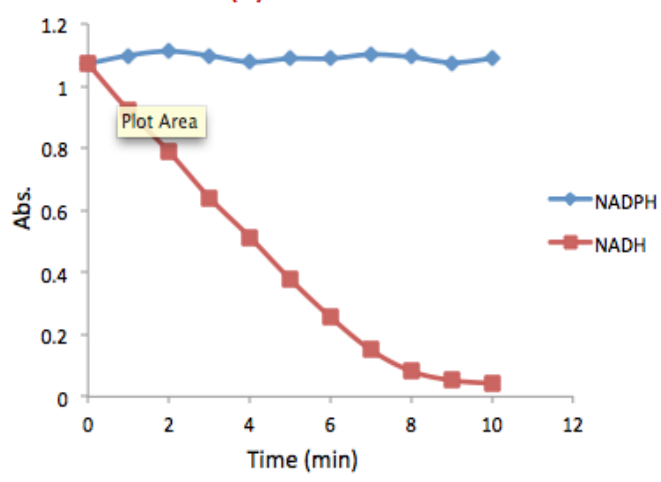

(B) Sc01345

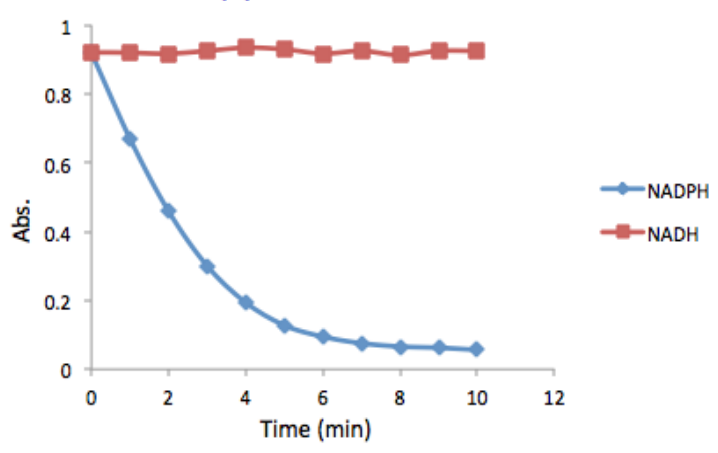

(D) E. coli FabG

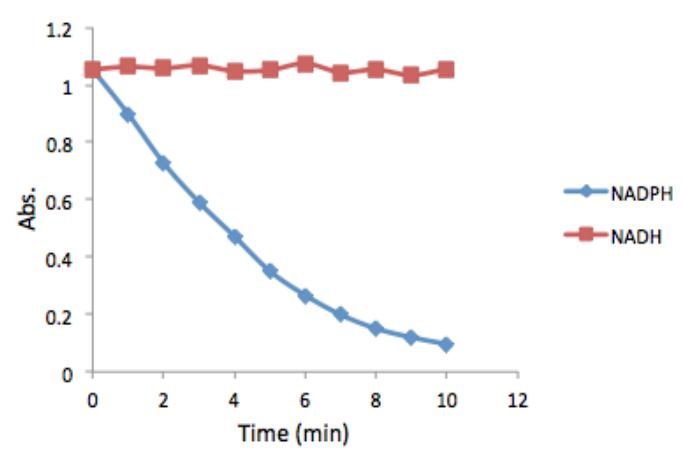

Figure 11. Comparison of S. coelicolor FabG's (SC01815, SCO1346, SCO1345), and E. coli FabG activities with NADPH and NADH. 
The cofactor preference of all the enzymes was also determined using both NADPH and NADH. SCO1815, SCO1345 and E.coli FabG all demonstrated at least 10 -fold higher catalytic activity with NADPH than NADH, consistent with previous studies of FabG proteins [66-68]. In contrast SCO1346 was highly specific for NADH and in this case the catalytic activity was at least 100 -fold higher than with NADPH (Fig.11).

ACP Specificity. Since the acyl-NAC is a poor mimic of the natural substrate for FabG, their activity with acyl-ACPs was also determined, using an LC/MS assay. The S. coelicolor SCO1815 was initially assayed by employing the reverse reaction i.e. oxidation of 3-hydroxyacyl-ZhuG to 3-oxoacyl-ZhuG (ZhuG is the ACP used in the biosynthesis of the polyketide R1128, a nonnative pathway which has been introduced into S. coelicolor). This approach was taken to avoid problems associated with 3-ketoacyl-ACP preparation and stability [62]. Studies have shown that the acyl group specificity of an enzyme can change when using nonnative ACPs [69]. Our approach was a) to generate the 3-ketoacyl-ACP enzymatically and then use it immediately to assay the reaction in the forward direction, and b) to test the S. coelicolor FabG homologs with the physiologically relevant acyl-ACPs (RedQ and FabC). The phosphopantetheine ejection assay was carried out to monitor the reaction with a previously described method [70]. While a detailed kinetic analysis was not possible because of limitations of acylACP substrate production, a broad assessment of acyl and ACP specificity was possible for the all the FabG proteins. 
Initially, FabH was incubated with butyryl-CoA and malonyl-FabC to generate the straight-chain $\beta$-ketoacyl-FabC and the product was analyzed with LC/MS (Fig. 12A).

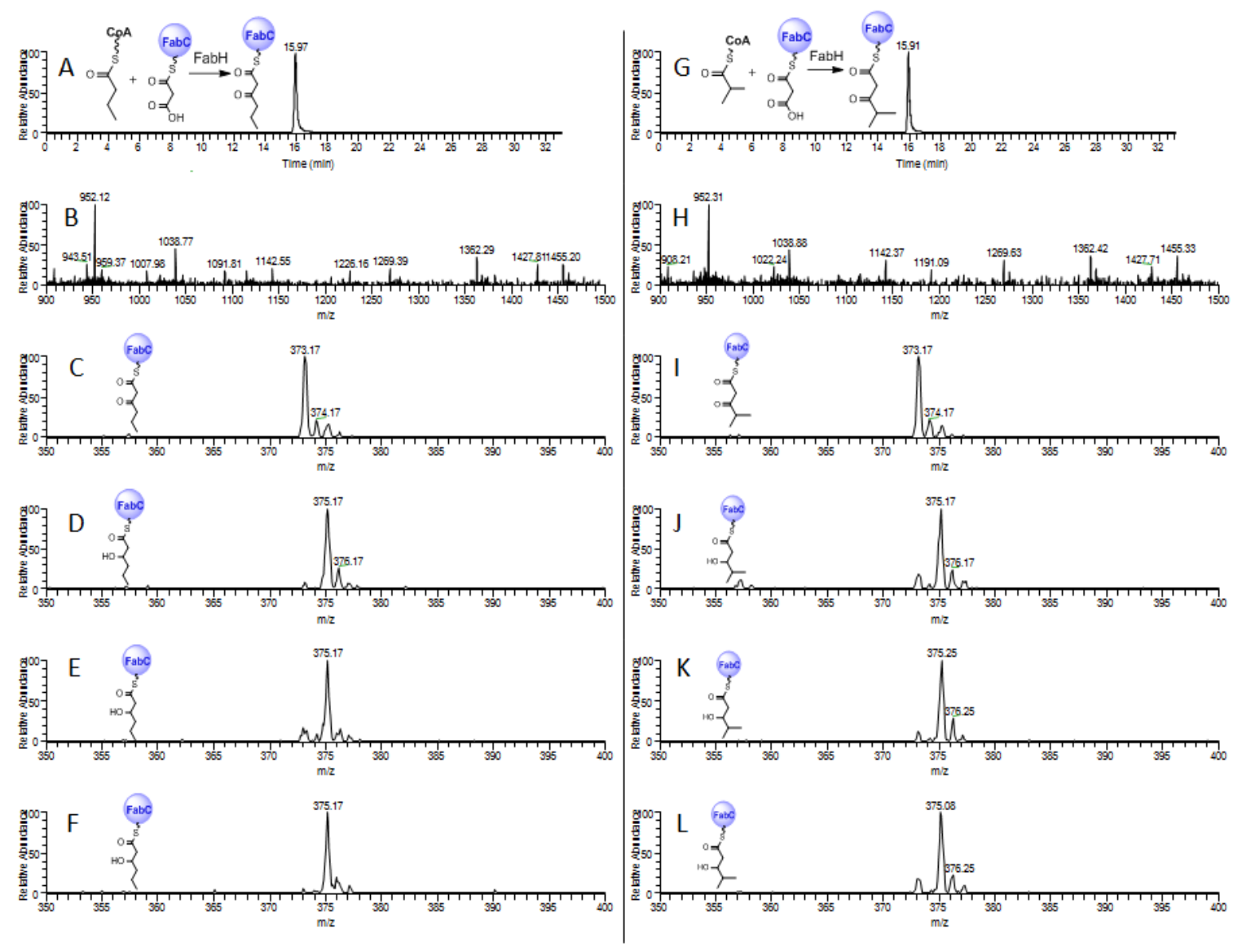

Figure 12. Coupled assay of FabH and FabG. Left panel, A) LC/MS extracted ion chromatogram of the FabH reaction with Butyryl-CoA and malonyl-FabC. B) Total ion chromatogram, $\mathrm{m} / \mathrm{z}$ of 952 corresponds to the major mass-charge ratio observed for ACP-bound 3-keto condensed product of FabH reaction. The $\mathrm{MS}^{2}$ spectra of 952 (373 corresponds to a phosphopantetheine thioester of expected 3-keto condensed product of $\mathrm{FabH}$ ) (C), and of the hydroxy product with 
SCO1815 (D), SCO1345 (E) and SCO1346 (F). In comparison to SCO1815 and SC01346, a 10-fold higher concentration of SCO1345 was necessary to obtain the complete conversion of 3-ketoacyl substrate to 3-hydroxyacyl product.

Similarly, Right Panel, G) LC/MS MS extracted ion chromatogram of the FabH reaction with Isobutyryl-CoA and malonyl-FabC, H) Total ion chromatogram of the FabH reaction product, I) The $\mathrm{MS}^{2}$ spectra of 952 . The phosphopentatheine fragment of hydroxy product of SCO1815 (J), SCO1345 (K) and SCO1346 (L).

A major $\mathrm{m} / \mathrm{z} 952$ was observed corresponding to the major mass-charge ratio for the condensed ACP bound product of FabH reaction (Fig. 12B). A MS ${ }^{2}$ of $\mathrm{m} / \mathrm{z} 952$ produced a major $\mathrm{m} / \mathrm{z} 373$ signal, consistent with the mass of phosphopantetheine thioester of the expected 3-keto condensed product of FabH (Fig. 12C). After addition of NADPH (or NADH) and all three FabGs to the $\beta$ ketoacyl-FabC product of $\mathrm{FabH}$, the same analysis provided a major $m / z 375$ (an increase in 2 atomic mass units) which is consistent with the expected mass of the $\beta$-hydroxyacyl-FabC product (Fig. 12D, E and F for SCO1815, SCO1345 and SC01346 respectively). The level of reduction using SCO1345 could only be achieved under the same assay conditions by using 10 -fold higher levels of the enzyme. This level of difference in catalytic efficiency was not observed when the acyl-NAC substrate mimics were used.

Assays were also carried out with branched-chain 3-ketoacyl-FabC. These were generated using isobutyryl-CoA (in place of butyryl-CoA) and malonyl-FabC 
with FabH (Fig. 12G, H and I). These assays revealed conversion of the 3ketoacyl-FabC with all three FabG homologs (Fig. 12J, K, and L). The lower catalytic efficiency for SCO1345 was observed with both the straight and branched-chain 3-ketoacyl-FabC substrates. The ability to process both straight and branched acyl-ACP substrates and the cofactor specificity of the FabG homologs is consistent with the observations using 3-ketoacyl- NAC substrate mimics.

Additionally, activity of each FabG was assayed with the 3-ketoacyl-ACP substrates using both the FAS ACP (FabC) and the prodiginine ACP (RedQ) (Fig. 13). The expectation was that both ACP substrates would be used if the FabG is involved in both processes. These assays were carried out in an analogous fashion to that used to look at straight and branched-chain specificity. The phosphopantetheine fragment of the starting substrate malonyl-FabC exhibited expected mass of 347 (Fig. 13A). The $\beta$-ketoacyl-chain substrates were generated by using butyryl-CoA and malonyl-FabC with FabH (Fig. 13B), and after addition of FabG, the expected reduced product was observed (Fig. 13C, D, E and F for SCO1815, SC01345 SCO1346 and E.coli FabG respectively).

Similarly, the $\beta$-ketoacyl-RedQ substrate was generated by the reaction of RedP with butyryl-CoA and malonyl-RedQ and was analyzed by LC/MS. The expected phosphopantetheine fragment of the starting substrate malonyl-RedQ was exhibited in the LC/MS assay (Fig. 13G). 
Similar to the FabH product, a condensed product ( $\beta$-ketoacyl-RedQ) of RedP was observed after incubation with malonyl-RedQ and butyryl-CoA (Fig. 13H). Again a reduced product was obtained after addition of FabG (Fig. 13I, K and L, SCO1815, SCO1346 and E.coli FabG). In contrast SCO1345 was not active with the RedQ substrates (Fig. 13J).
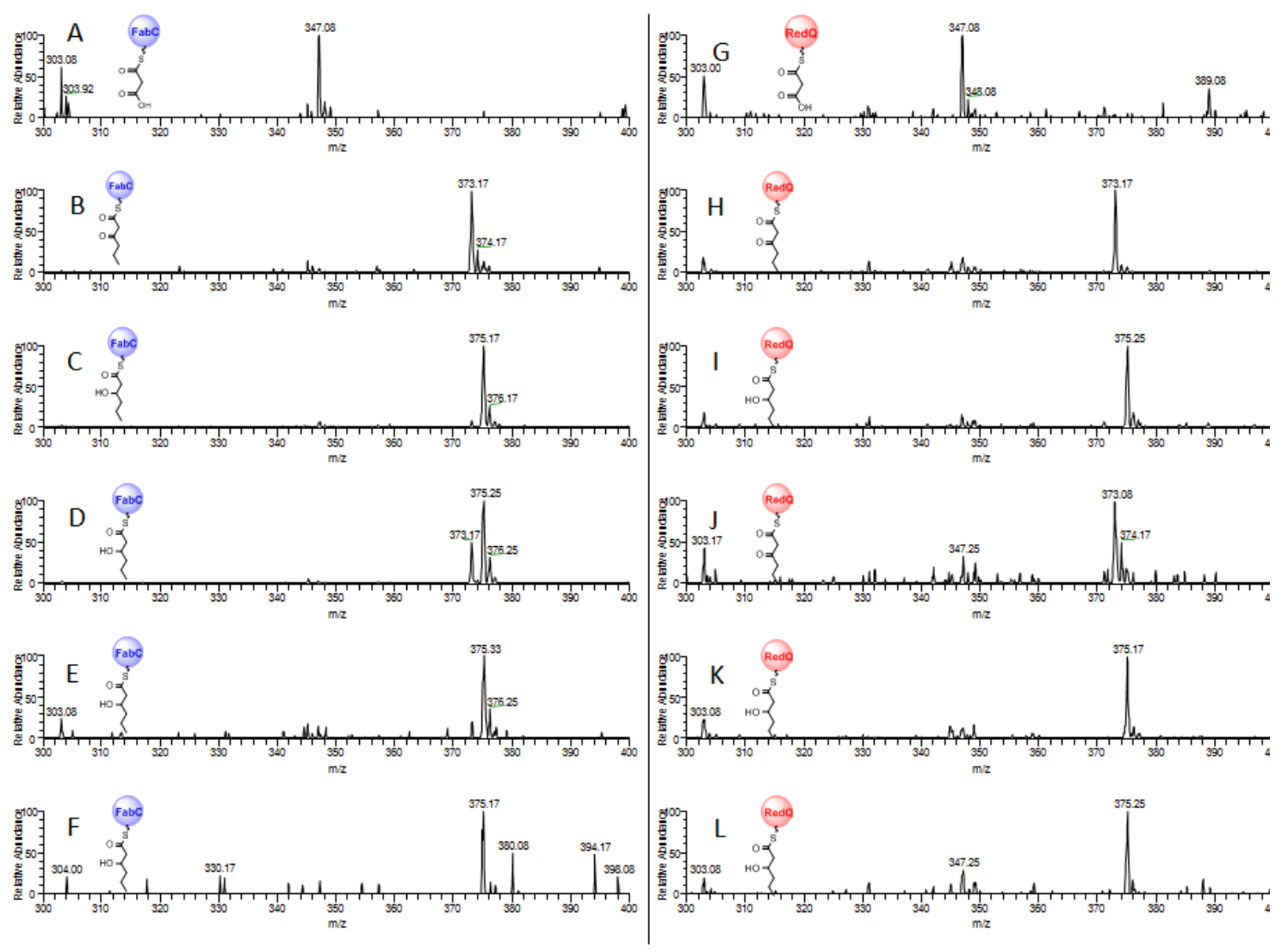

Figure 13. Coupled assay of FabH and FabG, with butyryl-CoA and malonylFabC (or malonyl-RedQ). Left panel, Phosphopantetheine fragment of, starting substrate malonyl-FabC (A), 3-keto product of FabH reaction with butyryl-CoA 
and malonyl-FabC (B), reduced product of SCO1815 (C), SCO1345 (D), SCO1346 (E) and E.coli FabG (F).

Similarly, Right panel, Phosphopantetheine fragment of, malonyl-RedQ (G), 3keto product of FabH reaction with butyryl-CoA and malonyl-RedQ $(\mathrm{H})$, reduced product of SCO1815 (I), SCO1346 (K), and E.coli FabG (L), no product was observed with SCO1345 (J).

These data demonstrate that out of three $S$. coelicolor FabGs enzymes, SCO1815 and SCO1346 have capability to process the ACPs from both fatty acid and undecylprodiginine biosynthesis. This is consistent with one or both of these FabGs processing 3-ketoacyl-FabC substrates for primary metabolism, and 3-ketoacyl-RedQ substrates for secondary metabolism. The ability of the $E$. coli FabG to process 3-ketoacyl-RedQ (Fig. 13L) demonstrates that this enzyme can tolerate changes in both the acyl and ACP components of the 3-ketacyl-ACP substrate.

These analyses are consistent with the predications for the activity and likely role of the FabG encoded by SCO1815. Notably it uses both straight and branched-chain 3-keotacyl-ACP substrates, using either FabC or RedQ. These observations in addition to the NADPH cofactor specificity and colocation of the gene with SCO1814 (and detailed below this has the enoyl-ACP reductase activity required for fatty acid biosynthesis) all support the hypothesis this is the primary FabG used for both fatty acid and undecylprodiginine biosynthesis. Colocation of genes for the FabG and Fabl are also observed in other organisms, 
notably mycobacterium [61]. Given all of this and the literature which to date supports the role of a single FabG in a type II dissociated fatty acid biosynthetic process [61], we were surprised to see 3-ketoacyl-NAC and 3-ketoacyl-ACP activity with FabG encoded by SCO1345 and SCO1346. The markedly lower activity of the FabG encoded by SCO1345 (compared to the other two FabG homologs) when 3-ketoacyl-ACP substrates were used indicates that these are not the physiological substrates and this reductase is involved in another cellular process. The same cannot be said for the FabG encoded by SCO1346, which differs from the SCO1815 encoded FabG by cofactor specificity. The physiological role of both of these FabG homologs thus remains elusive.

Enoyl-ACP reductase (Fabl). The analysis of the $S$. coelicolor genome sequence has revealed the presence of one fabl (SCO1814). In order to test the hypothesis that SCO1814 encodes the enoyl-ACP reductase used in fatty acid and undecylprodiginine biosynthesis, the fabl (SCO1814) was amplified from S. coelicolor genomic DNA, expressed in E. coli, and purified. The purified protein had the expected molecular mass of approximately $30 \mathrm{kDa}$ as determined by SDS-PAGE. In addition to SCO1814, the previously characterized E. coli fabl gene $[71,72]$ was also expressed and purified (also with the expected molecular mass of approximately $30 \mathrm{kDa}$ ) (Fig. 14). 

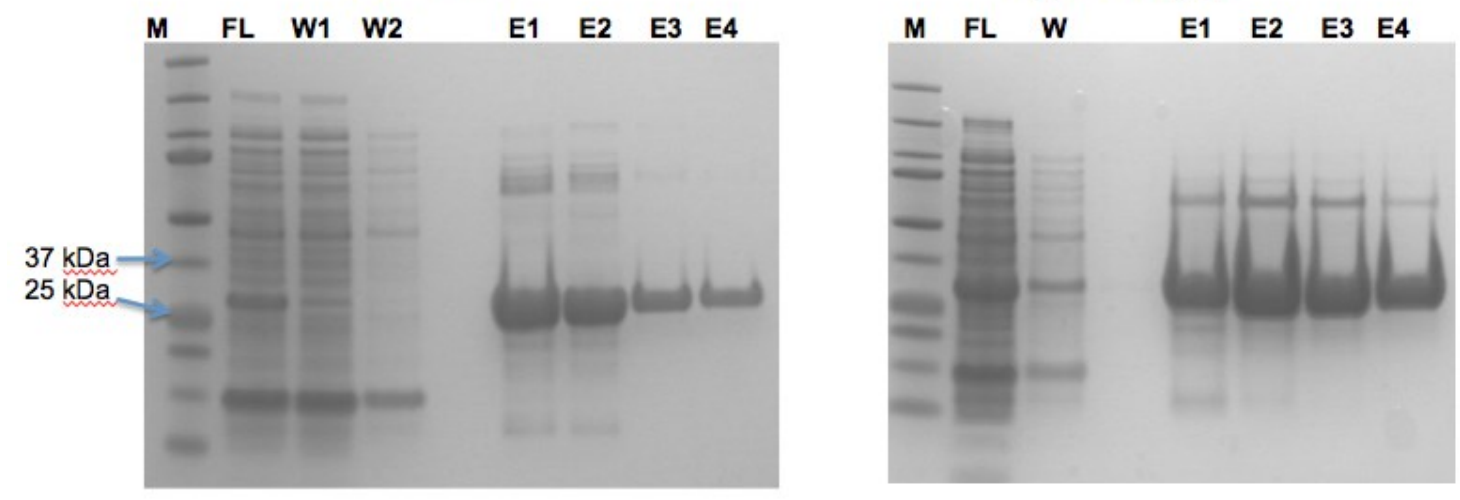

Figure 14. SDS-PAGE of purified S. coelicolor $\operatorname{Inh} A(A)$ and E. coli Fabl (B).

M-Standard protein marker; FL-Flow through; W-Wash; E-Protein elution fraction.

Since E. coli generates only straight-chain fatty acids we hypothesized that Fabl from E. coli would have a strong preference for straight-chain substrates (as in the case of E. coli FabH). To date no data has compared the Fabl activity with straight and branched-chain substrates. Therefore it would be useful to compare this Fabl acyl specificity with that of the S. coelicolor Fabl. In this study, a series of straight and branched-chain substrates varying in the chain length were synthesized (Scheme 1) and used in the spectrophotometric and LC/MS assay. Enoyl-NAC Specificity. The activity of Fabl with a series of straight and branched-chain enoyl-NAC substrates $\left(\mathrm{C}_{4}-\mathrm{C}_{10}\right)$ was determined using an $\mathrm{NADH}-$ dependent spectrophotometric assay. The apparent $K_{M}$ for all enoyl-NAC substrates was over $2 \mathrm{mM}$. Substrate solubility prevented the use of longer substrate (more than $\mathrm{C}_{10}$ ) and concentration well above the $K_{M}$. Therefore, the 
apparent catalytic efficiency $\left(k_{c a t} / K_{M}\right)$ values were obtained under substratelimited conditions as in the case of FabG. The high $K_{M}$ likely reflects the use of NAC thioesters in place of ACPs. Nonetheless, these kinetic analyses demonstrated that $S$. coelicolor Fabl has the capability of utilizing all of the straight and branched-chain enoyl-NAC substrates tested $\left(\mathrm{C}_{4}-\mathrm{C}_{10}\right)$ (Table 2$)$. No clear pattern was observed between catalytic efficiencies using straight and branched enoyl-NAC substrates of comparable chain length. These observations are consistent with the predicted activity of the Fabl and its role in both fatty acid and prodiginine biosynthesis (Fig. 9), wherein it processes both short and long chain products of FabH (or RedP) or FabF (or RedR) respectively. The catalytic efficiency of Fabl with various straight-chain enoyl-NAC ( $C_{4}$ to $C_{10}$ chain length) generally increased as substrate chain length increased and general trend was: 2-octenoyl-NAC $>$ 2-decenoic-NAC $>$ 2-hexenoic-NAC > 2-butenoic-NAC. A similar trend was also observed with the branched-chain substrates. The preference for processing longer straight-chain enoyl-substrates has previously been observed and is again likely the result of greater occupancy on the enoylgroup binding pocket of the enzyme $[73,74]$. Similar observations of processing both straight and branched-chain enoyl-NAC substrates were seen with the $E$. coli Fabl (Table 3).

Thus in both organisms that produce branched-chain fatty acids and those which produce only straight-chain fatty acid the reductive enzymes Fabl and FabG can process both straight and branched-chain substrates. The apparent 
catalytic efficiency of the $E$ coli Fabl was a several folds higher than the $S$. coelicolor Fabl, an observation made previously when the E. coli Fabl was compared with Fabl from other enzymes [75].

Table 3: Kinetic data of S. coelicolor and E.coli Fabl

\begin{tabular}{|c|c|c|}
\hline Substrates & $\begin{array}{ll}\text { Sc. } & \text { Fabl } \\
k_{\text {cat }} / K_{M}\left(\mathrm{mM}^{-1} \mathrm{~min}^{-}\right. \\
\left.{ }^{1}\right)\end{array}$ & $\begin{array}{l}\text { E. coli Fabl } \\
k_{\text {cat }} / K_{M}\left(\mathrm{mM}^{-1} \mathrm{~min}^{-}\right. \\
\left.{ }^{1}\right)\end{array}$ \\
\hline \multicolumn{3}{|l|}{ Straight-chain } \\
\hline 2-Butenoic-NAC & $10 \pm 1.9$ & $97 \pm 6.0$ \\
\hline 2-Hexenoic-NAC & $19 \pm 1.0$ & $231 \pm 12.0$ \\
\hline 2-Octenoic-NAC & $49 \pm 1.0$ & $611 \pm 15.0$ \\
\hline 2-Decenoic-NAC & $20 \pm 1.2$ & $157 \pm 27.0$ \\
\hline \multicolumn{3}{|l|}{ Branched-chain } \\
\hline 4-Methyl-2-pentenoic-NAC & $17 \pm 1.5$ & $12 \pm 2.0$ \\
\hline 5-Methyl-2-hexenoic-NAC & $2 \pm 0.1$ & $0.37 \pm 0.05$ \\
\hline 6-Methyl-2-heptenoic-NAC & $29 \pm 2.0$ & $302 \pm 6.0$ \\
\hline 7-Methyl-2-octenoic-NAC & $63 \pm 4.0$ & $361 \pm 19.0$ \\
\hline 9-Methyl-2-decenoic-NAC & $9.0 \pm 1.0$ & $10 \pm 1.0$ \\
\hline
\end{tabular}

It has also been observed that enoyl-reductase (Fabl) from other organisms prefer CoA over NAC thioesters (even though CoA is not the physiological substrate) and that NADH is the preferred cofactor [75]. Similar preferences were observed with the S. coelicolor Fabl in this study, and in fact no 
activity was observed with NADPH even when enzyme concentration was increased 20 -fold (Fig. 15).
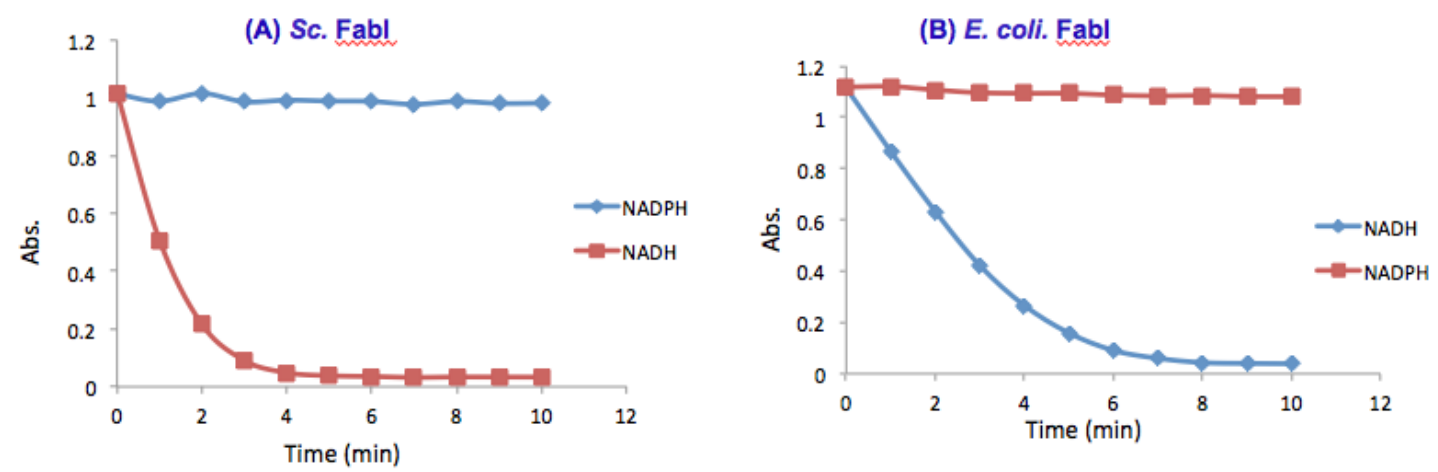

Figure 15. Comparison of $S$. coelicolor InhA (A) and E. coli Fabl (B).activities with NADPH and NADH.

ACP Specificity. Similar to FabG, an LC/MS assay was carried out to determine the Fabl specificity with the ACPs from both metabolic processes (Fig. 16). In this study an AcpP from E.coli fatty acid synthase was used because of technical difficulties in generating a sufficient amount of apo-FabC. Crotonoyl-AcpP was generated from apo-AcpP (the E. coli fatty acid synthase ACP) and crotonoylCoA, using Sfp (a phosphopantetheinyl transferase) and analyzed by LC/MS (Fig. 16A). 


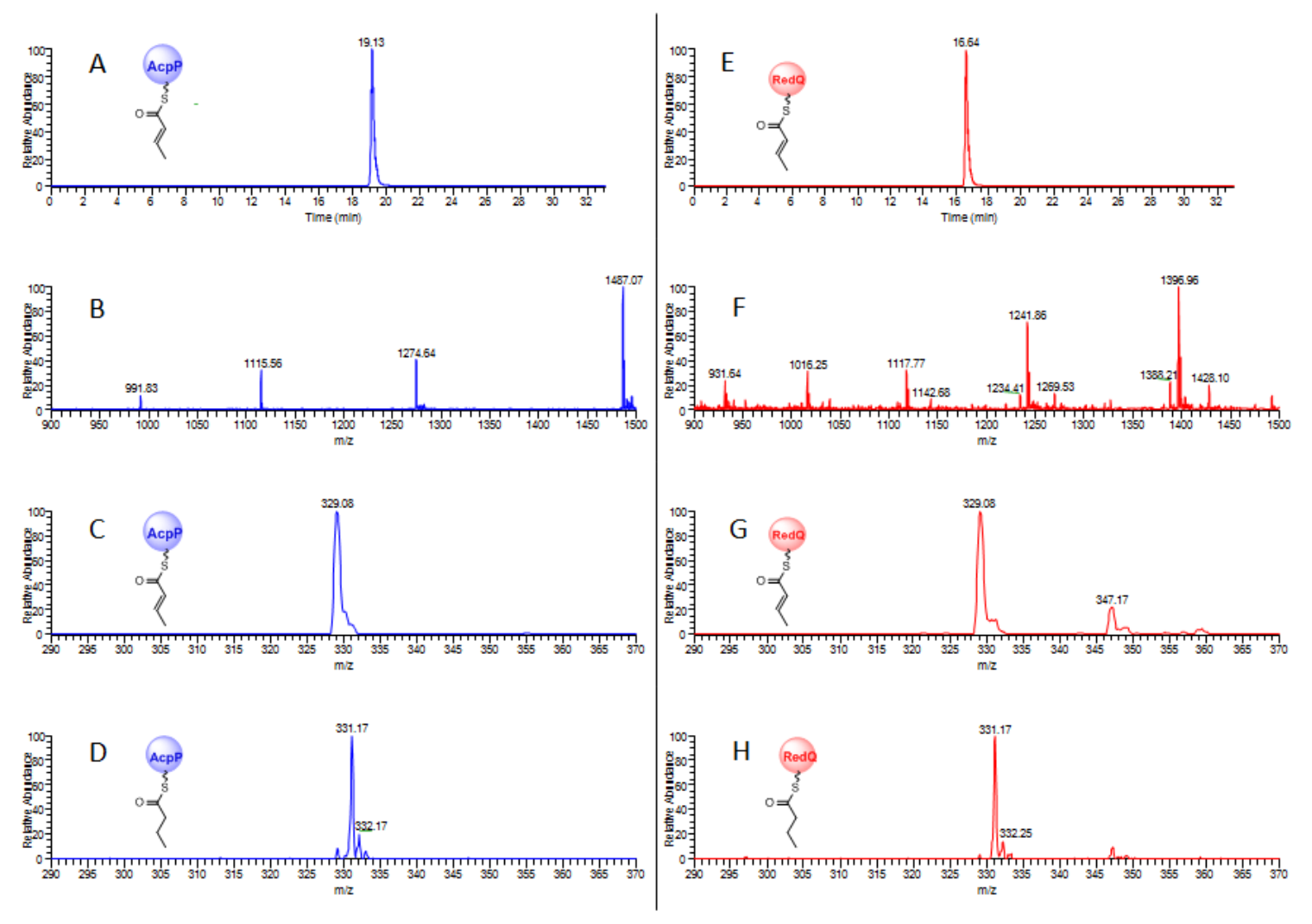

Figure 16. LC/MS analysis of Fabl reaction with crotonoyl-AcpP (or crotonoylRedQ) and NADH. Left panel A) mass spectrum of the starting substrate crotonoyl-AcpP B) Total ion chromatogram, $\mathrm{m} / \mathrm{z}$ C) The $\mathrm{MS}^{2}$ spectra of 1115 (329 corresponds to a phosphopantetheine thioester of.crotonoyl group) D) Saturated product of Fabl with crotonoyl-AcpP and NADH

Right panel E) mass spectrum of the crotonoyl-RedQ F) $\mathrm{m} / \mathrm{z}$ G) The $M \mathrm{~S}^{2}$ spectra of $1016 \mathrm{H}$ ) Saturated product of InhA 
An $m / z 1115$ was observed corresponding to the mass-charge ratio observed for crotonoyl-AcpP (Fig. 16B). An $\mathrm{MS}^{2}$ of the parent $\mathrm{m} / \mathrm{z} 1115$ provides a fragment $\mathrm{m} / \mathrm{z} 329$, which is consistent with the expected mass of phosphopantetheine thioester of crotonoyl group (Fig. 16C).

The Fabl catalyzed the reduction of crotonoyl-AcpP by NADH to the saturated product, (butyryl-AcpP) with a predicted mass 331 was observed (Fig. 16D). Similarly, crotonoyl-RedQ was generated to evaluate the role of Fabl in secondary metabolism, by the incubation of Sfp with apo-RedQ and crotonoylCoA (Fig.16E, F and G). Consistent with Fabl's role in secondary metabolism; it was able to process the crotonoyl-RedQ into the saturated product (Fig. 16H).

These assays clearly demonstrate that SCO1814 (Fabl) has both enoylNAC and enoyl-ACP reductase activity. In both cases Fabl utilizes various chain lengths of straight and branched-chain substrates. Furthermore, Fabl does not discriminate between ACPs from primary metabolism and secondary metabolism. A gene encoding the enoyl-ACP reductase (Fabl) is not present in the red biosynthetic gene cluster and thus all evidence support a role of SCO1814 in both fatty acid and undecylprodiginine biosynthetic process in S. coelicolor (Fig. 9).

In this study we have cloned all three 3-ketoacyl-ACP reductases homologues (SCO1815, SCO1345, and SCO1346), along with the SCO1814 enoyl-ACP reductase homologue from S. coelicolor and purified all proteins. We have carried out the first kinetic analyses of these streptomycetes enzymes and 
demonstrated that all three FabGs homologues have 3-ketoacyl-ACP reductases activity, and the Fabl homologue has enoyl-ACP reductase activity. The activities of the SCO1815 encoded FabG and the SCO1814 Fabl provide compelling support for a role of these enzymes in providing both fatty acids for primary metabolism and dodecanoic acid for undecylprodiginine biosynthesis. Thus data now provides experimental evidence to support the role of FabG and Fabl, in addition to FabD, in both processes and suggests they may exert no control over the products. In contrast the condensing enzymes ( $F a b H$ and RedP) are the key controlling factors. 


\subsection{NMR spectral data of the intermediates and final compounds}

All (E)-S-(2-acetamidoethyl) alk-2-enethioate (enoyl-NAC) compounds were synthesized according to the general procedures as shown in Scheme1.

NMR spectral data of the intermediates for one representative compound.

\section{7-Methyloctan-1-ol:}<smiles>CC(C)CCCCCCO</smiles>

${ }^{1} \mathrm{H} \mathrm{NMR}\left(\mathrm{CDCl}_{3}, 400 \mathrm{MHz}\right) \delta 3.65(\mathrm{t}, J=6.6 \mathrm{~Hz}, 2 \mathrm{H}), 1.60-1.51(\mathrm{~m}, 3 \mathrm{H}), 1.37-1.28$ (m, 6H), 1.18-1.16 (m, 2H), $0.91(\mathrm{~d}, J=6.6 \mathrm{~Hz}, 6 \mathrm{H})$.

\section{7-Methyloctanal:}<smiles>CC(C)CCCCCC=O</smiles>

${ }^{1} \mathrm{H}$ NMR $\left(\mathrm{CDCl}_{3}, 400 \mathrm{MHz}\right) \delta 9.78(\mathrm{t}, J=1.8 \mathrm{~Hz}, 1 \mathrm{H}) \cdot 2.45-2.41(\mathrm{~m}, 2 \mathrm{H}), 1.67-1.63$ (m, 2H), 1.53-1.52 (m, 1H), 1.34-1.30 (m, 4H), 1.19-1.17 (m, 2H), $0.88(\mathrm{~d}, J=6.6$ $\mathrm{Hz}, 6 \mathrm{H})$.

\section{Methyl (E)-9-methyldec-2-enoate:}<smiles>COC(=O)/C=C/CCCCCC(C)C</smiles> 
${ }^{1} \mathrm{H} \mathrm{NMR}\left(\mathrm{CDCl}_{3}, 400 \mathrm{MHz}\right) \delta 7.0-6.97(\mathrm{~m}, 1 \mathrm{H}), 5.83(\mathrm{dd}, J=1.5,15.6 \mathrm{~Hz}, 1 \mathrm{H})$, $3.74(\mathrm{~s}, 3 \mathrm{H}), 2.22-2.18(\mathrm{~m}, 2 \mathrm{H}), 1.54-1.45(\mathrm{~m}, 3 \mathrm{H}), 1.32-1.28(\mathrm{~m}, 4 \mathrm{H}), 1.19-1.16$ (m, 2H), $0.87(\mathrm{~d}, J=6.6 \mathrm{~Hz}, 6 \mathrm{H})$.

\section{(E)-9-methyldec-2-enoic acid:}<smiles>CC(C)CCCCC/C=C/C(=O)O</smiles>

${ }^{1} \mathrm{H} \mathrm{NMR}\left(\mathrm{CDCl}_{3}, 400 \mathrm{MHz}\right) \delta 7.12-7.08(\mathrm{~m}, 1 \mathrm{H}), 5.83(\mathrm{dd}, J=1.5,15.6 \mathrm{~Hz}, 1 \mathrm{H})$, 2.25-2.23 (m, 2H), 1.54-1.46 (m, 3H), 1.32-1.28 (m, 4H), 1.19-1.16 (m, $2 \mathrm{H}), 0.87$ $(\mathrm{d}, J=6.6 \mathrm{~Hz}, 6 \mathrm{H})$.

\section{S-(2-acetamidoethyl) (E)-9-methyldec-2-enethioate:}<smiles>CC(=O)NCCSC(=O)/C=C/CCCCCC(C)C</smiles>

${ }^{1} \mathrm{H}$ NMR $\left(\mathrm{CDCl}_{3}, 400 \mathrm{MHz}\right) \delta 6.95-6.91(\mathrm{~m}, 1 \mathrm{H}), 6.14(\mathrm{dd}, J=6.6,15.5 \mathrm{~Hz} 1 \mathrm{H})$, $5.96(\mathrm{br} \mathrm{s}, 1 \mathrm{H}), 3.48(\mathrm{q}, J=6.2 \mathrm{~Hz}, 2 \mathrm{H}), 3.11(\mathrm{t} J=6.4 \mathrm{~Hz}, 2 \mathrm{H}), 2.25-2.19(\mathrm{~m}, 2 \mathrm{H})$, $1.98(\mathrm{~s}, 3 \mathrm{H}), 1.54-1.46(\mathrm{~m}, 3 \mathrm{H}), 1.32-1.27(\mathrm{~m}, 4 \mathrm{H}), 1.20-1.16(\mathrm{~m}, 2 \mathrm{H}), 0.88(\mathrm{~d}, J$ $=6.6 \mathrm{~Hz}, 6 \mathrm{H})$.

NMR Spectral data of all the final (E)-S-(2-acetamidoethyl) alk-2-enethioate (enoyl-NAC) compounds.

$\underline{\text { S-(2-acetamidoethyl) (E)-but-2-enethioate: }}$ 
<smiles>C/C=C/C(=O)SCCNC(C)=O</smiles>

${ }^{1} \mathrm{H}$ NMR $\left(\mathrm{CDCl}_{3}, 400 \mathrm{MHz}\right) \delta 6.94-6.92(\mathrm{~m}, 1 \mathrm{H}), 6.17(\mathrm{dd}, J=1.6,15.6 \mathrm{~Hz}, 1 \mathrm{H})$, 5.98 (br s, 1H), 3.47 (q, J =6.2 Hz, 2H), 3.10 (t, J =6.2 Hz, 2H), 1.97 (s, 3H), 1.91 (dd, $J=1.6,6.8 \mathrm{~Hz}, 3 \mathrm{H})$.

\section{S-(2-acetamidoethyl) (E)-hex-2-enethioate:}<smiles>CCC/C=C/C(=O)SCCNC(C)=O</smiles>

${ }^{1} \mathrm{H}$ NMR $\left(\mathrm{CDCl}_{3}, 400 \mathrm{MHz}\right) \delta 6.98-6.91((\mathrm{~m}, 1 \mathrm{H}), 6.15(\mathrm{dd}, J=1.5,15.5 \mathrm{~Hz}, 1 \mathrm{H})$, 5.94 (br s, 1H), 3.48 (q, J =6.5 Hz, 2H), $3.11(\mathrm{t}, J=6.6 \mathrm{~Hz}, 2 \mathrm{H}), 2.24-2.18(\mathrm{~m}, 2 \mathrm{H})$, $1.98(\mathrm{~s}, 3 \mathrm{H}), 1.55-1.49(\mathrm{~m}, 2 \mathrm{H}), 0.96(\mathrm{t}, \mathrm{J}=7.3 \mathrm{~Hz}, 3 \mathrm{H})$.

\section{S-(2-acetamidoethyl) (E)-oct-2-enethioate:}<smiles>CCCCC/C=C/C(=O)SCCNC(C)=O</smiles>

${ }^{1} \mathrm{H}$ NMR $\left(\mathrm{CDCl}_{3}, 400 \mathrm{MHz}\right) \delta 6.99-6.91((\mathrm{~m}, 1 \mathrm{H}), 6.14(\mathrm{dd}, J=1.5,15.5 \mathrm{~Hz} 1 \mathrm{H})$, 5.93 (br s, 1H), 3.48 (q, J =6.4 Hz, 2H), 3.11 (t, $J=6.5 \mathrm{~Hz}, 2 \mathrm{H}), 2.25-2.19(\mathrm{~m}, 2 \mathrm{H})$, $1.98(\mathrm{~s}, 3 \mathrm{H}), 1.51-1.47(\mathrm{~m}, 2 \mathrm{H}), 1.35-1.30(\mathrm{~m}, 4 \mathrm{H}), 0.91(\mathrm{t}, J=6.8 \mathrm{~Hz}, 3 \mathrm{H})$.

\section{S-(2-acetamidoethyl) (E)-dec-2-enethioate:}


<smiles>CCCCCCC/C=C/C(=O)SCCNC(C)=O</smiles>

${ }^{1} \mathrm{H}$ NMR $\left(\mathrm{CDCl}_{3}, 400 \mathrm{MHz}\right) \delta 6.99-6.91((\mathrm{~m}, 1 \mathrm{H}), 6.14(\mathrm{dd}, J=1.5,15.5 \mathrm{~Hz} 1 \mathrm{H})$, 5.92 (br s, 1H), 3.48 (q, J =6.4 Hz, 2H), $3.11(\mathrm{t}, J=6.5 \mathrm{~Hz}, 2 \mathrm{H}), 2.25-2.19(\mathrm{~m}, 2 \mathrm{H})$, $1.98(\mathrm{~s}, 3 \mathrm{H}), 1.50-1.47(\mathrm{~m}, 2 \mathrm{H}), 1.32-1.29(\mathrm{~m}, 8 \mathrm{H}), 0.91(\mathrm{t}, J=6.7 \mathrm{~Hz}, 3 \mathrm{H})$.

\section{S-(2-acetamidoethyl) (E)-4-methylpent-2-enethioate:}<smiles>CC(=O)NCCSC(=O)/C=C/C(C)C</smiles>

${ }^{1} \mathrm{H}$ NMR $\left(\mathrm{CDCl}_{3}, 400 \mathrm{MHz}\right) \delta 6.92(\mathrm{dd}, J=6.6,15.6 \mathrm{~Hz} 1 \mathrm{H}), 6.10(\mathrm{dd}, J=1.4,15.6$ Hz 1H), 5.91 (br s, 1H), 3.48 (q, J = 6.5 Hz, 2H), 3.11 (t, $J=6.6 \mathrm{~Hz}, 2 \mathrm{H}), 2.50-2.48$ (m, 1H), $1.98(\mathrm{~s}, 3 \mathrm{H}), 1.10(\mathrm{~d}, \mathrm{~J}=6.8 \mathrm{~Hz}, 6 \mathrm{H})$.

\section{S-(2-acetamidoethyl) (E)-5-methylhex-2-enethioate:}<smiles>CC(=O)NCCSC(=O)/C=C/CC(C)C</smiles>

${ }^{1} \mathrm{H}$ NMR $\left(\mathrm{CDCl}_{3}, 400 \mathrm{MHz}\right) \delta 6.95-6.88(\mathrm{~m}, 1 \mathrm{H}), 6.13(\mathrm{dd}, J=1.4,15.4 \mathrm{~Hz} 1 \mathrm{H})$, 5.99 (br s, 1H), 3.47 (q, J = 6.4 Hz, 2H), 3.10 (t, J = 6.6 Hz, 2H), 2.12-2.08 (m, 2H), $1.97(\mathrm{~s}, 3 \mathrm{H}), 1.81-1.78(\mathrm{~m}, 1 \mathrm{H}), 0.94(\mathrm{~d}, J=6.6 \mathrm{~Hz}, 6 \mathrm{H})$.

\section{S-(2-acetamidoethyl) (E)-6-methylhept-2-enethioate:}


<smiles>CC(=O)NCCSC(=O)/C=C/CCC(C)C</smiles>

${ }^{1} \mathrm{H}$ NMR $\left(\mathrm{CDCl}_{3}, 400 \mathrm{MHz}\right) \delta 6.96-6.90(\mathrm{~m}, 1 \mathrm{H}), 6.13(\mathrm{dd}, J=1.5,15.5 \mathrm{~Hz} 1 \mathrm{H})$, 6.04 (br s, 1H), 3.46 (q, J = 6.1 Hz, 2H), 3.10 (t, J = 6.5 Hz, 2H), 2.25-2.19 (m, 2H), $1.97(\mathrm{~s}, 3 \mathrm{H}), 1.60-1.56(\mathrm{~m}, 1 \mathrm{H}), 1.38-1.33(\mathrm{~m}, 2 \mathrm{H}), 0.91(\mathrm{~d}, J=6.6 \mathrm{~Hz}, 6 \mathrm{H})$.

\section{S-(2-acetamidoethyl) (E)-7-methyloct-2-enethioate:}<smiles>CC(=O)NCCSC(=O)/C=C/CCCC(C)C</smiles>

${ }^{1} \mathrm{H}$ NMR $\left(\mathrm{CDCl}_{3}, 400 \mathrm{MHz}\right) \delta 6.95-6.89(\mathrm{~m}, 1 \mathrm{H}), 6.13(\mathrm{dd}, J=1.5,15.5 \mathrm{~Hz} 1 \mathrm{H})$, 6.07 (br s, 1H), 3.46 (q, J = 6.32 Hz, 2H), $3.10(\mathrm{t}, J=6.6 \mathrm{~Hz},, 2 \mathrm{H}), 2.21-2.16(\mathrm{~m}$, $2 \mathrm{H}), 1.97(\mathrm{~s}, 3 \mathrm{H}), 1.56-1.53(\mathrm{~m}, 1 \mathrm{H}), 1.48-1.45(\mathrm{~m}, 2 \mathrm{H}), 1.22-1.21(\mathrm{~m}, 2 \mathrm{H}), 0.88$ (d, $J=6.6 \mathrm{~Hz}, 6 \mathrm{H})$.

\section{S-(2-acetamidoethyl) (E)-9-methyldec-2-enethioate:}<smiles>CC(=O)NCCSC(=O)/C=C/CCCCCC(C)C</smiles>

${ }^{1} \mathrm{H}$ NMR $\left(\mathrm{CDCl}_{3}, 400 \mathrm{MHz}\right) \delta 6.95-6.91(\mathrm{~m}, 1 \mathrm{H}), 6.14(\mathrm{dd}, J=6.6,15.5 \mathrm{~Hz} 1 \mathrm{H})$, 5.96 (br s, 1H), 3.48 (q, $J=6.2 \mathrm{~Hz}, 2 \mathrm{H}), 3.11$ (t $J=6.4 \mathrm{~Hz}, 2 \mathrm{H}), 2.25-2.19(\mathrm{~m}, 2 \mathrm{H})$, $1.98(\mathrm{~s}, 3 \mathrm{H}), 1.54-1.46(\mathrm{~m}, 3 \mathrm{H}), 1.32-1.27(\mathrm{~m}, 4 \mathrm{H}), 1.20-1.16(\mathrm{~m}, 2 \mathrm{H}), 0.88(\mathrm{~d}, J$ $=6.6 \mathrm{~Hz}, 6 \mathrm{H})$. 
All S-(2-acetamidoethyl) 3-oxoalkanethioate (3-ketoacyl-NAC) compounds were synthesized according to the general procedures as shown in Scheme2.

NMR spectral data of the intermediates for one representative compound.

\section{5-Methylhexanoyl chloride:}<smiles>CC(C)CCCC(=O)Cl</smiles>

${ }^{1} \mathrm{H}$ NMR $\left(\mathrm{CDCl}_{3}, 400 \mathrm{MHz}\right) \delta 2.88(\mathrm{t}, J=7.3 \mathrm{~Hz}, 2 \mathrm{H}), 1.77-1.69(\mathrm{~m}, 2 \mathrm{H}), 1.60-1.56$ (m, 1H), 1.28-1.22 (m, 2H), $0.91(\mathrm{~d}, J=6.6 \mathrm{~Hz}, 6 \mathrm{H})$.

\section{Methyl 7-methyl-3-oxooctanoate:}<smiles>COC(=O)CC(=O)CCCC(C)C</smiles>

${ }^{1} \mathrm{H} \mathrm{NMR}\left(\mathrm{CDCl}_{3}, 400 \mathrm{MHz}\right) \delta 3.74(\mathrm{~s}, 3 \mathrm{H}), 3.46(\mathrm{~s}, 2 \mathrm{H}), 2.52(\mathrm{t}, J=7.3 \mathrm{~Hz}, 2 \mathrm{H})$, 1.64-1.53 (m, 3H), 1.21-1.15 (m, 2H), $0.90(\mathrm{~d}, J=6.6 \mathrm{~Hz}, 6 \mathrm{H})$.

\section{Methyl 3-hydroxy-7-methyloctanoate:}<smiles>COC(=O)CC(O)CCCC(C)C</smiles>

${ }^{1} \mathrm{H}$ NMR $\left(\mathrm{CDCl}_{3}, 400 \mathrm{MHz}\right) \delta 4.03(\mathrm{~m}, 1 \mathrm{H}), 3.72(\mathrm{~s}, 3 \mathrm{H}), 2.55-2.43(\mathrm{~m}, 2 \mathrm{H}), 1.56-$ $1.19(\mathrm{~m}, 7 \mathrm{H}), 0.90-.88(\mathrm{~m}, 6 \mathrm{H})$.

\section{3-Hydroxy-7-methyloctanoic acid:}


<smiles>CC(C)CCCC(O)CC(=O)O</smiles>

${ }^{1} \mathrm{H}$ NMR $\left(\mathrm{CDCl}_{3}, 400 \mathrm{MHz}\right) \delta 4.05(\mathrm{~m}, 1 \mathrm{H}), 2.60-2.44(\mathrm{~m}, 2 \mathrm{H}), 1.59-1.18(\mathrm{~m}, 7 \mathrm{H})$, 0.91-.89 (m, 6H).

S-(2-acetamidoethyl) 3-hydroxy-7-methyloctanethioate:<smiles>CC(=O)NCCSC(=O)CC(O)CCCC(C)C</smiles>

${ }^{1} \mathrm{H}$ NMR $\left(\mathrm{CDCl}_{3}, 400 \mathrm{MHz}\right) \delta 6.10(\mathrm{br} \mathrm{s}, 1 \mathrm{H}), 4.13-4.11(\mathrm{~m}, 1 \mathrm{H}), 3.46-3.43(\mathrm{~m}, 2 \mathrm{H})$, 3.06-3.02 (m, 2H), 2.74-2.66 (m, 2H), $1.97(\mathrm{~s}, 3 \mathrm{H}), 1.55-1.18(\mathrm{~m}, 7 \mathrm{H}), 0.88-0.86$ $(\mathrm{m}, 6 \mathrm{H})$.

S-(2-acetamidoethyl) 7-methyl-3-oxooctanethioate:<smiles>CC(=O)NCCSC(=O)CC(=O)CCCC(C)C</smiles>

${ }^{1} \mathrm{H}$ NMR $\left(\mathrm{CDCl}_{3}, 400 \mathrm{MHz}\right) \delta 5.98(\mathrm{br} \mathrm{s}, 1 \mathrm{H}), 3.71(\mathrm{~s}, 2 \mathrm{H}), 3.49-3.45(\mathrm{~m}, 2 \mathrm{H}), 3.12-$ $3.09(\mathrm{~m}, 2 \mathrm{H}), 2.52(\mathrm{t}, J=7.3 \mathrm{~Hz}, 2 \mathrm{H}), 1.99(\mathrm{~s}, 3 \mathrm{H}), 1.62-1.53(\mathrm{~m}, 3 \mathrm{H}), 1.20-1.18$ $(\mathrm{m}, 2 \mathrm{H}), 0.90-0.89(\mathrm{~m}, 6 \mathrm{H})$.

NMR spectral data of the final S-(2-acetamidoethyl) 3-oxoalkanethioate (3ketoacyl-NAC) compounds.

\section{S-(2-acetamidoethyl) 3-oxohexanethioate:}


<smiles>CCCC(=O)CC(=O)SCCNC(C)=O</smiles>

${ }^{1} \mathrm{H}$ NMR $\left(\mathrm{CDCl}_{3}, 400 \mathrm{MHz}\right) \delta 5.92(\mathrm{br} \mathrm{s}, 1 \mathrm{H}), 3.71(\mathrm{~s}, 2 \mathrm{H}), 3.51-3.46(\mathrm{~m}, 2 \mathrm{H}), 3.13-$ $3.09(\mathrm{~m}, 2 \mathrm{H}), 2.54(\mathrm{t}, J=7.2 \mathrm{~Hz}, 2 \mathrm{H}), 2.00(\mathrm{~s}, 3 \mathrm{H}), 1.68-1.61(\mathrm{~m}, 2 \mathrm{H}), 1.00-0.95$ $(\mathrm{m}, 3 \mathrm{H})$.

\section{S-(2-acetamidoethyl) 3-oxooctanethioate:}<smiles>CCCCCC(=O)CC(=O)SCCNC(C)=O</smiles>

${ }^{1} \mathrm{H} \mathrm{NMR}\left(\mathrm{CDCl}_{3}, 400 \mathrm{MHz}\right) \delta 5.91(\mathrm{br} \mathrm{s}, 1 \mathrm{H}), 3.71(\mathrm{~s}, 2 \mathrm{H}), 3.51-3.46(\mathrm{~m}, 2 \mathrm{H}), 3.13-$ $3.09(\mathrm{~m}, 2 \mathrm{H}), 2.55(\mathrm{t}, J=7.4 \mathrm{~Hz}, 2 \mathrm{H}), 2.00(\mathrm{~s}, 3 \mathrm{H}), 1.65-1.58(\mathrm{~m}, 4 \mathrm{H}), 1.35-1.31$ $(\mathrm{m}, 2 \mathrm{H}), 0.93-0.91(\mathrm{~m}, 3 \mathrm{H})$.

\section{S-(2-acetamidoethyl) 3-oxodecanethioate:}<smiles>CCCCCCCC(=O)CC(=O)SCCNC(C)=O</smiles>

${ }^{1} \mathrm{H} \mathrm{NMR}\left(\mathrm{CDCl}_{3}, 400 \mathrm{MHz}\right) \delta 5.90(\mathrm{br} \mathrm{s}, 1 \mathrm{H}), 3.71(\mathrm{~s}, 2 \mathrm{H}), 3.51-3.46(\mathrm{~m}, 2 \mathrm{H}), 3.13-$ $3.10(\mathrm{~m}, 2 \mathrm{H}), 2.55(\mathrm{t}, J=7.4 \mathrm{~Hz}, 2 \mathrm{H}), 2.00(\mathrm{~s}, 3 \mathrm{H}), 1.61(\mathrm{~m}, 4 \mathrm{H}), 1.32-1.29(\mathrm{~m}$, $6 \mathrm{H}), 0.91-0.88(\mathrm{~m}, 3 \mathrm{H})$.

\section{S-(2-acetamidoethyl) 5-methyl-3-oxohexanethioate:}


<smiles>CC(=O)NCCSC(=O)CC(=O)CC(C)C</smiles>

${ }^{1} \mathrm{H}$ NMR $\left(\mathrm{CDCl}_{3}, 400 \mathrm{MHz}\right) \delta 6.04(\mathrm{br} \mathrm{s}, 1 \mathrm{H}), 3.68(\mathrm{~s}, 2 \mathrm{H}), 3.50-3.44(\mathrm{~m}, 2 \mathrm{H}), 3.11-$ $3.07(\mathrm{~m}, 2 \mathrm{H}), 2.42(\mathrm{~d}, J=7.4 \mathrm{~Hz}, 2 \mathrm{H}), 2.17-2.14(\mathrm{~m}, 1 \mathrm{H}), 1.98(\mathrm{~s}, 3 \mathrm{H}), 0.98-0.93$ $(\mathrm{m}, 6 \mathrm{H})$.

\section{S-(2-acetamidoethyl) 6-methyl-3-oxoheptanethioate:}<smiles>CC(=O)NCCSC(=O)CC(=O)CCC(C)C</smiles>

${ }^{1} \mathrm{H}$ NMR $\left(\mathrm{CDCl}_{3}, 400 \mathrm{MHz}\right) \delta 6.00(\mathrm{br} \mathrm{s}, 1 \mathrm{H}), 3.72(\mathrm{~s}, 2 \mathrm{H}), 3.49-3.45(\mathrm{~m}, 2 \mathrm{H}), 3.12-$ $3.09(\mathrm{~m}, 2 \mathrm{H}), 2.54(\mathrm{t}, J=7.5 \mathrm{~Hz}, 2 \mathrm{H}), 1.98(\mathrm{~s}, 3 \mathrm{H}), 1.56-1.47(\mathrm{~m}, 3 \mathrm{H}), 0.93-0.89$ $(\mathrm{m}, 6 \mathrm{H})$.

\section{S-(2-acetamidoethyl) 7-methyl-3-oxoctanethioate:}<smiles>CC(=O)NCCSC(=O)CC(=O)CCCC(C)C</smiles>

${ }^{1} \mathrm{H}$ NMR $\left(\mathrm{CDCl}_{3}, 400 \mathrm{MHz}\right) \delta 5.98(\mathrm{br} \mathrm{s}, 1 \mathrm{H}), 3.71(\mathrm{~s}, 2 \mathrm{H}), 3.49-3.45(\mathrm{~m}, 2 \mathrm{H}), 3.12-$ $3.09(\mathrm{~m}, 2 \mathrm{H}), 2.52(\mathrm{t}, J=7.3 \mathrm{~Hz}, 2 \mathrm{H}), 1.99(\mathrm{~s}, 3 \mathrm{H}), 1.62-1.53(\mathrm{~m}, 3 \mathrm{H}), 1.20-1.18$ $(\mathrm{m}, 2 \mathrm{H}), 0.90-0.89(\mathrm{~m}, 6 \mathrm{H})$. 


\section{NMR spectrum of the intermediates and final compounds}

All (E)-S-(2-acetamidoethyl)alk-2-enethioate(enoyl-NAC) compounds were synthesized according to the general procedures as shown in Scheme1.

NMR spectrum of the intermediates for one representative compound.

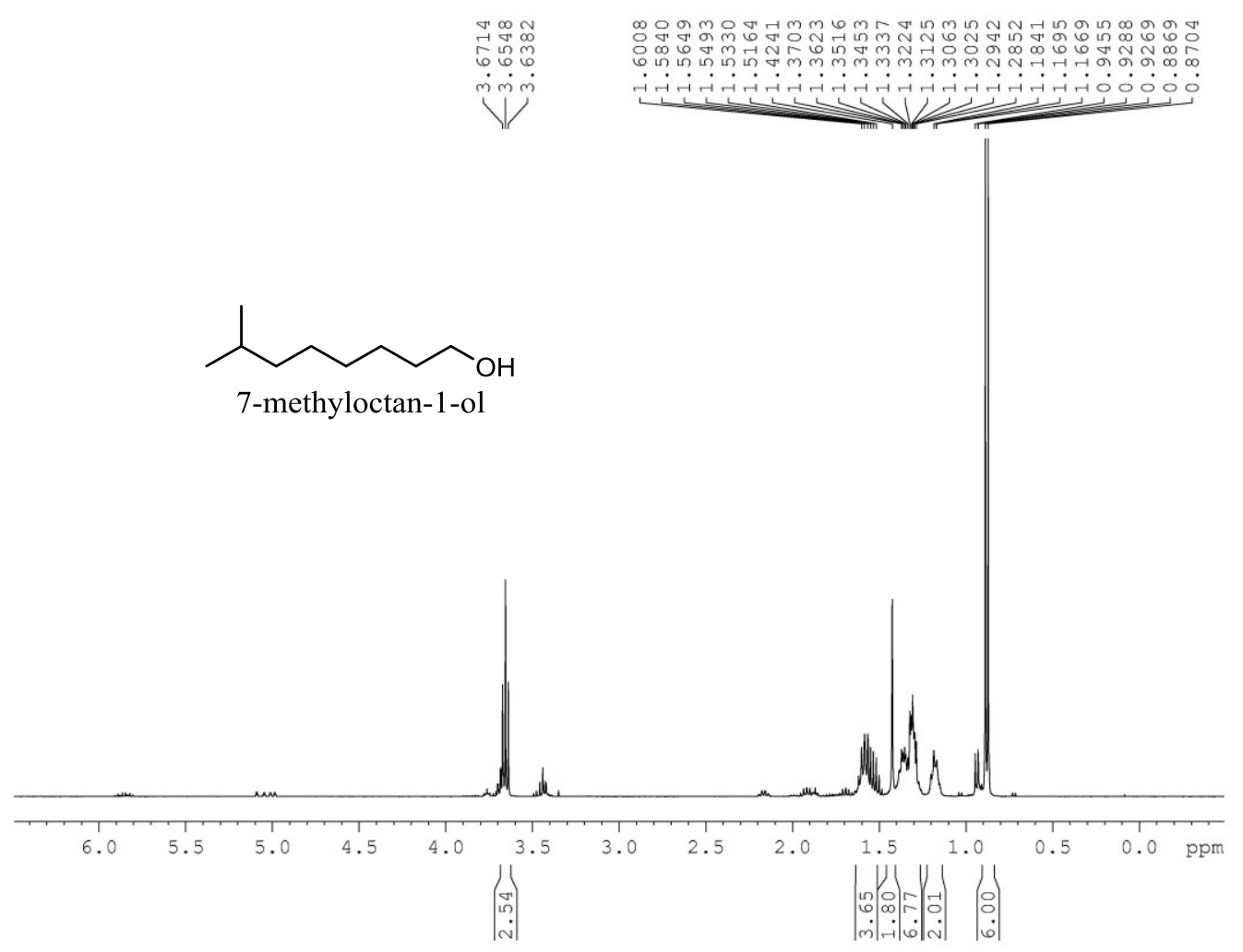



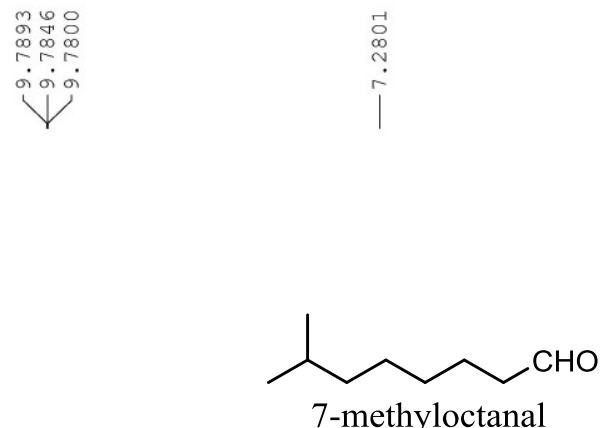

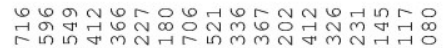

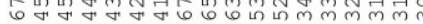

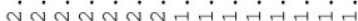

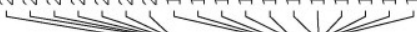

7-methyloctanal

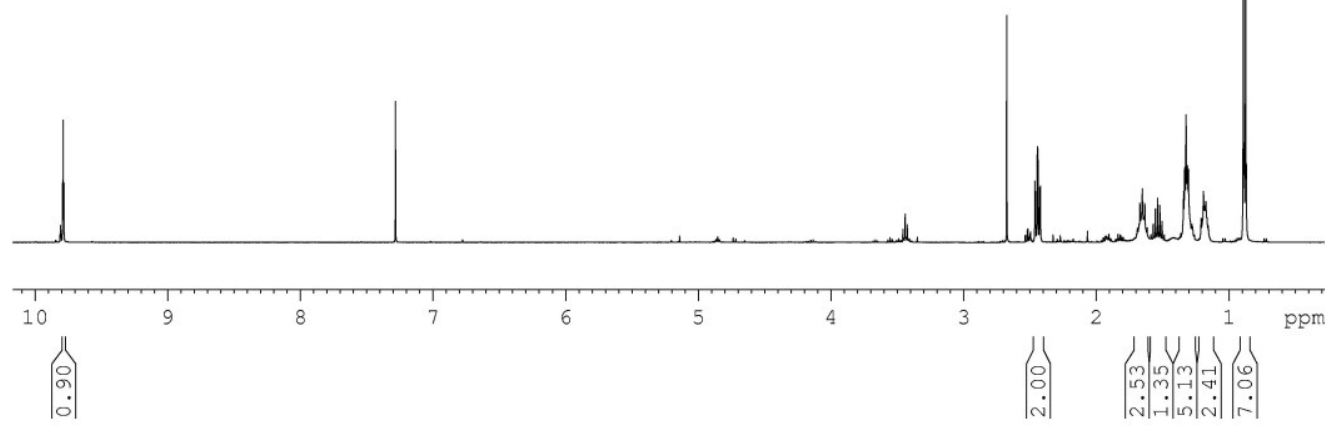




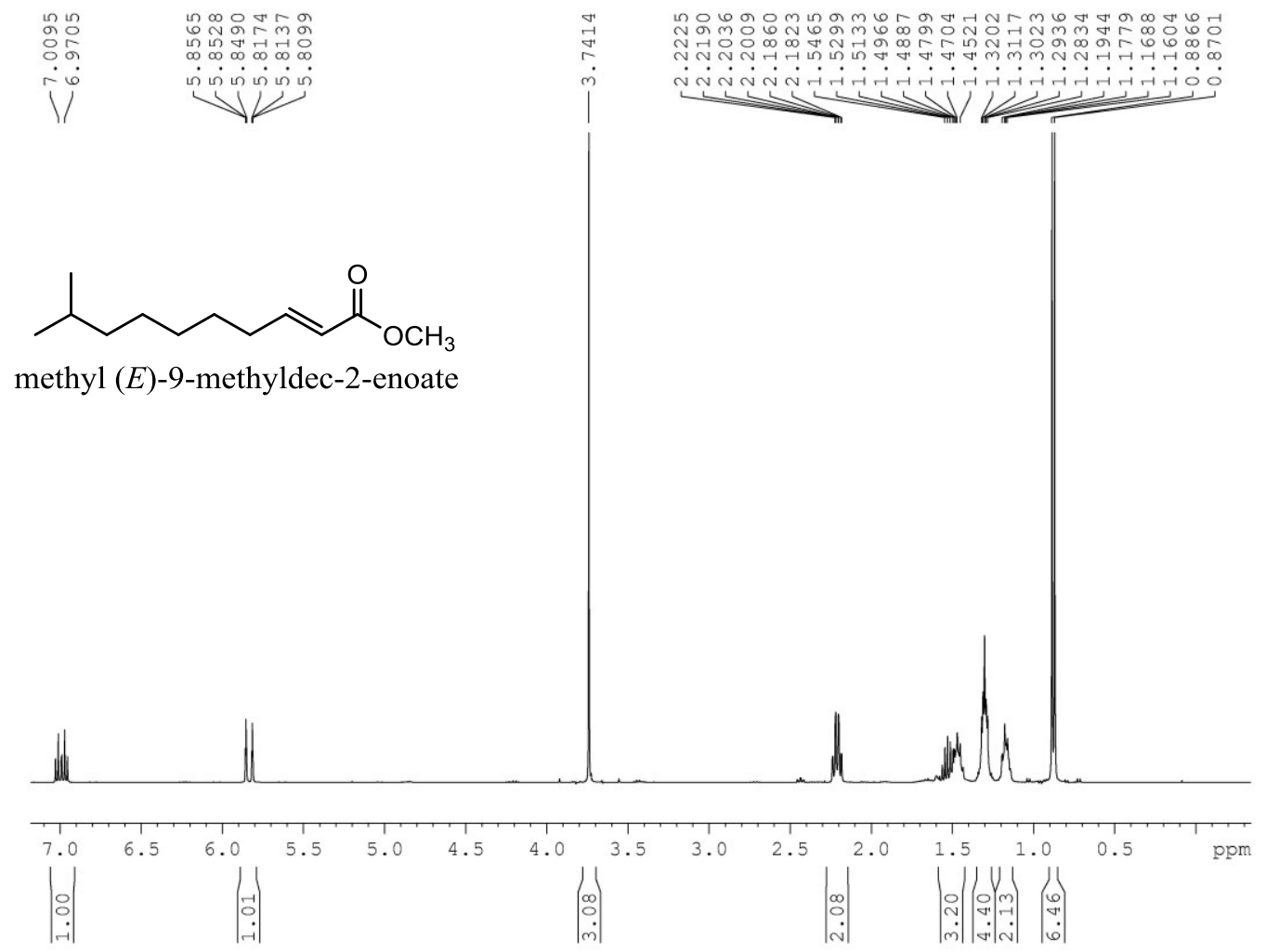


$\mathbb{1}$
$\mathbb{1}$

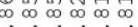

ค่ं ถุं

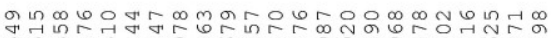
แn
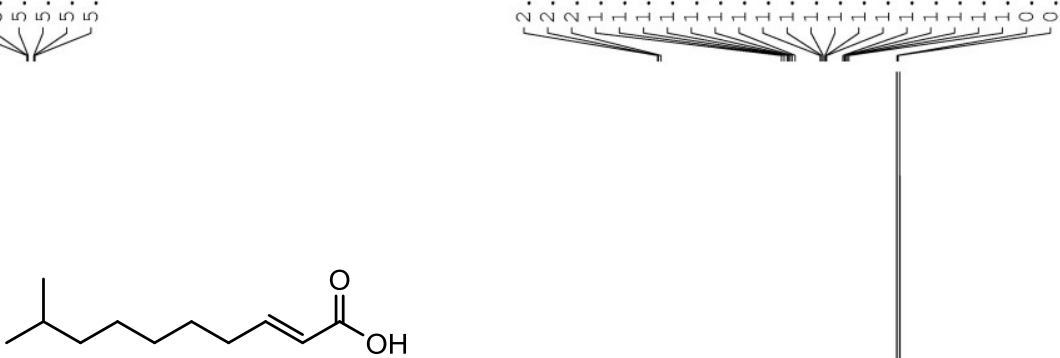

(E)-9-methyldec-2-enoic acid

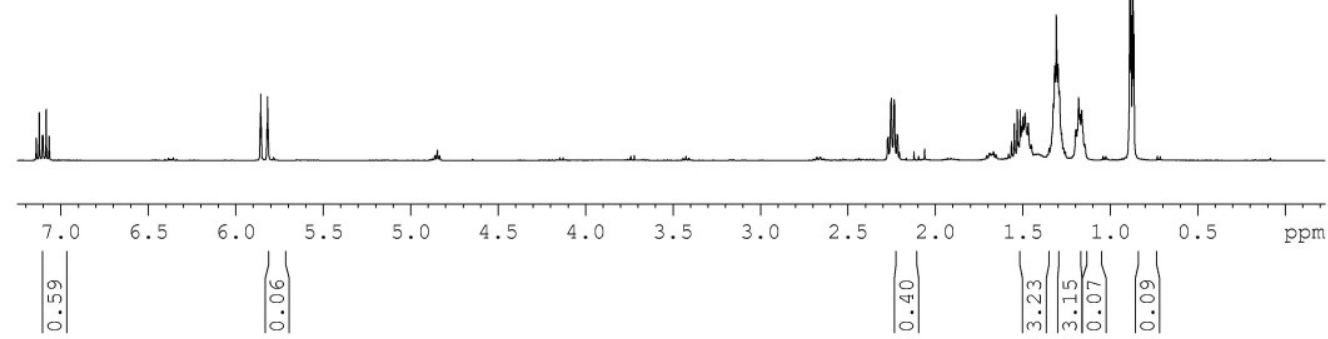



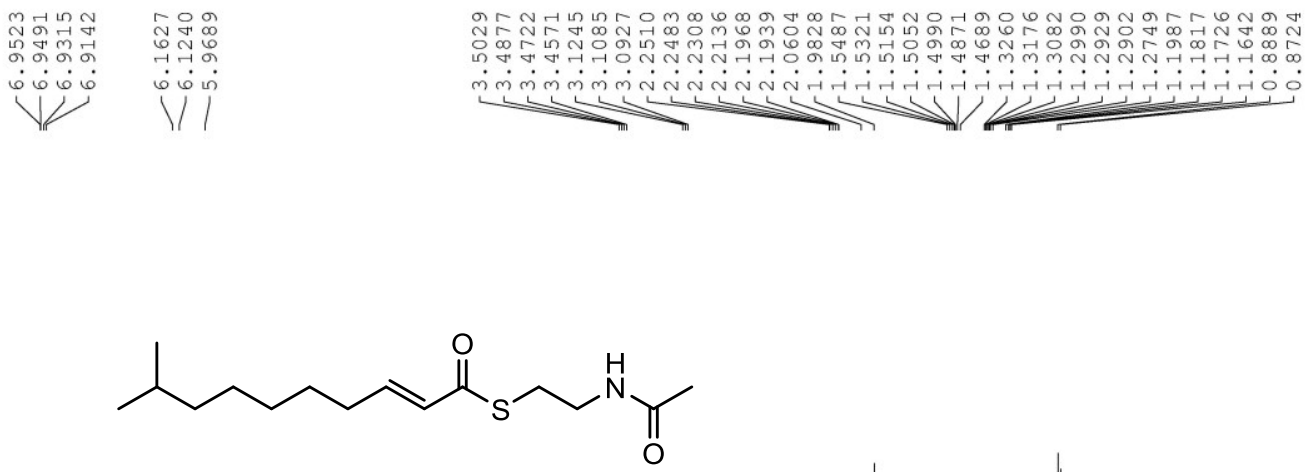

$S$-(2-acetamidoethyl) (E)-9-methyldec-2-enethioate

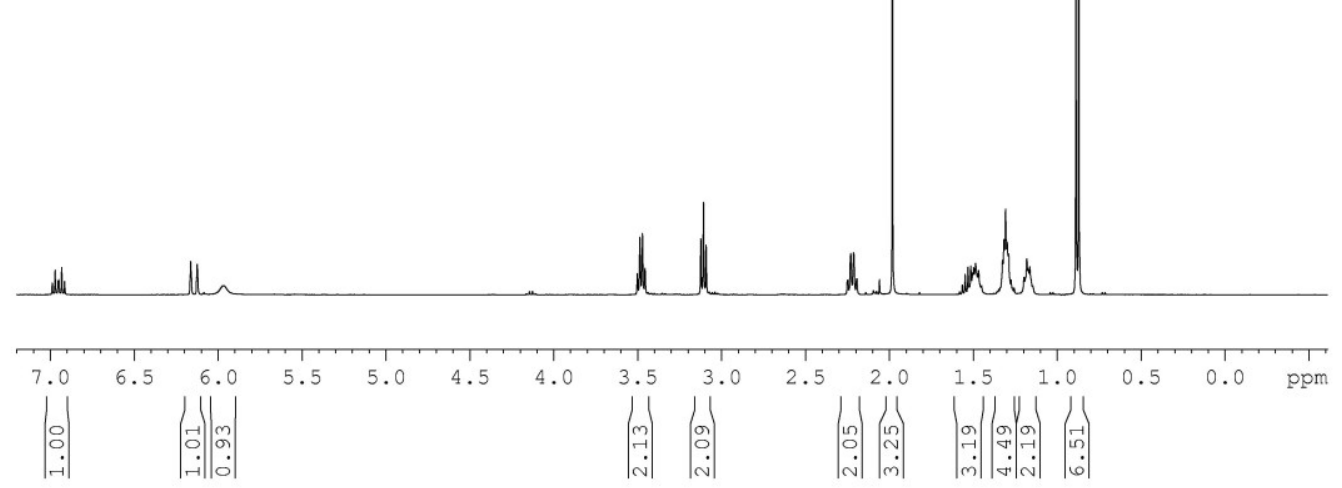


NMR Spectrum of all the final (E)-S-(2-acetamidoethyl)alk-2-enethioate (enoyl-NAC) compounds.
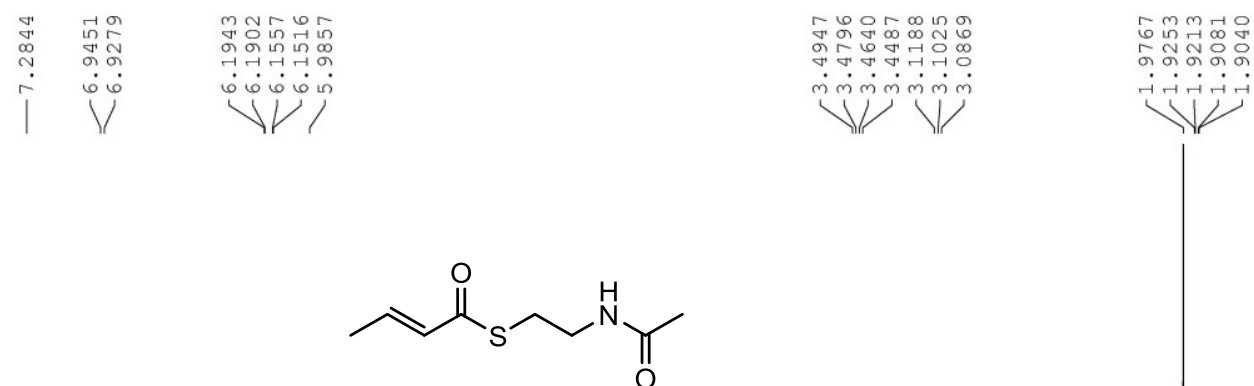

$S$-(2-acetamidoethyl) (E)-but-2-enethioate

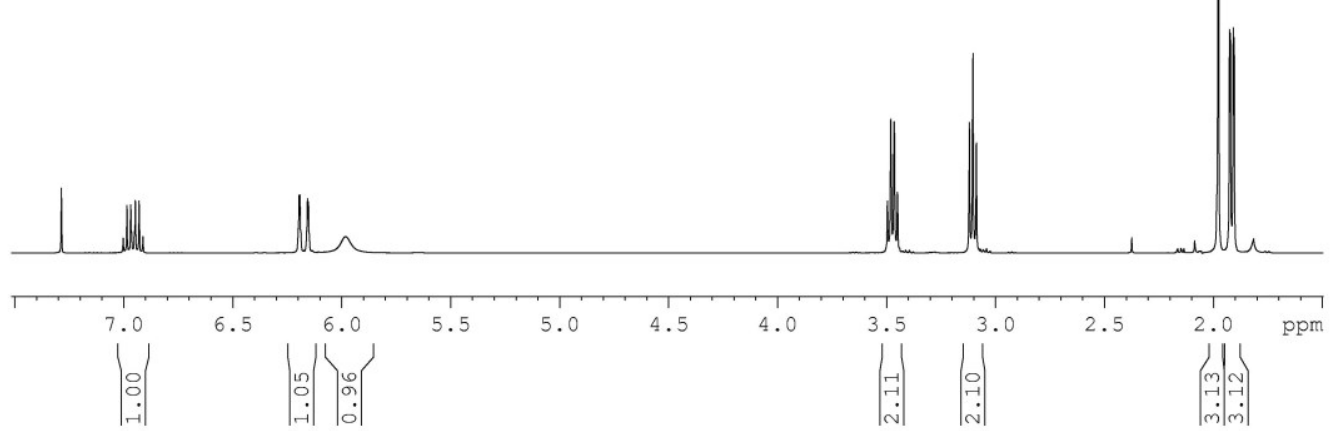



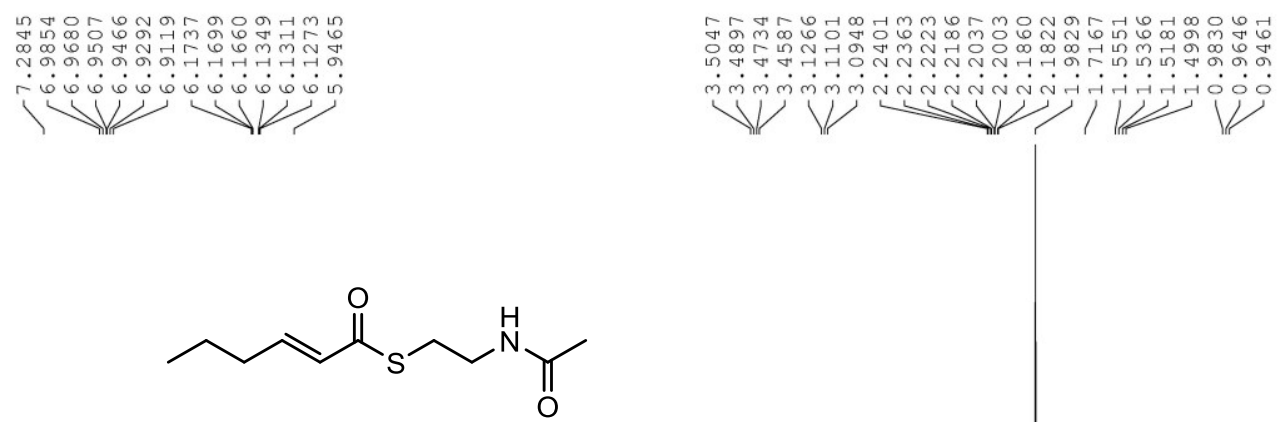

$S$-(2-acetamidoethyl) (E)-hex-2-enethioate

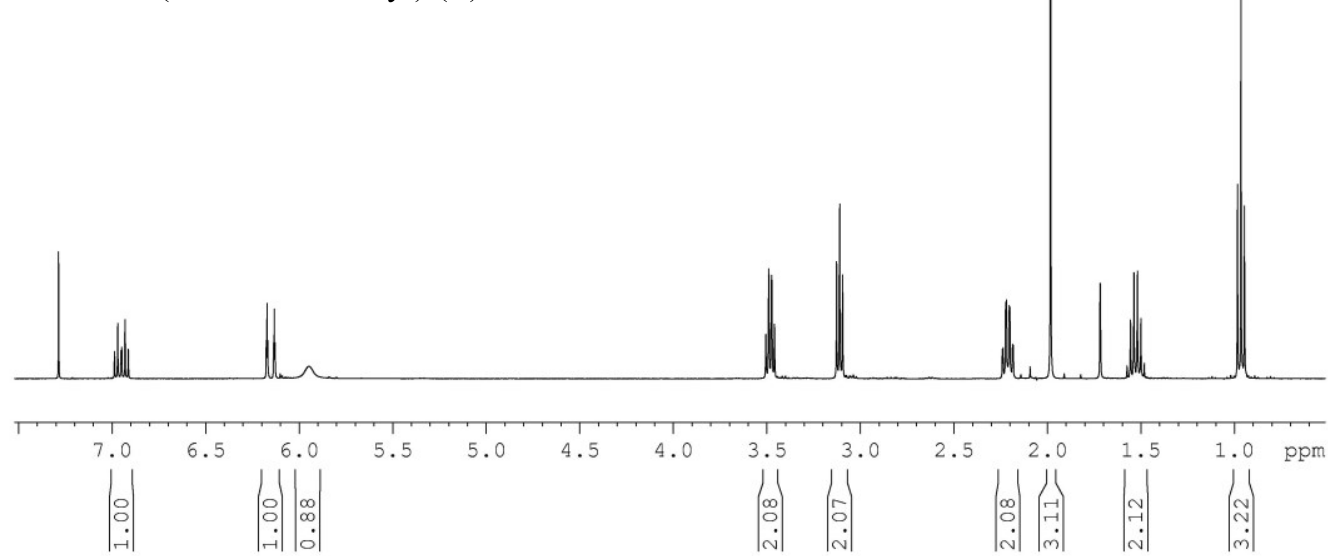



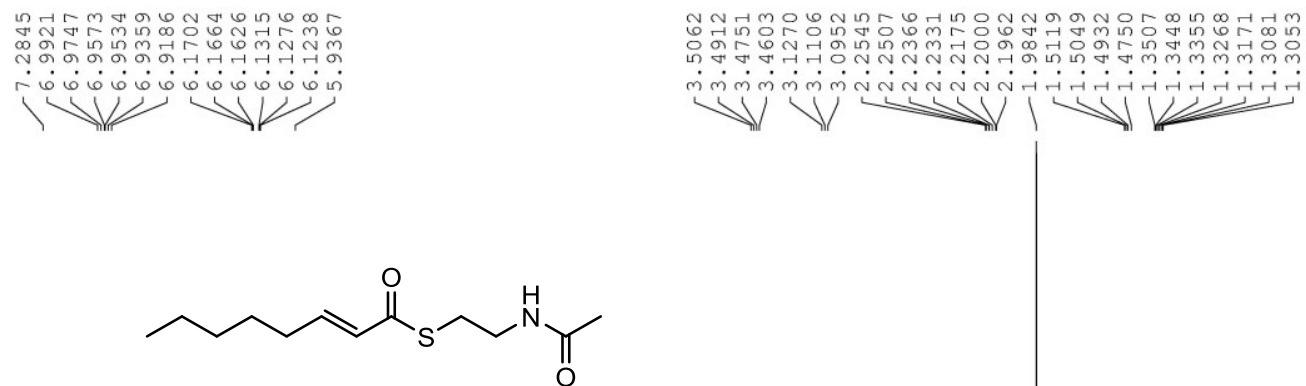

$S$-(2-acetamidoethyl) (E)-oct-2-enethioate

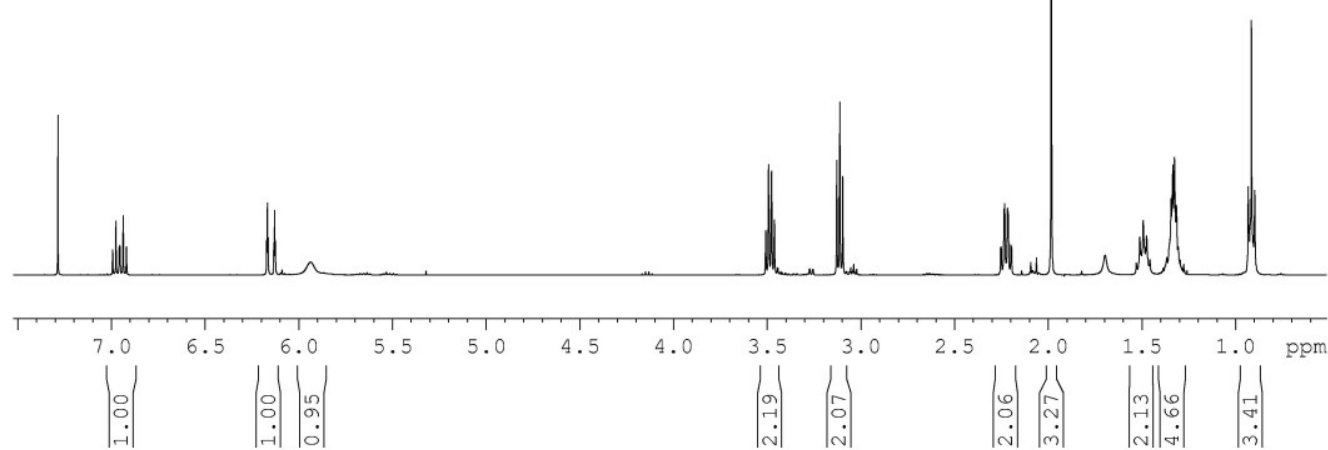



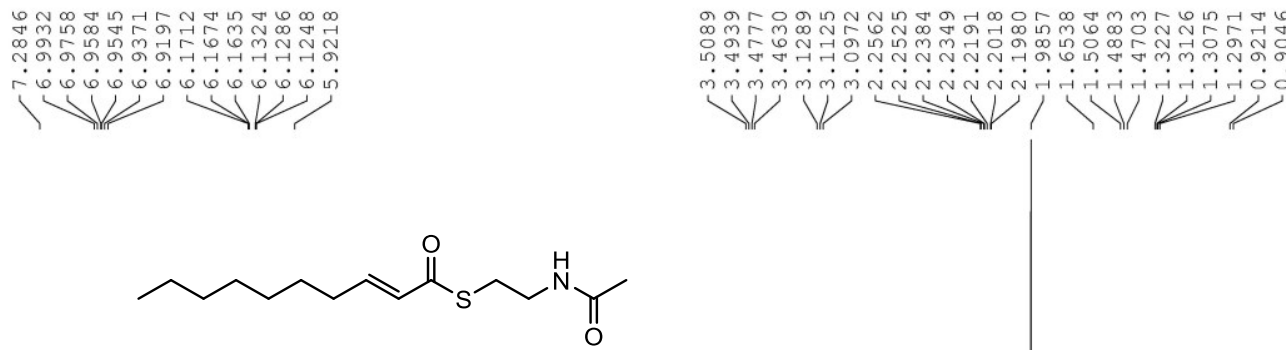

$S$-(2-acetamidoethyl) (E)-dec-2-enethioate

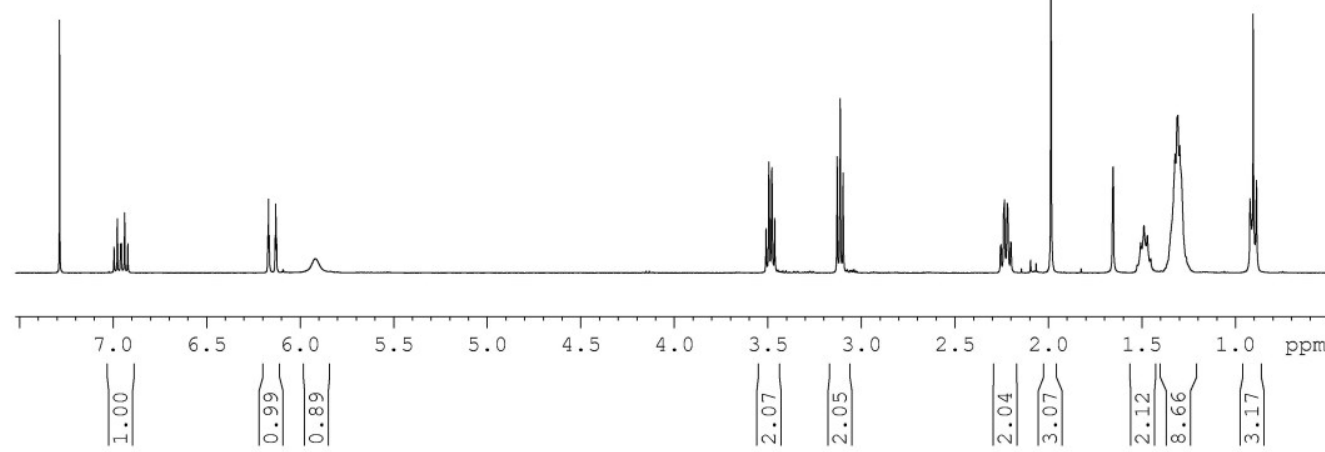



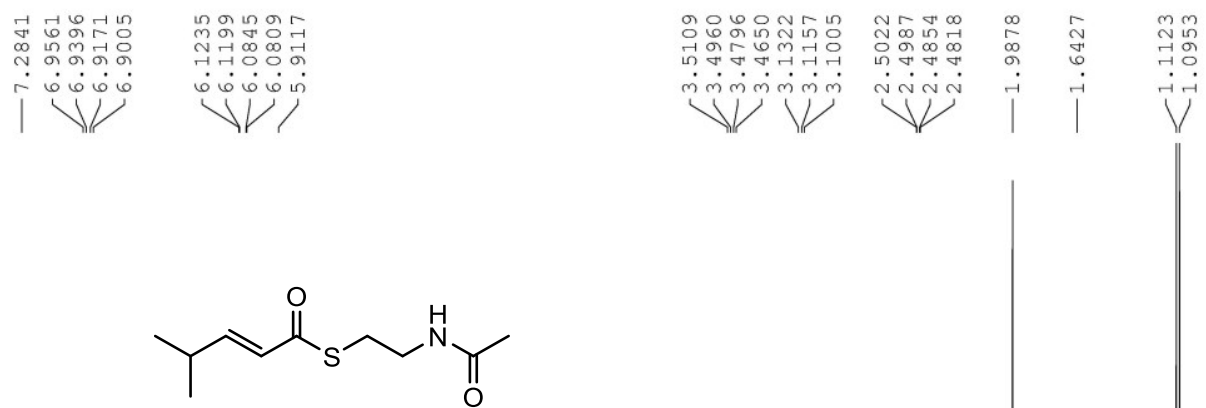

$S$-(2-acetamidoethyl) (E)-4-methylpent-2-enethioate

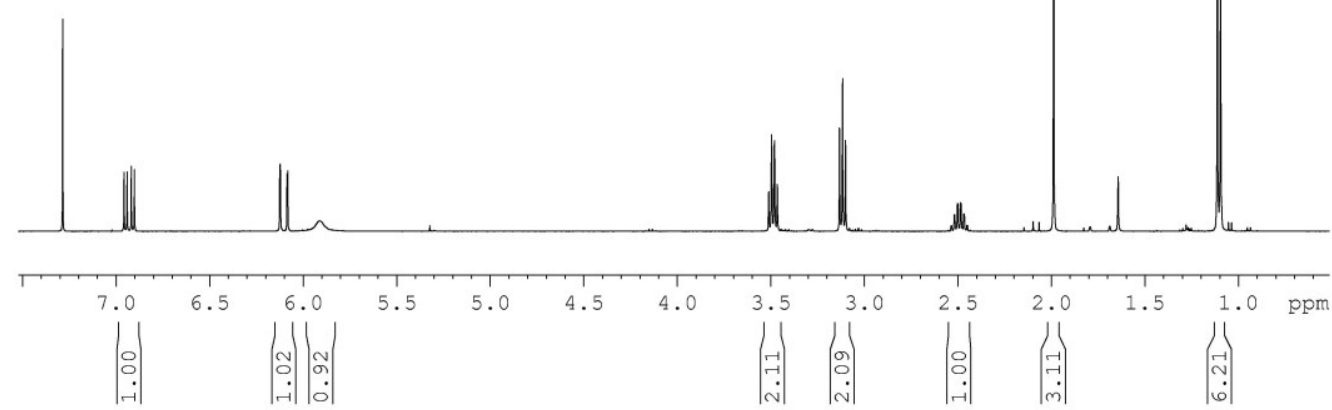



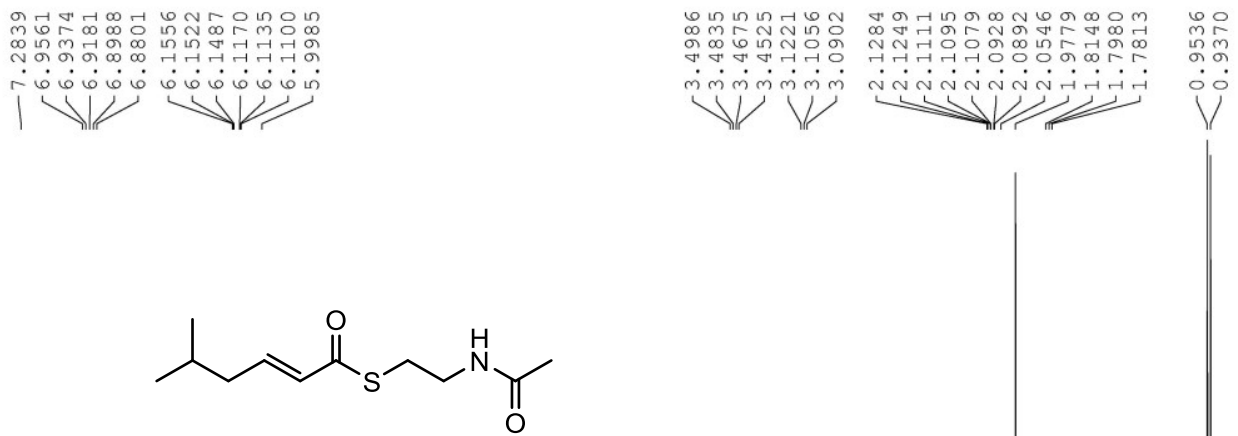

$S$-(2-acetamidoethyl) (E)-5-methylhex-2-enethioate

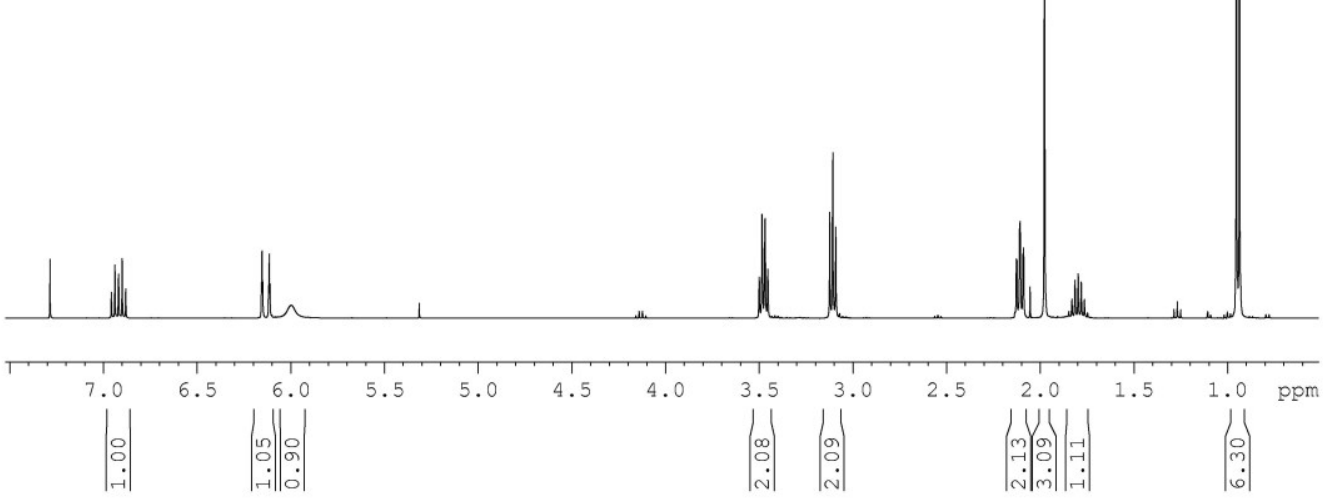




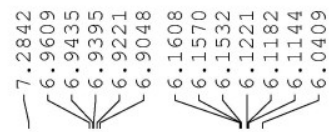

m구에

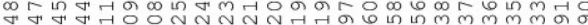

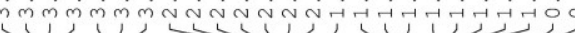

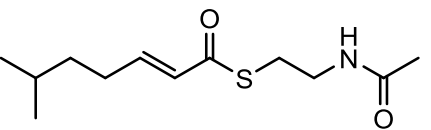

$S$-(2-acetamidoethyl) (E)-6-methylhept-2-

enethioate

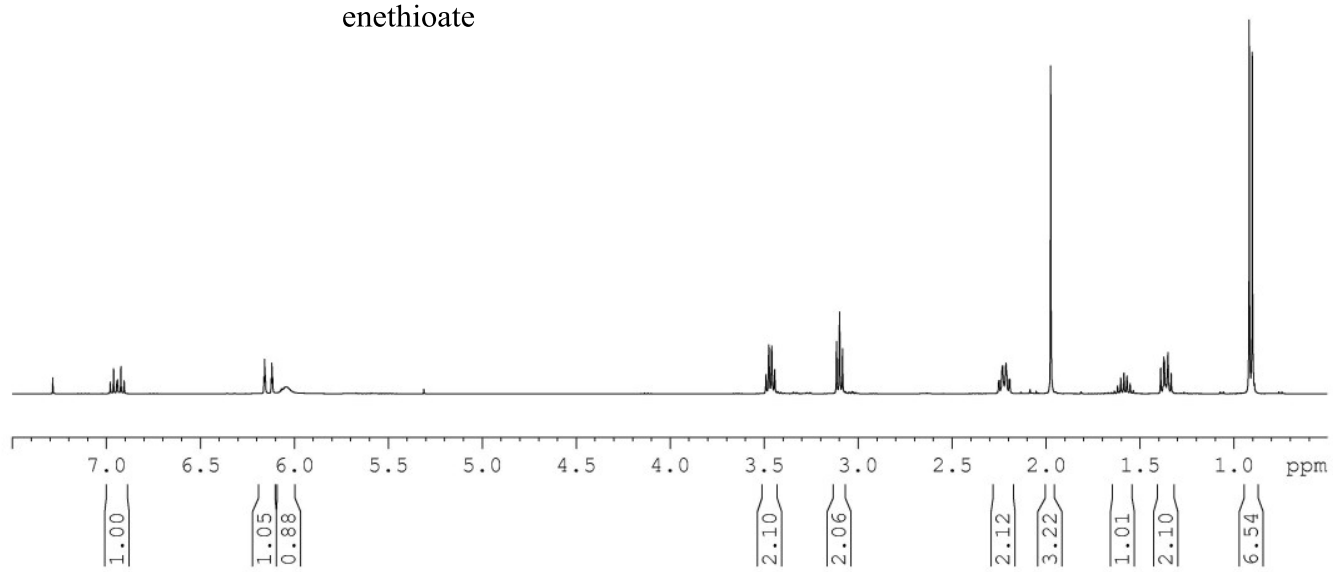



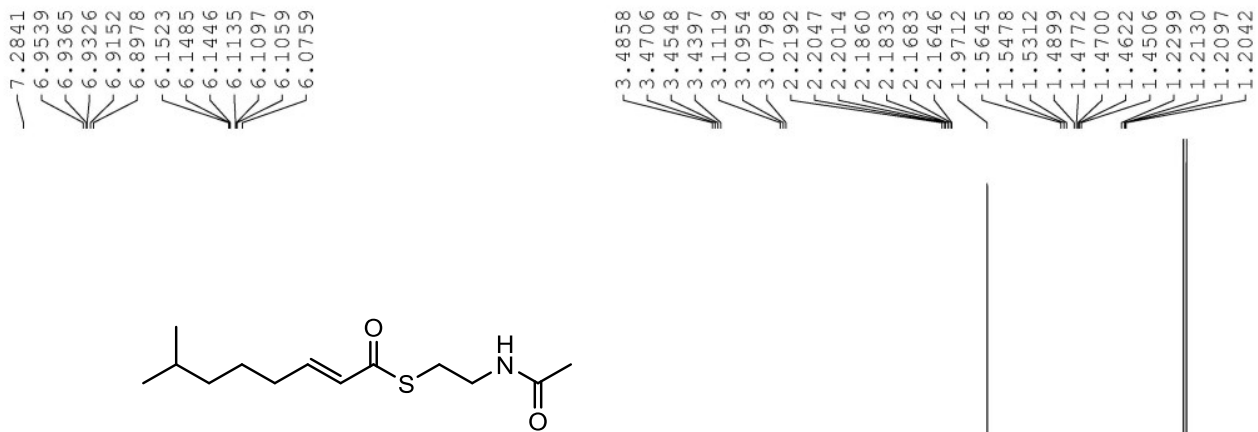

$S$-(2-acetamidoethyl) (E)-7-methyloct-2-enethioate

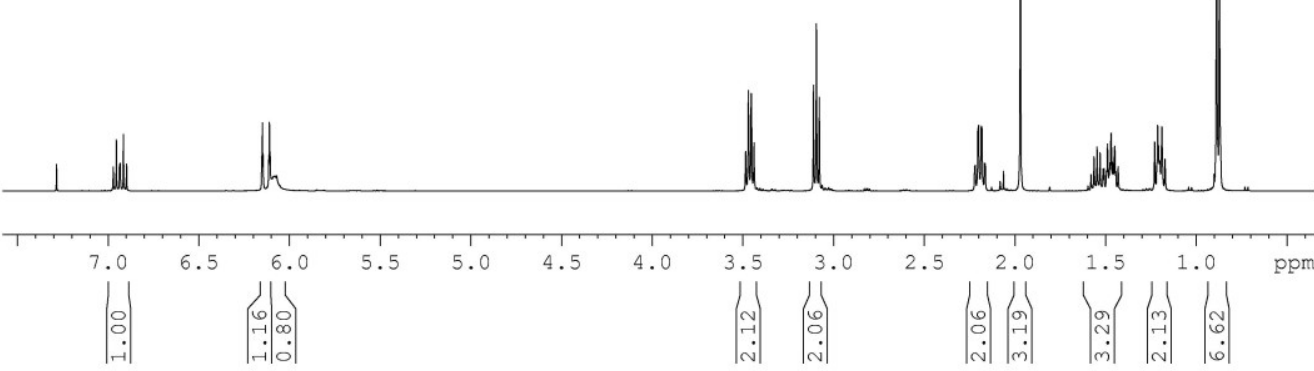



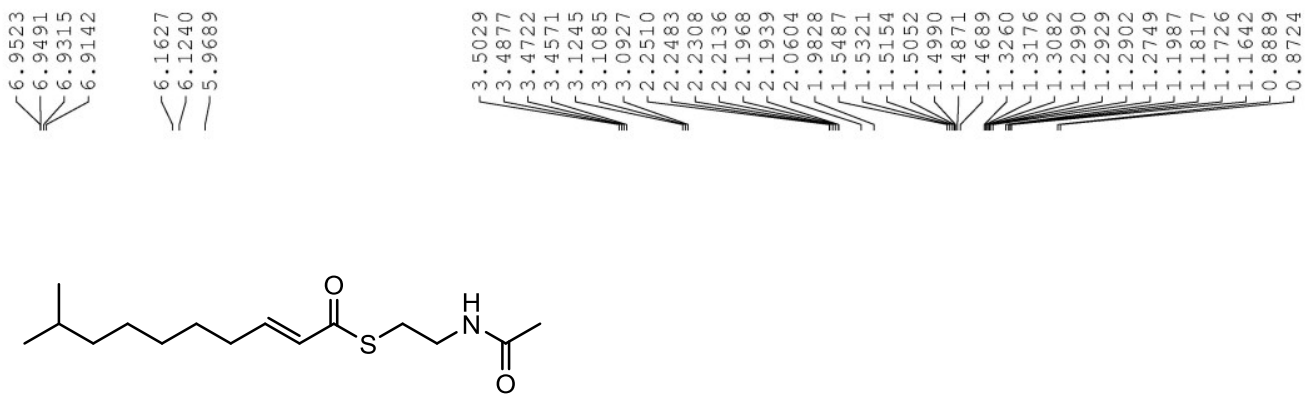

$S$-(2-acetamidoethyl) (E)-9-methyldec-2-enethioate

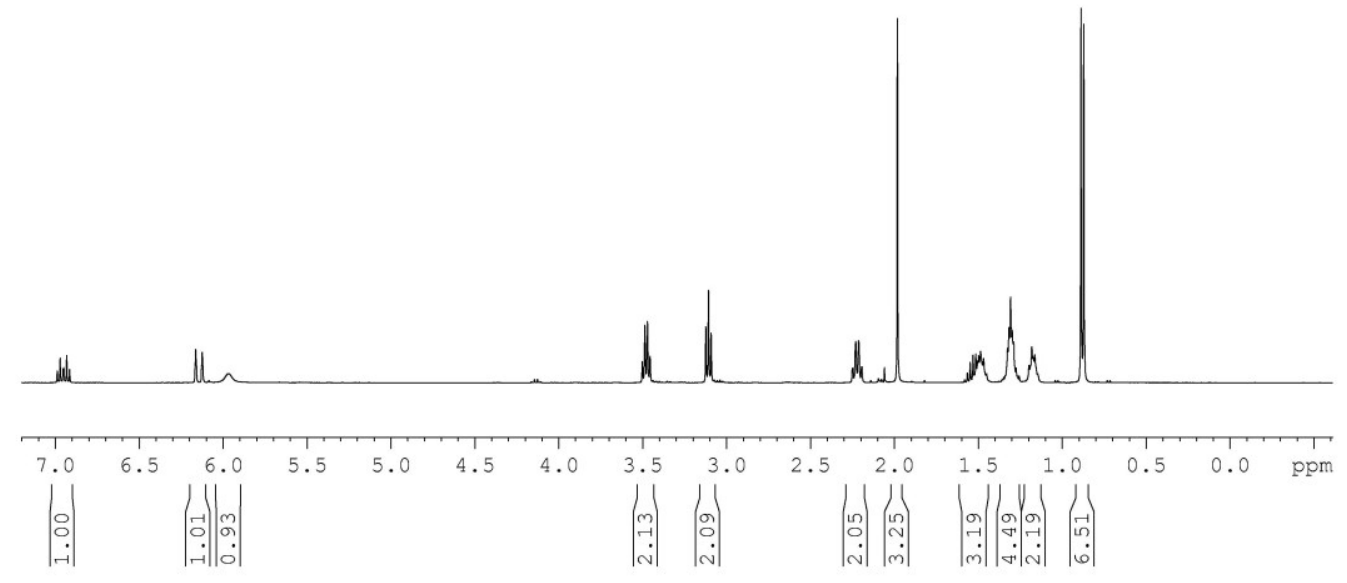


All S-(2-acetamidoethyl) 3-oxoalkanethioate (3-ketoacyl-NAC) compounds were synthesized according to the general procedures as shown in Scheme2.

NMR spectra of the intermediates for one representative compound.
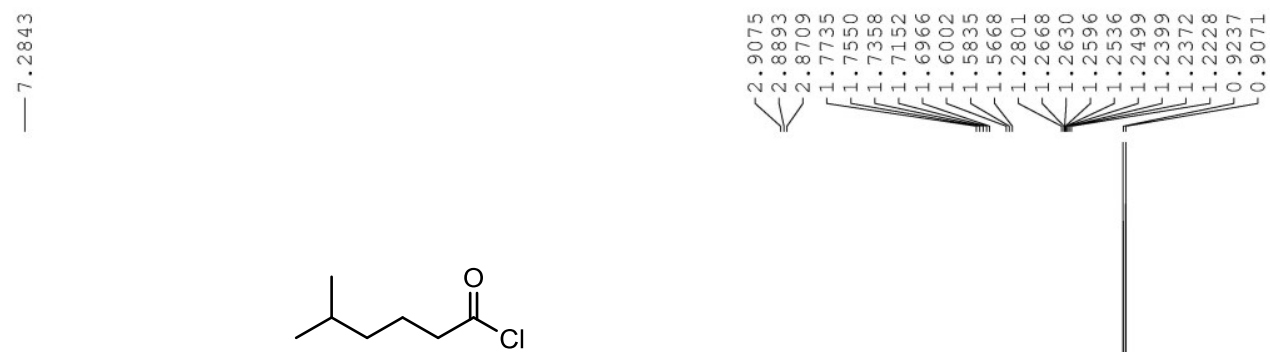

5-methylhexanoyl chloride

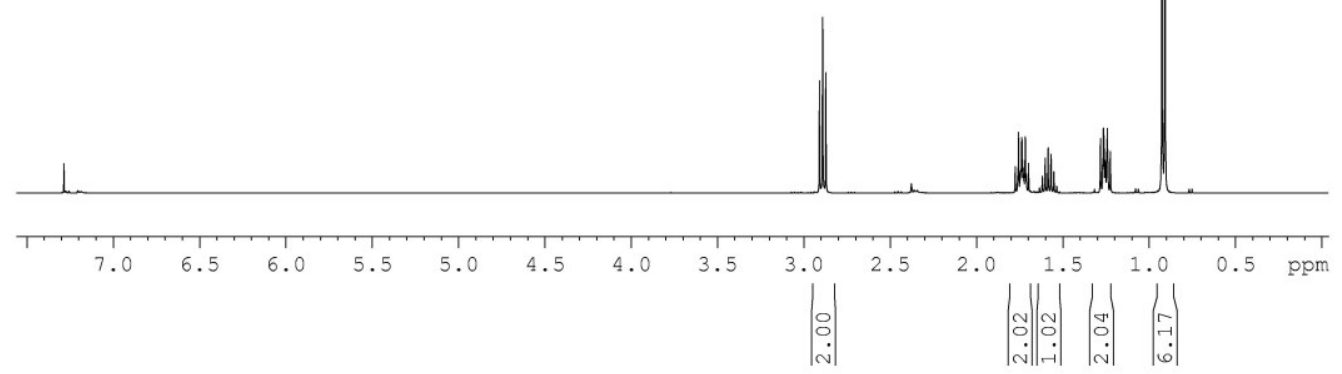




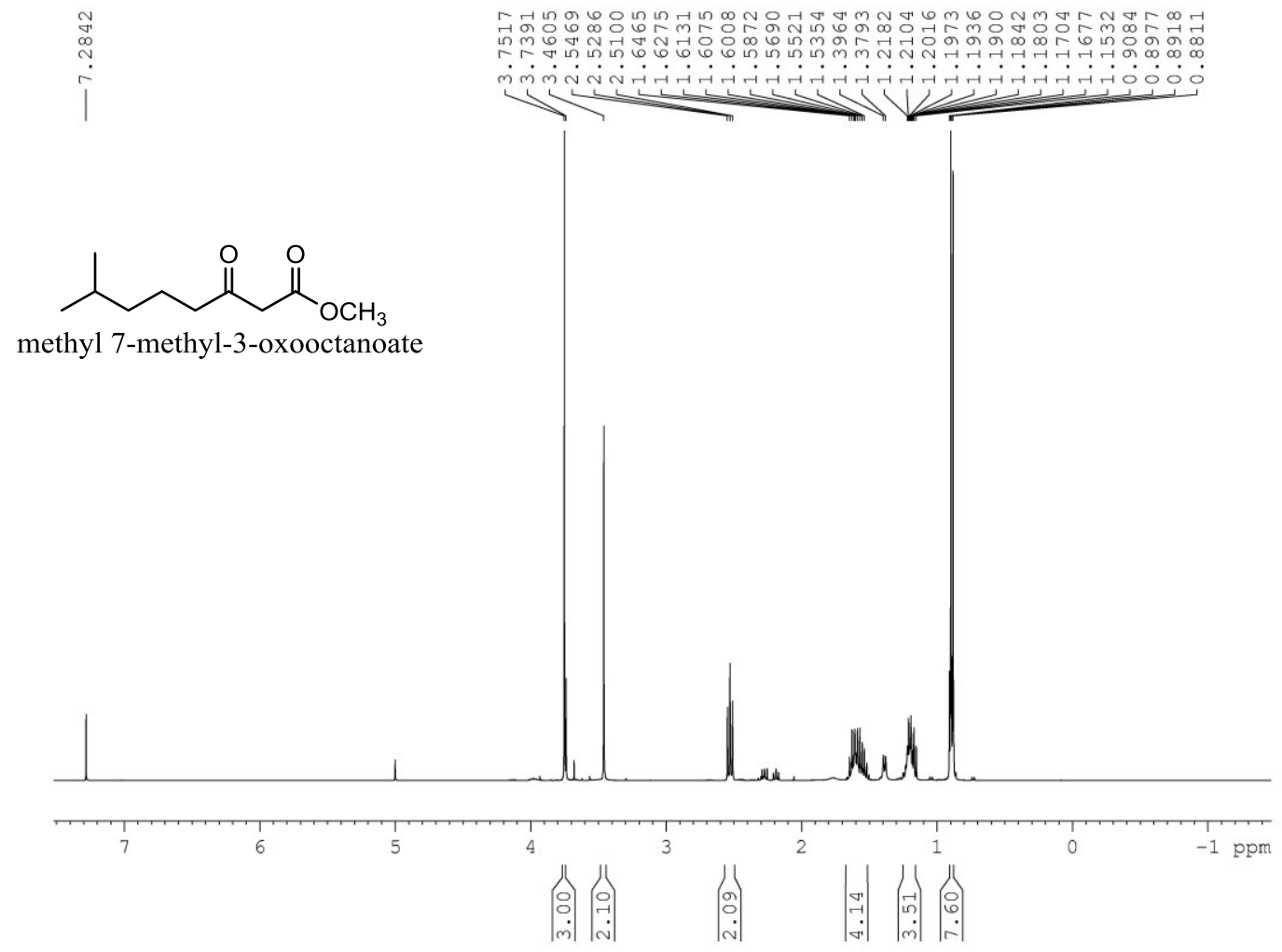




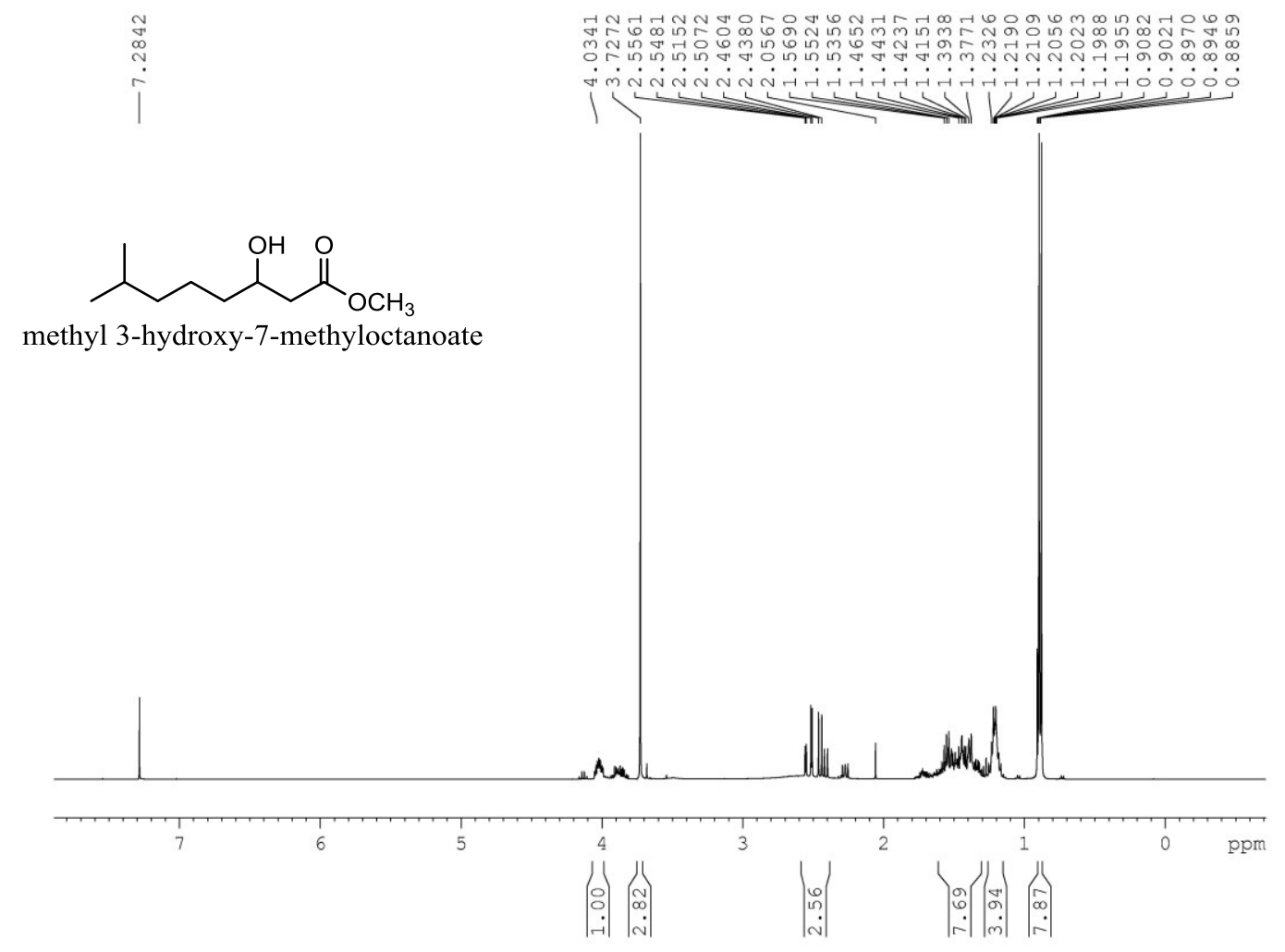




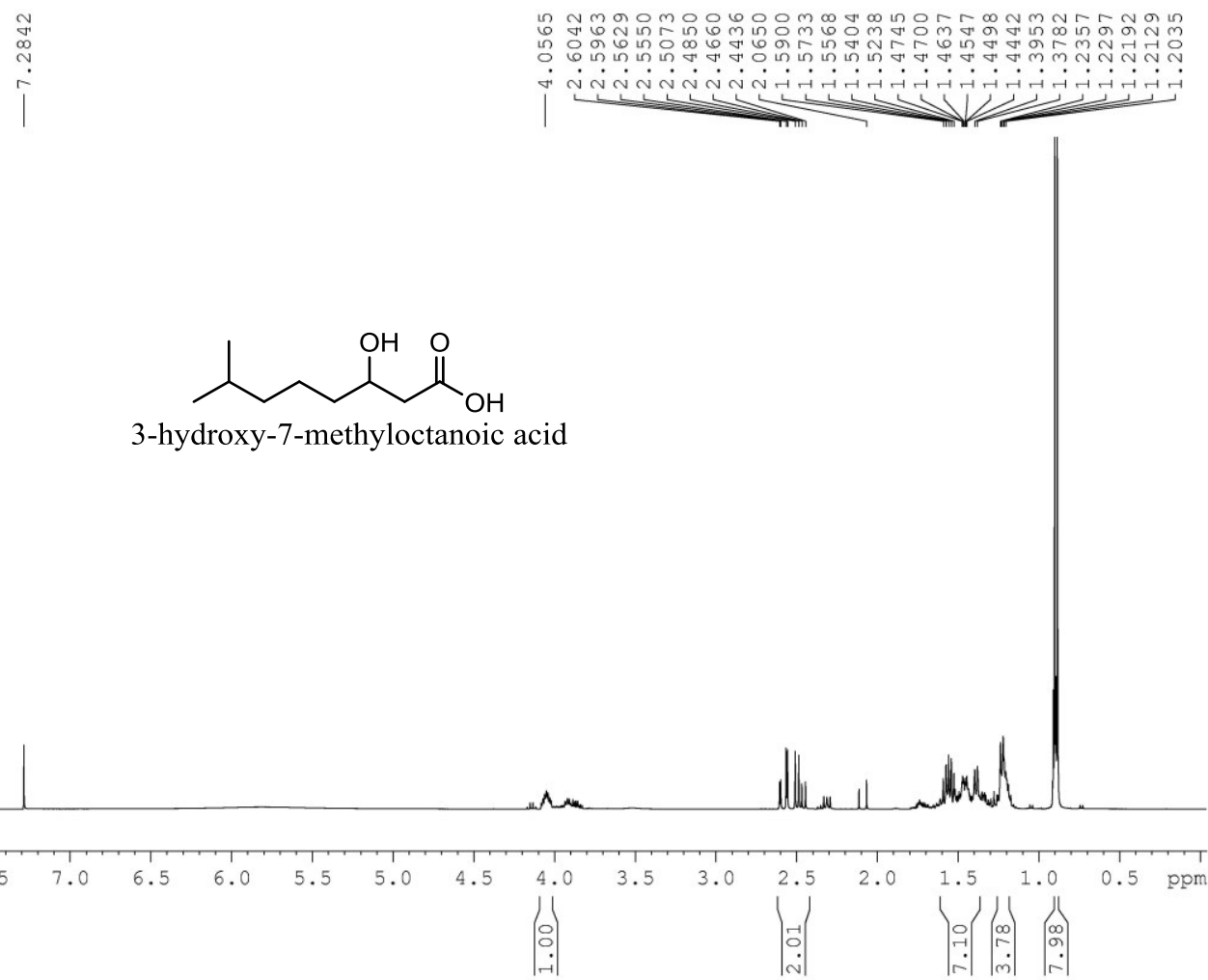



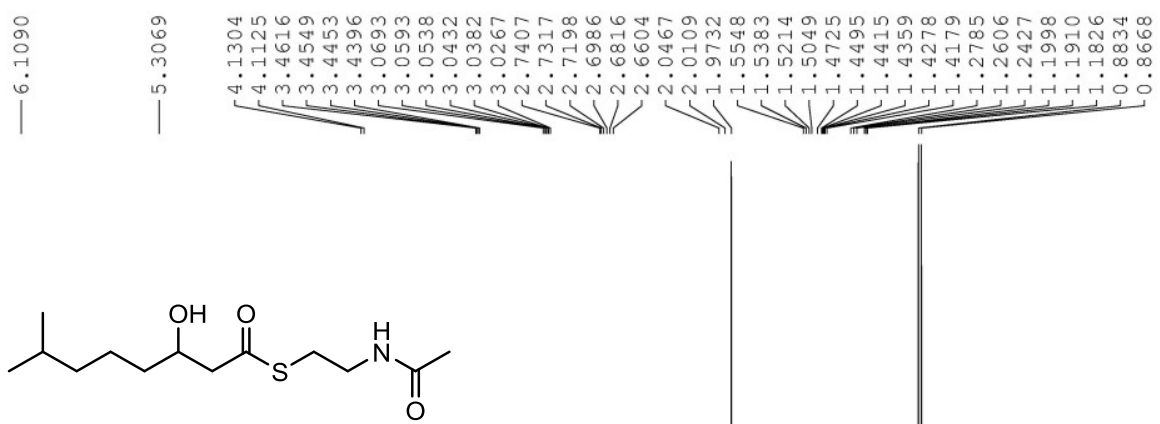

$S$-(2-acetamidoethyl) 3-hydroxy-7-methyloctanethioate

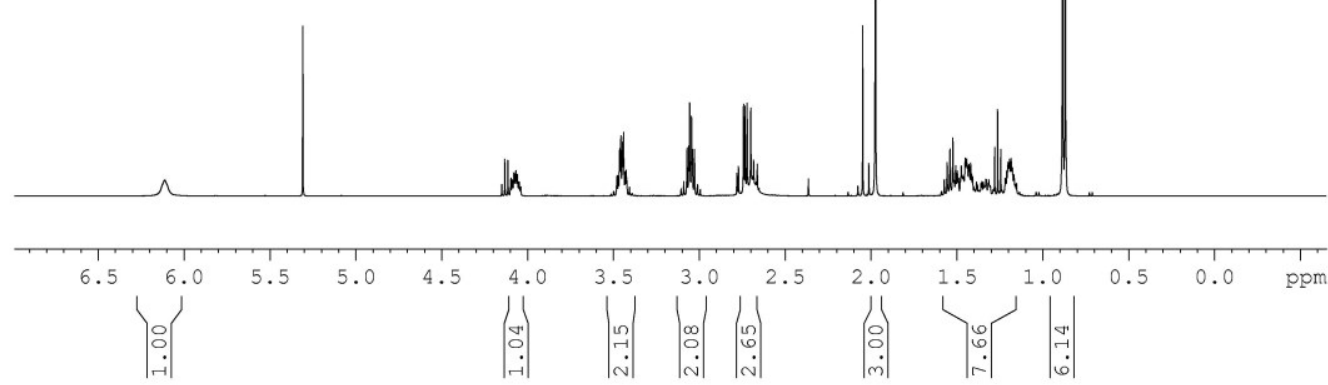



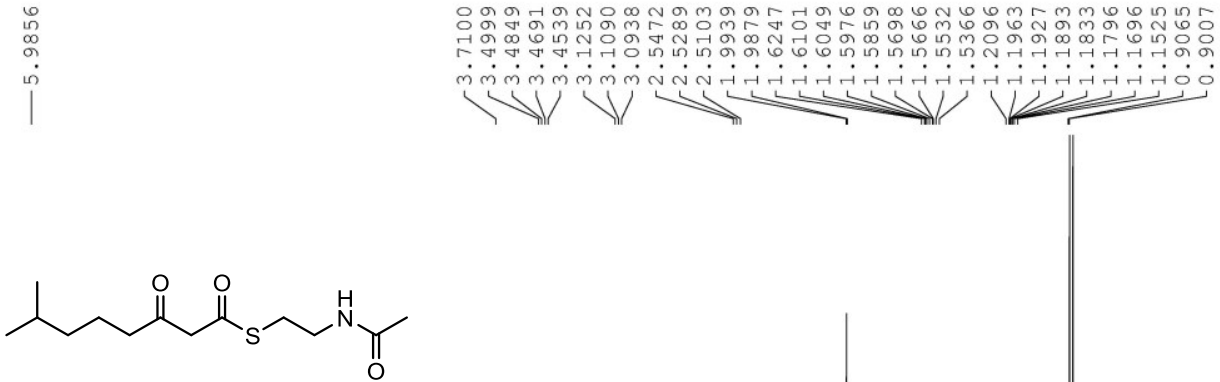

$S$-(2-acetamidoethyl) 7-methyl-3-oxooctanethioate

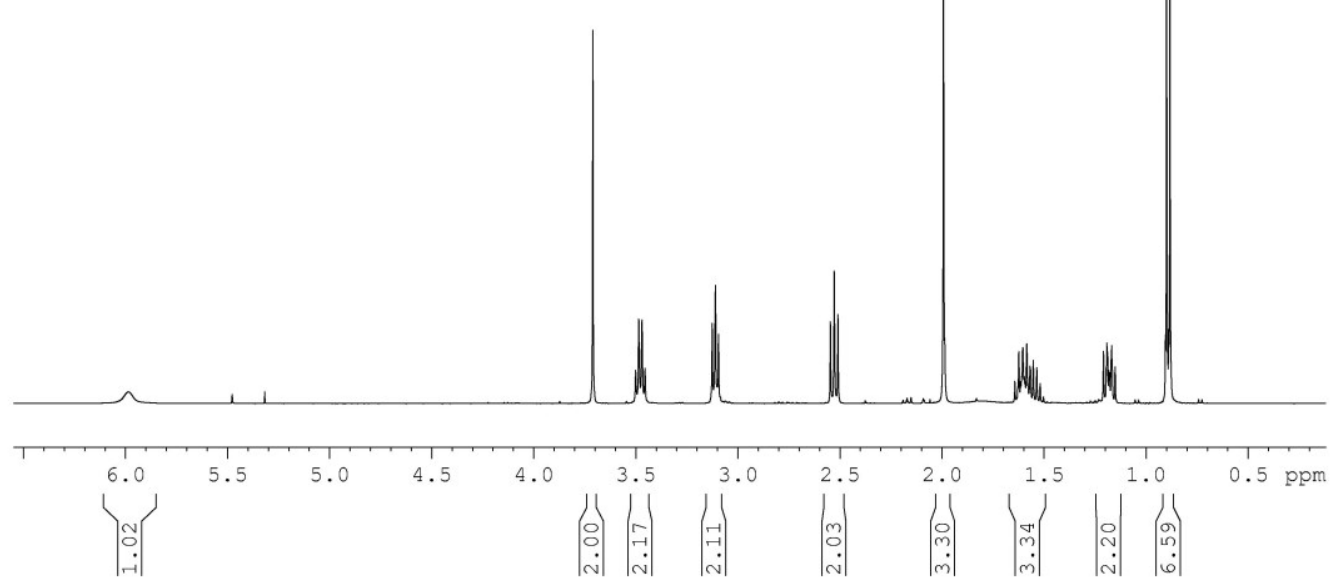


NMR spectral data of the final $S$-(2-acetamidoethyl) 3-oxoalkanethioate (3ketoacyI-NAC) compounds.

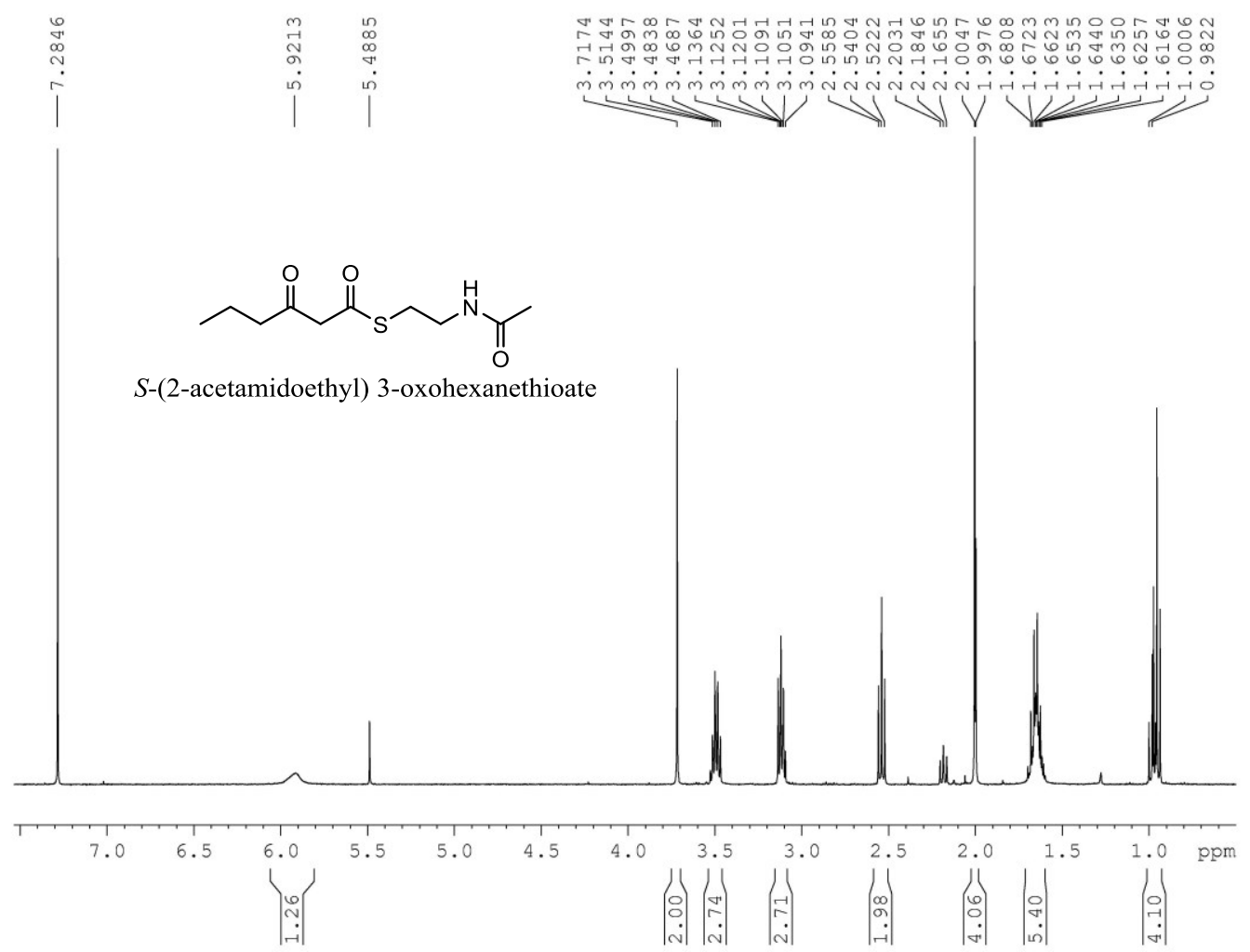




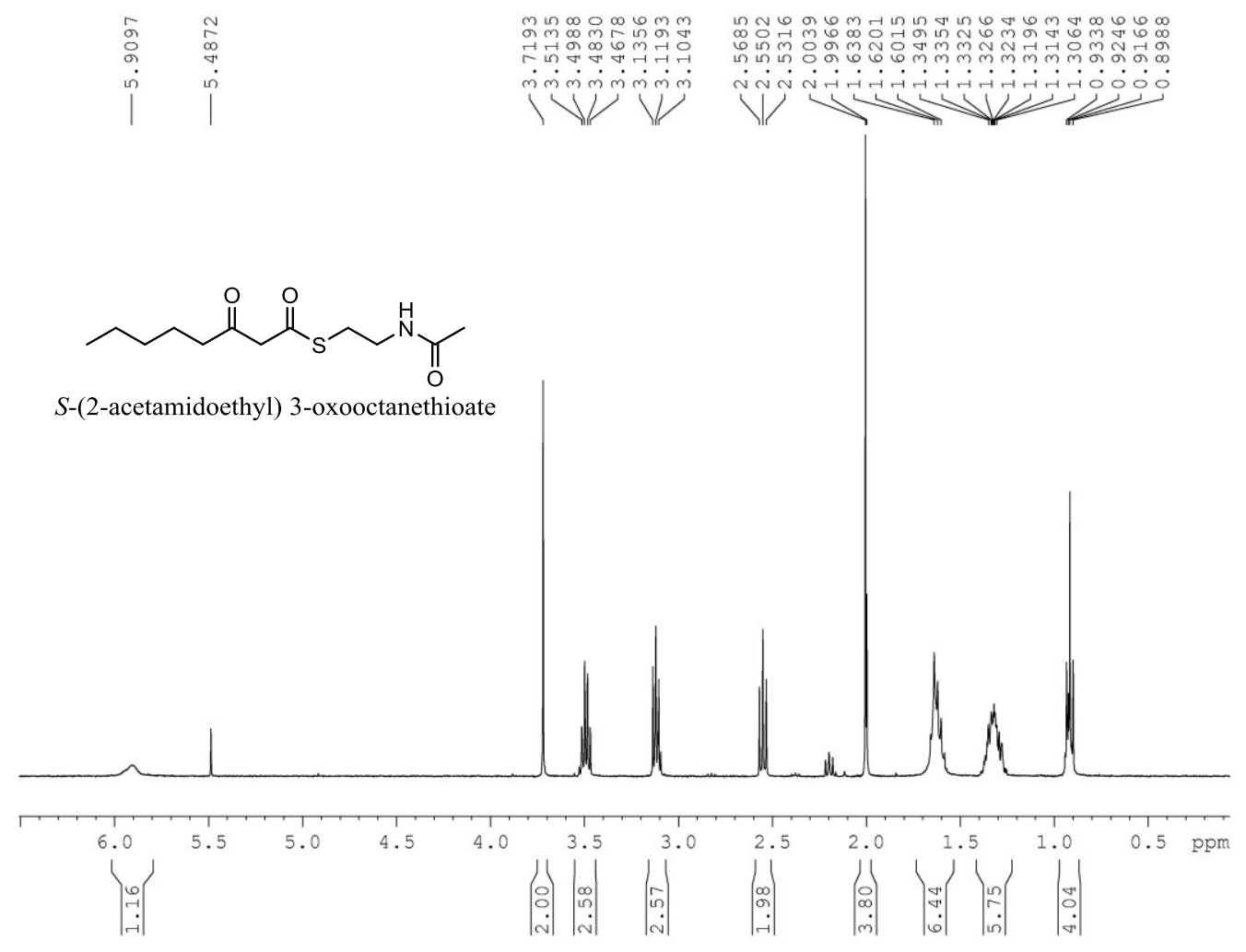




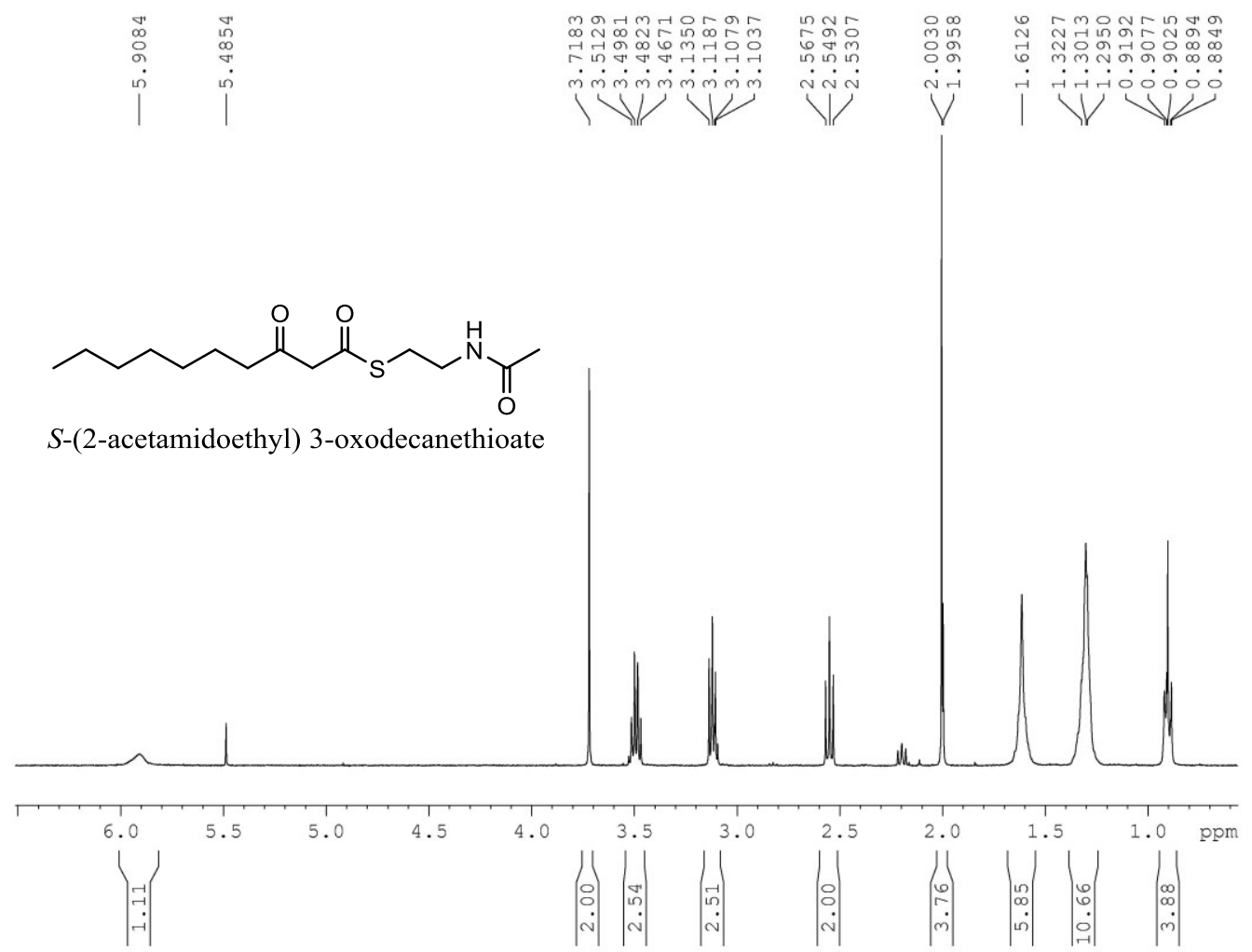



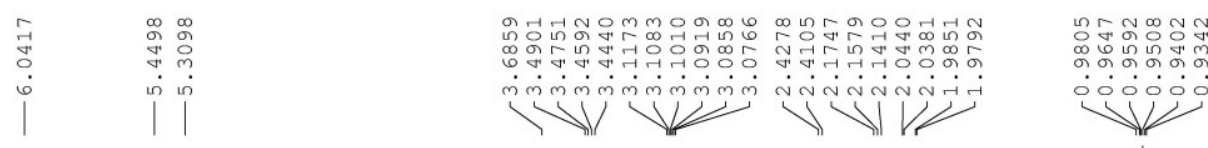

คं०ீं.

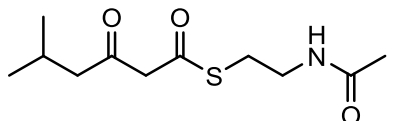

$S$-(2-acetamidoethyl) 5-methyl-3oxohexanethioate

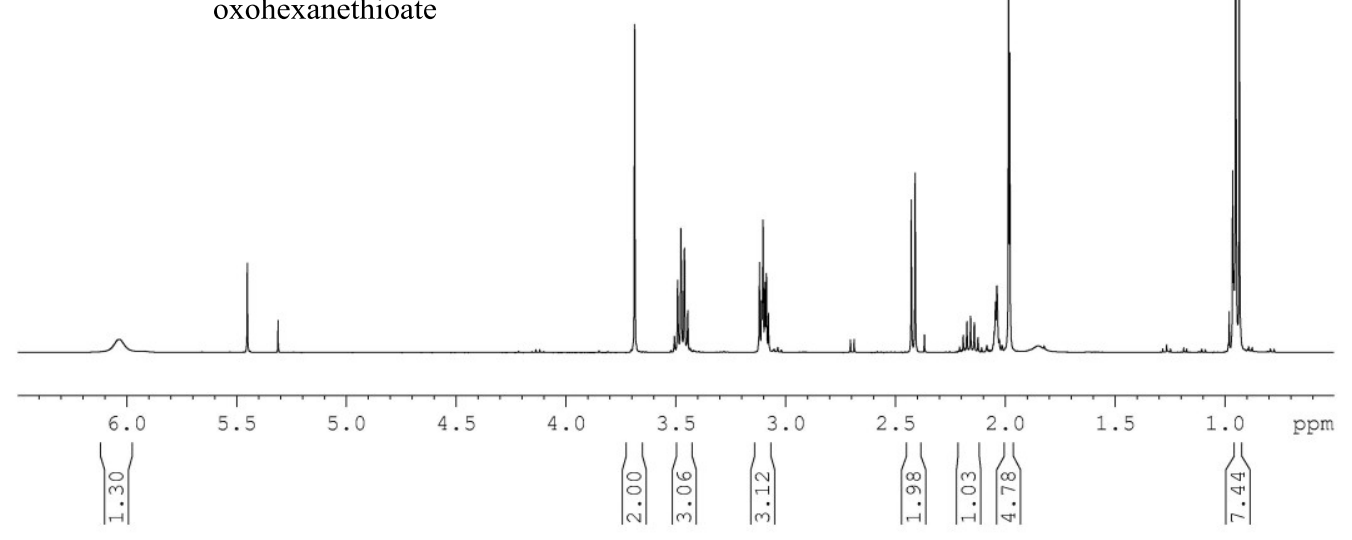



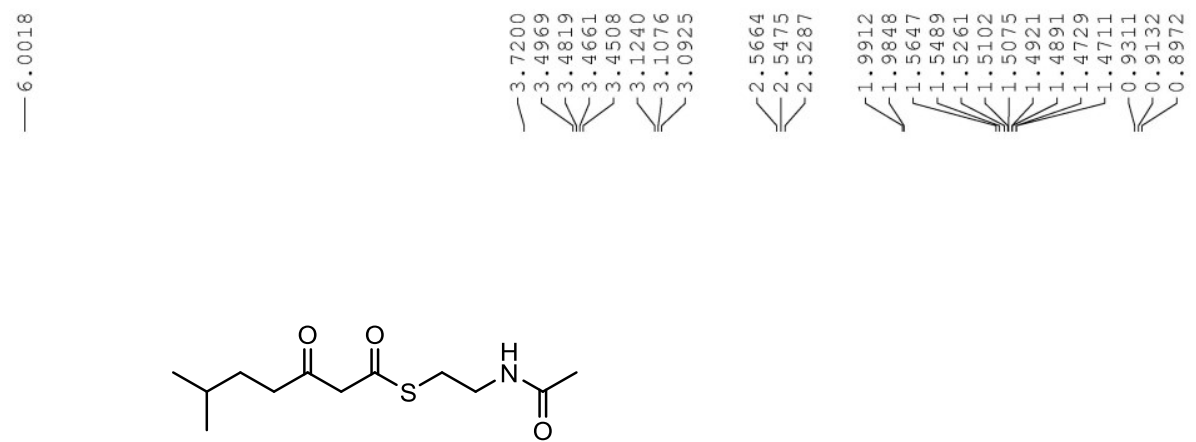

$S$-(2-acetamidoethyl) 6-methyl-3-oxoheptanethioate

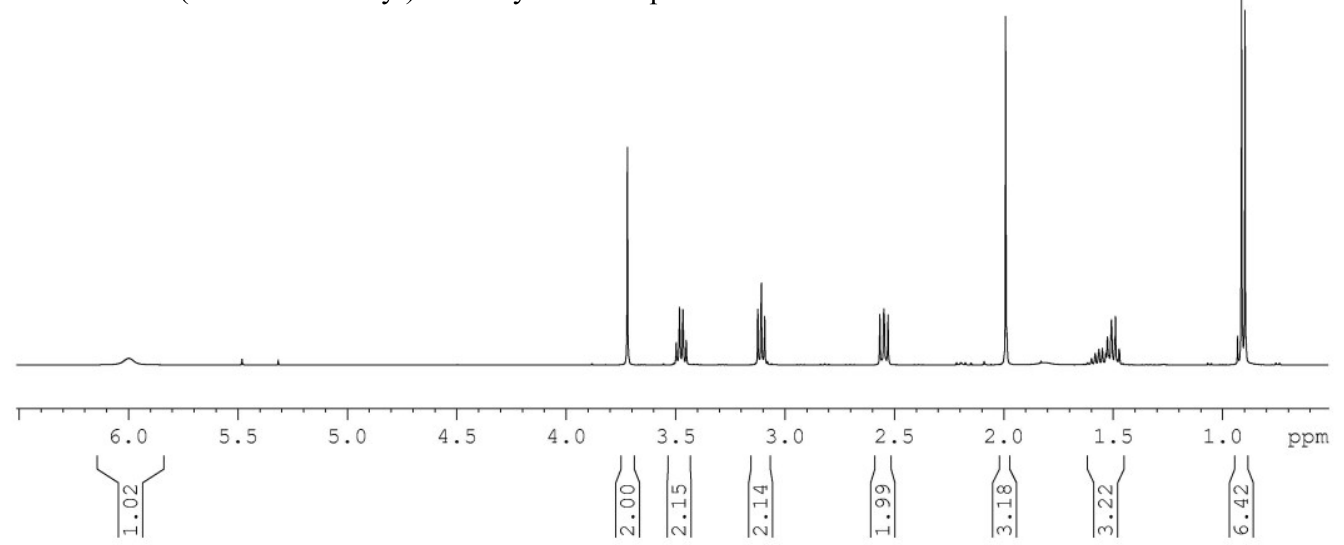




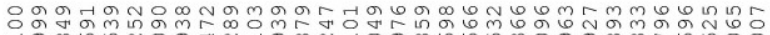

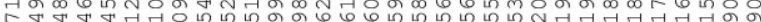
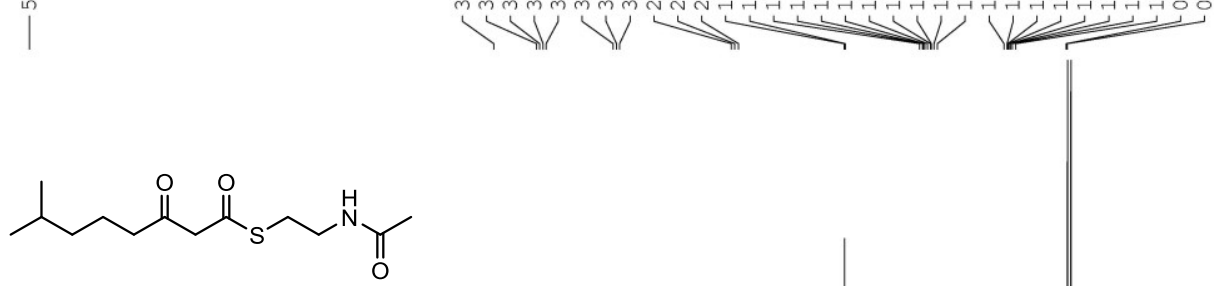

$S$-(2-acetamidoethyl) 7-methyl-3-oxooctanethioate

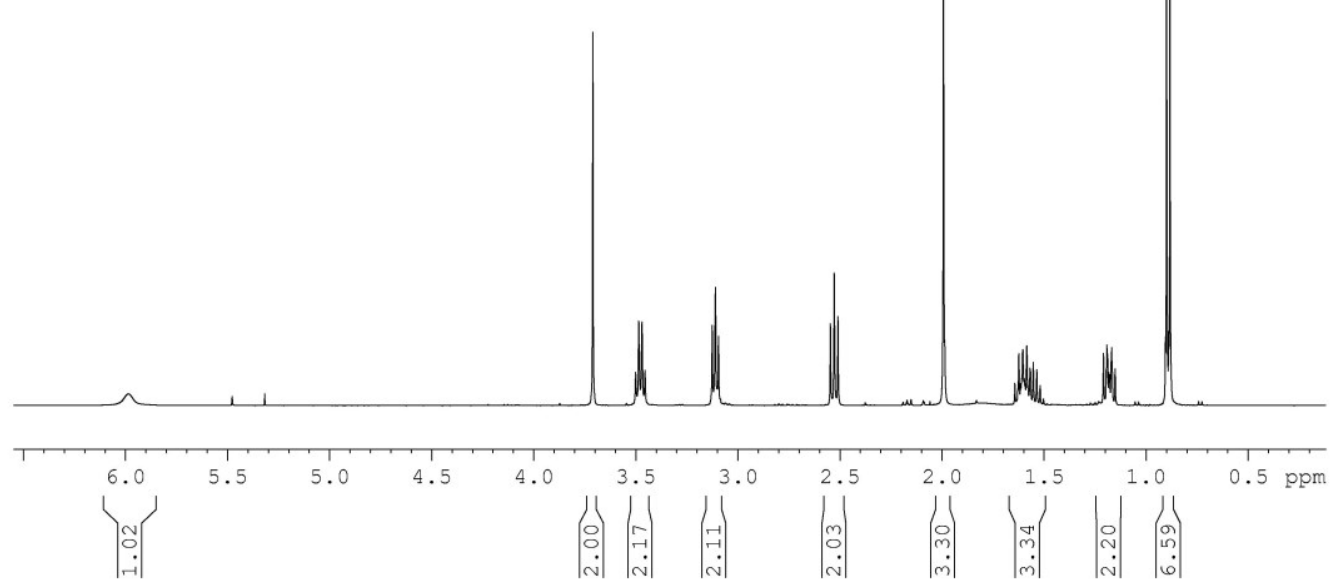




\subsection{Conclusions and recommendations for future work}

In summary, undecylprodiginine biosynthesis involves numerous intriguing enzymes and a fascinating interface with fatty acid biosynthesis. The overall objective of this study was to build a compressive understanding of the enzymology of both bacterial FAS and undecylprodiginine biosynthetic processes and the interface between them.

Conclusion 1: In the current study kinetic analyses of the enzymes, which initiate fatty acid and prodiginine, biosynthesis in Streptomyces coelicolor using a range of different substrate pairings was carried out. Data demonstrates that RedP is specific for the straight chain acetyl-CoA, and FabH for the branched chain isobutyryl-CoA. The results also demonstrate the key role that acyl carrier protein specificity of these enzymes plays in keeping these two processes separate. Therefore FabH and its homolog RedP play an important role for efficient initiation of fatty acid and undecylprodiginine biosynthesis and serve as the first gate-keepers determining the type of fatty acids and prodiginines made in S. coelicolor

Future work: RedR is proposed to catalyze condensation between an acyl-ACP with malonyl-ACP for undecylprodiginine biosynthesis in S. coelicolor and is homologous to the FabF, which catalyzes the same reaction during the elongation cycle of fatty acid biosynthesis (Cerdeno et. al 2002). The fabF gene is located within fatty acid biosynthetic genes cluster (Revill et. al 1995) and is 
most likely responsible for catalyzing the elongation of both straight and branched-chain acyl-ACP substrates in streptomycetes (Fig. 5). The observations that plasmid-based expression of fabF in the SJM3 mutant increased overall production of prodiginine suggest that FabF can substitute for the role of RedR (Mo et. al; 2008), although FabF was less efficient and exerted less control than RedR in this role. Therefore RedR must have substrate specificity for elongation of straight-chain acyl-ACP (similar to the initiating enzyme RedP in aim 1), and this elongation process must terminate at an activated dodecanoic acid (Fig 5). However, the FabF catalyzed process would not be expected to terminate at this point. Given that branched-chain fatty acids predominant in streptomycetes, FabF might have preference for elongating branched-chain acyl-ACP (similar to the FabH in aim 1). Additionally similar to the initiating enzymes FabF and RedR) might have differing ACP specificity. Both of these enzymes have not yet been characterized in vivo. We cloned, express and tried to purify both FabF and RedR enzymes to characterize these enzymes with respect to substrate specificity. We were able to get pure FabF protein and to set up the assay conditions. However, we had difficulties in getting pure RedR protein and were not able to conduct these studies. Both of these enzymes need to be characterized in vitro.

Conclusion 2: Kinetic analyses demonstrate that all three S. coelicolor enzymes (SC01815, SCO1345 and SCO1346) have $\beta$-ketoacyl-reductase activity. Spectrophotometric and LC/MS assay demonstrated that FabG does not 
differentiate between straight and branched chain substrates, and has equal preference for FabC and RedQ ACPs (except for SCO1345 for RedQ). Also, genes encoding $\beta$-ketoacyl-reductase enzymes are not present in the secondary metabolic gene cluster. These observations suggest that these enzymes are shared and process the intermediates in the elongation cycle of both fatty acid and undecylprodiginine biosynthesis. Surprisely, all three have $\beta$-ketoacylreductase activity. Therefore it's difficult to determine which ketoacyl-reductase is most relevant for S. coelicolor in vivo. Nevertheless, SCO1345 has less activity with FabC, and does not have any activity with RedQ. Additionally these enzymes have different cofactor preference; out of three SCO1815 and SC01345 along with E. coli FabG have NADPH preference, in contrast to SC01346, which has NADH preference. Furthermore, the SC01815 gene lies directly adjacent to the SCO1814 gene (putative enoyl-ACP reductase) as is the case for the relevant in vivo enzyme in the other organism such as M.tuberculosis, M. smegmatis, S.griseous, and S. avermitilis. (Gago et. al., 2011)

Conclusion 3: Spectrophotometric assay and LC/MS assay demonstrated that SC01814 (InhA) has enoyl-ACP reductase activity. InhA is capable of utilizing various chain lengths of straight and branched chain substrates. Furthermore it does not discriminate between ACPs from primary metabolism and secondary metabolism. Also a gene encoding the enoyl-ACP reductase (Fabl) required for converting enoyl-ACPs to acyl-ACPs is not present in the secondary metabolic 
gene cluster. These observations demonstrate that SCO1814 is shared by both fatty acid and undecylprodiginine biosynthetic process in S. coelicolor.

Future work: The missing piece of the FAS II system from S. coelicolor is a dehydratase. The enzyme encoded by fabA (or fabZ) is responsible for dehydration of 3-hydroxyacyl-ACP during the elongation cycles of the bacterial FAS-II. This gene has not been characterized in S. coelicolor. Therefore genetic analysis is required to identify the gene cluster containing the homologue of a FabA. The fabA gene encoding putative 3-hydroxyacyl-ACP dehydratase should be expressed, and the corresponding protein should be purified. Biochemical studies are required to elucidate the functional role and substrate specificity of $S$. coelicolor FabA. On the basis of our data (Aims 2 and 3) FabA should not have acyl and ACP specificity. According to our prediction FabA should not possess any acyl and ACP specificity similar to FabG and Fabl (Aims 2 and 3) which will allow it to process the acyl chains for both the primary and secondary metabolism. 


\section{References}

1. Kieser, T., Buttner, M. J., Chater, K. F., Bibb, M. J., Hopwood, D. A. (2000) Practical Streptomyces Genetics. Norwich, United Kingdom: The John Innes Foundation.

2. Berdy. J., Horvath, I., and Szentirmai, A. (1964) Antibiotics produced by Streptomyces II. The tautomeric transformation of Xanthomycin. Z. Allg. Mikrobiol. 4, 232-235

3. Hopwood, D. A., Chater, K. F., and Bibb, M. J., (1995) Genetics of antibiotic production in Streptomyces coelicolor A3(2), a model streptomycete. Biotechnology 28, 65-102

4. Hopwood, D. A., (1989) Antibiotics: opportunities for genetic manipulation. Philos. Trans. R. Soc. Lond. B. Biol. Sci. 324, 549-562

5. Hardisson, C, Manzanal, M. B., Salas, J. A., and Suarez, J. E., (1978) Fine structure, physiology and biochemistry of arthrospore germination in Streptomyces antibiotics. J. Gen. Microbiol. 2, 203-14

6. Chater, K. F., (1989) Multilevel regulation of Streptomyces differentiation. Trends Genet. 5, 372-377.

7. Magnuson, K., Jackowski, S., Rock, C. O., and Cronan, J. E. (1993) Regulation of fatty acid biosynthesis in Escherichia coli. Microbiol. Mol. Biol. Rev. 57, 522-542.

8. Kaneda, T. (1991) Iso- and anteiso-fatty acids in bacteria: biosynthesis, function and taxonomic significance. Microbiol. Rev. 55, 288-302 
9. Wallace, K. K., Zhao, B., McArthur, H. A. I., and Reynolds, K. A. (1995) In vivo analysis of straight-chain and branched-chain fatty acid biosynthesis in three actinomycetes. FEMS Microbiol. Lett. 131, 227-234.

10. Han, L., Lobo. S., and Reynolds, K. A. (1998) Characterization of $\beta$-ketoacylacyl carrier protein synthase III from Streptomyces glaucescens and its role in initiation of fatty acid synthesis. J. Bacteriol. 180, 4481-4486.

11. Kieser, H. M., Kieser, T, and Hopwood, D. A. (1992) A combined genetic and physical map of Streptomyces coelicolor A3(2) chromosome. J. Bacteriol. $174,5496-5507$.

12.Williamson, N. R., Fineran, P. C., Gristwood, T., Chawrai, S. R., Leeper, F. J., and Salmond, G. PC. (2007) Anticancer and immunosuppressive properties of bacterial prodiginines. Future. Microbial. 2, 605-618.

13.Papireddy, K., Smilkstein, M., Kelly, J. X., Shweta. Salem, S. M , Alhamadsheh, M., Haynes, S. W., Challis, G. L., and Reynolds, K. A. (2011) Antimalarial activity of natural and synthetic prodiginines. J. Med. Chem. 54, $5296-5306$.

14.Cerdeno, A. M., Bibb, M. J., and Challis, G. L. (2001) Analysis of the prodiginine biosynthesis gene cluster of Streptomyces coelicolor A3(2): new mechanisms for chain initiation and termination in modular multienzymes. Chem. Biol. 8, 817-829.

15. Whicher JR, Florova G, Sydor P K, Singh R, Alhamadsheh MM, Challis G, Reynolds KA \& Smith JL (2011) Structure and function of RedJ, a thioesterase 
from the prodiginine biosynthetic pathway in Streptomyces coelicolor. J. Biol. Chem 286: 22558-22569.

16. Hopwood, D. A., and Sherman, D. H. (1990) Molecular genetics of polyketides and its comparision to fatty acid biosynthesis. Annu. Rev. Genet. 24, 37-66.

17.Smith, D. S., Wood, N. J., and Hodgson, D. A. (1995) Interaction between primary and secondary metabolism in Streptomyces coelicolor $A 3(2)$ : role of pyrroline-5-carboxylate dehydrogenase. Microbiology 141, 1739-1744.

18. Florova, G., Kazanina, G., and Reynolds, K. A. (2002) Enzymes involved in fatty acid and polyketide biosynthesis in Streptomyces glaucescens: role of FabH and FabD and their acyl carrier protein specificity. Biochemistry 41, $10461-10471$

19. Gago, G., Diacovich, L., Arabolaza, A., Tsai, S., and Gramajo, H. (2011). Fatty acid biosynthesis in actinomycetes. FEMS Microbiol. Rev. 35, 475-497.

20. Heath RJ, White SW \& Rock CO (2002) Inhibition of fatty acid synthesis as antimicrobial chemotherapeutics. Appl Microbiol Biotech 58: 695-703.

21.Tsay JT, Oh W, Larson TJ, Jackowski S \& Rock CO (1992) Isolation and characterization of the $\beta$-ketoacyl-acyl carrier protein synthase III gene $(\mathrm{fabH})$ from Escherichia coli K-12. J Biol Chem 267: 6807-6814.

22. Han L, Lobo S \& Reynolds KA (1998) Characterization of $\beta$-ketoacyl-acyl carrier protein synthase III from Streptomyces glaucescens and its role in initiation of fatty acid synthesis. J Bacteriol 180: 4481-4486. 
23. Florova G, Kazanina G, \& Reynolds KA (2002) Enzymes involved in fatty acid and polyketide biosynthesis in Streptomyces glaucescens: role of FabH and FabD and their acyl carrier protein specificity. Biochemistry 41: 10461-10471.

24. Qiu X, Choudhry AE, Janson CA, Grooms M, Daines RA, Lonsdale JT \& Khandekar SS (2005) Crystal structure and substrate specificity of the $\beta$ ketoacyl-acyl carrier protein synthase III (FabH) from Staphylococcus aureus. Protein Sci 14: 2087-2094.

25. Sachdeva S, Musayev FN, Alhamadsheh MM, Scarsdale JN, Wright HT, \& Reynolds KA (2008) Separate entrance and exit portals for ligand traffic in Mycobacterium tuberculosis FabH. Chem Biol 15: 402-412.

26. Li Y, Florova G \& Reynolds KA (2005) Alternation of the fatty acid profile of Streptomyces coelicolor by replacement of the initiation enzyme 3-ketoacyl acyl carrier protein synthase III (FabH). J Bacteriol 187: 3795-3799.

27.Bibb MJ, Sherman DH, Omura S \& Hopwood DA (1994) Cloning, sequencing and deduced functions of a cluster of Streptomyces genes probably encoding biosynthesis of the polyketide antibiotic frenolicin. Gene 142: 31-39.

28. Bililign T, Hyun CG, Williams JS, Czisny AM \& Thorson JS (2004) The hedamycin locus implicates a novel aromatic PKS primary mechanism. Chem Biol 11: 959-969.

29. Marti T, Hu Z, Pohl NL, Shah AN \& Khosla C (2000) Cloning, nucleotide sequences and heterologous expression of the biosynthetic gene cluster for 
R1128, a non-steroidal estrogen receptor antagonist. Insight into an unusual priming mechanism. J Biol Chem 275: 33443-33448.

30. Cerdeno AM, Bibb MJ \& Challis GL (2001) Analysis of the prodiginine biosynthesis gene cluster of Streptomyces coelicolor A3(2): new mechanisms for chain initiation and termination in modular multienzymes. Chem Biol 8: 817-829.

31. Williamson NR, Fineran PC, Gristwood T, Chawrai SR, Leeper FJ \& Salmond GPC (2007) Anticancer and immunosuppressive properties of bacterial prodiginines. Future microbiol 2: 605-618.

32. Papireddy K, Smilkstein M, Kelly JX, Shweta, Salem SM, Alhamadsheh M, Haynes SW, Challis GL \& Reynolds KA (2011) Antimalarial activity of natural and synthetic prodiginines. J Med Chem 54: 5296-5306.

33.Mo S, Kim BS \& Reynolds KA (2005) Production of branched-chain alkylprodiginines in S. coelicolor by replacement of the 3-ketoacyl ACP synthase III initiation enzyme, RedP. Chem Biol 12: 191-200.

34. He X, Muller JP \& Reynolds KA (2000) Development of a scintillation proximity assay for $\beta$-ketoacyl-acyl carrier protein synthase III. Anal Biochem 282: 107114.

35. Lobo S, Florova G \& Reynolds KA (2001) A Streptomyces collinus thiolase with novel acetyl-CoA: acyl carrier protein transacylase activity. Biochemistry 40: $11955-11964$. 
36. Whicher JR, Florova G, Sydor P K, Singh R, Alhamadsheh MM, Challis G, Reynolds KA \& Smith JL (2011) Structure and function of RedJ, a thioesterase from the prodiginine biosynthetic pathway in Streptomyces coelicolor. J Biol Chem 286: 22558-22569.

37. Revill WP, Bibb MJ \& Hopwood DA (1996) Relationship between fatty acid and polyketide synthases from Streptomyces coelicolor A3(2): Characterization of the fatty acid synthase acyl carrier protein. J Bacteriol 178: 5660-5667.

38. Mo S, Sydor PK, Corre C, Alhamadsheh MM, Stanley AE, Haynes SW, Song L, Reynolds KA, \& Challis GL (2008) Elucidation of the Streptomyces coelicolor pathway to 2-undecylpyrrole, a key intermediate in undecylprodiginine and streptorubin B biosynthesis. Chem Biol 15: 137-148.

39. Choi KH, Heath RJ \& Rock CO (2000a) $\beta$-ketoacyl-acyl carrier protein synthase III $(\mathrm{FabH})$ is a determining factor in branched-chain fatty acid biosynthesis. J Bacteriol 182: 365-370.

40. Choi KH, Kremer L, Besra GS \& Rock CO (2000b) Identification and substrate specificity of $\beta$-ketoacyl (acyl carrier protein) synthase III (mtFabH) from Mycobacterium tuberculosis. J Biol Chem 275: 28201-28207.

41. Khandekar SS, Gentry DR, Van Aller GS, et al. (2001) Identification, substrate specificity, and inhibition of the Streptococcus pneumoniae $\beta$-ketoacyl-acyl carrier protein synthase III (FabH). J Biol Chem 276: 30025-30030.

42. Brown AK, Sridharan S, Kremer L, Lindenberg S, Dover LG, Sacchetini JC \& Besra GS (2005) Probing the mechanism of the Mycobacterium tuberculosis $\beta$ - 
ketoacyl-acyl carrier protein synthase III $m t F a b H$ : factors influencing catalysis and substrate specificity. J Biol Chem 280: 32539-32547.

43. Heath RJ \& Rock CO (1996) Inhibition of $\beta$-ketoacyl-acyl carrier protein synthase III (FabH) by acyl-acyl carrier protein in Escherichia coli. J Biol Chem 271: $10996-11000$

44. Qiu X, Janson CA, Konstantinidis AK, Nwagwu S, Silverman C, Smith WW, Khandekar S, Lonsdale J \& Abdul-Meguid SS (1999) Crystal structure of $\beta$ ketoacyl-acyl carrier protein synthase III. A key condensing enzyme in bacterial fatty acid biosynthesis. J Biol Chem 274: 36465-36471.

45.Davies C, Heath RJ, White SW \& Rock CO (2000) The 1.8 A crystal structure and active-site architecture of $\beta$-ketoacyl-acyl carrier protein synthase III (FabH) from Escherichia coli. Structure 8: 185-195.

46. Han, L., Lobo. S., and Reynolds, K. A. (1998) Characterization of $\beta$-ketoacylacyl carrier protein synthase III from Streptomyces glaucescens and its role in initiation of fatty acid synthesis. J. Bacteriol. 180, 4481-4486.

47. Revill, W. P., Bibb, M. J., and Hopwood, D. A. (1996) Relationship between fatty acid and polyketide synthases from Streptomyces coelicolor $A 3(2)$ : Characterization of the fatty acid synthase acyl carrier protein. J. Bacteriol. $178,5660-5667$.

48. Hopwood, D. A., (1989) Antibiotics: opportunities for genetic manipulation. Philos. Trans. R. Soc. Lond. B. Biol. Sci. 324, 549-562. 
49. Mchenney, M. A., Hosted, T. J., Dehoff, B. S., Rosteck, P. R., and Baltz, R. H., (1998) Molecular Cloning and Physical Mapping of the Daptomycin Gene Cluster from Streptomyces roseosporus. J. Biol. Chem. 180, 143-151.

50.Bibb, M.J., Sherman, D.H., Omura, S., and Hopwood, D. A. (1994) Cloning, sequencing and deduced functions of a cluster of Streptomyces genes probably encoding biosynthesis of the polyketide antibiotic frenolicin. Gene 142, 31-39.

51.Marti, T., Hu, Z., Pohl, N. L., Shah, A. N., and Khosla, C. (2000) Cloning, nucleotide sequences and heterologous expression of the biosynthetic gene cluster for R1128, a non-steroidal estrogen receptor antagonist. Insights into an unusual priming mechanism. J. Biol. Chem. 275, 33443-33448.

52.Wyszynski, F. J., Hesketh A. R., Bibb, M. J., and Davis, B. G. (2010) Dissecting tunicamycin biosynthesis by genome mining: cloning and heterologous expression of a minimal gene cluster. Chem. Sci., 1, 581-589.

53.Wyszynski, F. J., Lee, S.S., Yabe, T., Wang, H., Gomez-Escribann J. P., Bibb, M. J., Lee, S. J., Davies, G. J., and Davis, B. G., (2012) Biosynthesis of the tunicamycin antibiotics proceeds via unique exo-glycal intermediates. Nature Chemistry, 4, 539-546.

54.Cerdeno, A. M., Bibb, M. J., and Challis, G. L. (2001) Analysis of the prodiginine biosynthesis gene cluster of Streptomyces coelicolor A3(2): new 
mechanisms for chain initiation and termination in modular multienzymes. Chem. Biol. 8, 817-829.

55. Williamson, N. R., Fineran, P. C., Gristwood, T., Chawrai, S. R., Leeper, F. J., and Salmond, G. PC. (2007) Anticancer and immunosuppressive properties of bacterial prodiginines. Future. Microbial. 2, 605-618.

56.Papireddy, K., Smilkstein, M., Kelly, J. X., Shweta. Salem, S. M , Alhamadsheh, M., Haynes, S. W., Challis, G. L., and Reynolds, K. A. (2011) Antimalarial activity of natural and synthetic prodiginines. J. Med. Chem. 54, $5296-5306$.

57.Tsay, J. T., Oh, W., Larson, T. J., Jackowski, S., and Rock, C. O. (1992) Isolation and characterization of the $\beta$-ketoacyl-acyl carrier protein synthase III gene $(f a b H)$ from Escherichia coli K-12. J. Biol. Chem. 267, 6807-6814.

58. Choi, K. H., Heath, R. J., and Rock, C. O. (2000) $\beta$-ketoacyl-acyl carrier protein synthase III $(\mathrm{FabH})$ is a determining factor in branched-chain fatty acid biosynthesis. J. Bacteriol. 182, 365-370.

59. Singh, R., Mo, S., Florova, G., and Reynolds, K. A. (2012) Streptomyces coelicolor RedP and FabH enzymes, initiating undecylprodiginine and fatty acid biosynthesis, exhibit distinct acyl-CoA and malonyl-acyl carrier protein substrate specificities. FEMS microbio. Lett. 328, 32-38. 
60. Florova, G., Kazanina, G., and Reynolds, K. A. (2002) Enzymes involved in fatty acid and polyketide biosynthesis in Streptomyces glaucescens: role of FabH and FabD and their acyl carrier protein specificity. Biochemistry 41, 10461-10471.

61.Gago, G., Diacovich, L., Arabolaza, A., Tsai, S., and Gramajo, H. (2011). Fatty acid biosynthesis in actinomycetes. FEMS Microbiol. Rev. 35, 475-497.

62.Tang, Y., Lee, H. Y., Tang, Y., Kim, C-Y., Mathews, I., and Khosla, C. (2006) Structural and functional studies on SC01815: A $\beta$-ketoacyl-acyl carrier protein reductase from Streptomyces coelicolor A3 (2). Biochemistry 45, 14085-14093.

63.Lobo, S., Florova, G., and Reynolds, K. A. (2001) A Streptomyces collinus thiolase with novel acetyl-CoA: acyl carrier protein transacylase activity. Biochemistry 40, 11955-11964.

64. Whicher, J. R., Florova, G., Sydor, P. K., Singh, R., Alhamadsheh, M. M., Challis, G., Reynolds, K. A., and Smith, J. L. (2011) Structure and function of RedJ, a thioesterase from the prodiginine biosynthetic pathway in Streptomyces coelicolor. J. Biol. Chem. 286, 22558-22569.

65.Smirnona, N., and Reynolds, K. A. (2001) Engineered fatty acid biosynthesis in Streptomyces by altered catalytic function of beta-keto-acyl carrier protein synthase III. J. Bacteriol. 183, 2335-2342. 
66. Bloch, K. (1977). Control mechanism for fatty acids biosynthesis in Mycobacterium smegmatis. Adv. Enzymol 45, 1-84.

67. Marrakchi, H., Ducasse, S., Labesse, G., Montrozier, H., Margeat, E., Emorine, L., Charpentier, X., Daffe, M., and Quelmard, A. (2002) MabA (FabG1), a Mycobacterium tuberculosis protein involved in the long-chain fatty acid elongation system FAS-II. Microbiol., 148, 951-960.

68.Patel, M. P., Liu, W.S, West, J., Tew, D., Meek, T. D. and Thrall, S. H. (2005) Kinetic and Chemical Mechanism of the fabG-Encoded Streptococcus pneumonia. Beta-ketoacyl-ACP reductase. Biochemistry 44, 16753-16765.

69. Brown, A. K., Sridharan, S., Kremer, L., Lindenberg, S., Dover, L. G, Sacchetini, J. C, and Besra, G. S. (2005) Probing the mechanism of the Mycobacterium tuberculosis $\beta$-ketoacyl-acyl carrier protein synthase III mtFabH: factors influencing catalysis and substrate specificity. $J$ Biol Chem 280: 32539-32547.

70. Meluzzi, D., Zheng, W. H., Hensler, M., Nizet, V., and Dorrestein, P. C. (2008) Top-down mass spectrometry on low-resolution instruments: Characterization of phosphopantetheinylated carrier domains in polyketide and non-ribosomal biosynthetic pathways. Bioorg. Med. Chem. Lett. 18, 3107-3111.

71.Berglert, H., Wallnert, P., Ebelingt, A., Leitingert, B., Fuchsbichlers, S., Aschaued, H., Kollenz, G., Hogenauert, G., and Turnowskyt, F. (1994). 
Protein EnvM Is the NADH-dependent Enoyl-ACP Reductase (Fabl) of Escherichia coli. J. Biol. Chem. 269, 5493-5496.

72. Heath, R. J., and Rock, C. O. (1995) Enoyl-Acyl Carrier Protein Reductase $(f a b l)$ Plays a Determinant Role in Completing Cycles of Fatty Acid Elongation in Escherichia coli. J. Biol. Chem. 270, 26538-26542.

73. Schiebel, J., Chang, A., Lu, H., Baxter, M. V., Tonge, P. J., and Kisker, C. (2012) Staphylococcus aureus Fabl: Inhibition, Substrate Recognition and Potential Implications for In Vivo Essentiality. Structure 20, 802-813.

74.Chang, A., Schiebel, J., Yu, W., Bommineni, G. R., Pan, P., Baxter, M. V., Khanna, A., Sotriffer, C. A., Kisker, C., Tonge, P. J. (2013) Rational optimization of drug-target residence time: insights from inhibitor binding to the Staphylococcus aureus Fabl enzyme-product complex. Biochemistry 52, 4217-4228.

75. Heath, R. J., Su, N., Murphy, C. K., and Rock, C. O. (2000) The Enoyl-[acylcarrier-protein] Reductases Fabl and FabL from Bacillus subtilis. J. Biol. Chem. 275, 40128-40133. 